\title{
Engineering aspects of the design, construction and performance of modular redox flow batteries for energy storage
}

\author{
L.F. Arenas, ${ }^{a}{ }^{\ddagger}$ C. Ponce de León, ${ }^{a,+}$ F.C. Walsh ${ }^{a, *}$ \\ ${ }^{a}$ Electrochemical Engineering Laboratory, Energy Technology Research Group, Faculty of \\ Engineering and the Environment, University of Southampton SO17 1BJ, UK. \\ * Author for correspondence; F.C. Walsh: F.C.Walsh@soton.ac.uk. \\ +Email: capla@soton.ac.uk \\ *Email: lfam1g13@soton.ac.uk, fernando2113@gmail.com
}

\begin{abstract}
Despite many studies and several extensive reviews of redox flow batteries (RFBs) over the last three decades, information on engineering aspects is scarce, which hinders progress with scale-up and implementation of this energy storage technology. This review summarises cell design requirements then critically considers design, construction and cell features together with their benefits and problems, leading to good practice through improved cell performance, knowledge and experience. Techniques for the characterisation of the reaction environment are illustrated by measurements of mass transport to (and from) electrode surfaces as a function of flow conditions, as well as pressure drop and electrolyte flow dispersion. The effect of design features on performance is illustrated by the effect of process conditions on the components of cell potential. Adequate attention to engineering aspects is seen to be critical to the effective performance of RFBs, particularly during scale-up and long-term operation. Techniques for the characterisation of reaction environment are summarised and a list of essential design and construction factors is provided. Finally, critical areas needing research and development are highlighted.
\end{abstract}

Keywords: electrochemical engineering, energy storage, flow dispersion, fluid flow, porous electrode, pressure drop, reaction environment, redox flow battery. 


\section{Highlights}

- The history and relevance of redox flow batteries in energy storage are highlighted.

- Electrochemical engineering principles of cell design and operation are summarised.

- Performance can be quantified at a known state of charge and modelled by multiphysics.

- Reaction environment can be described by dimensionless relationships.

- The importance of operational parameters is illustrated by experimental data.

\section{Graphical abstract}

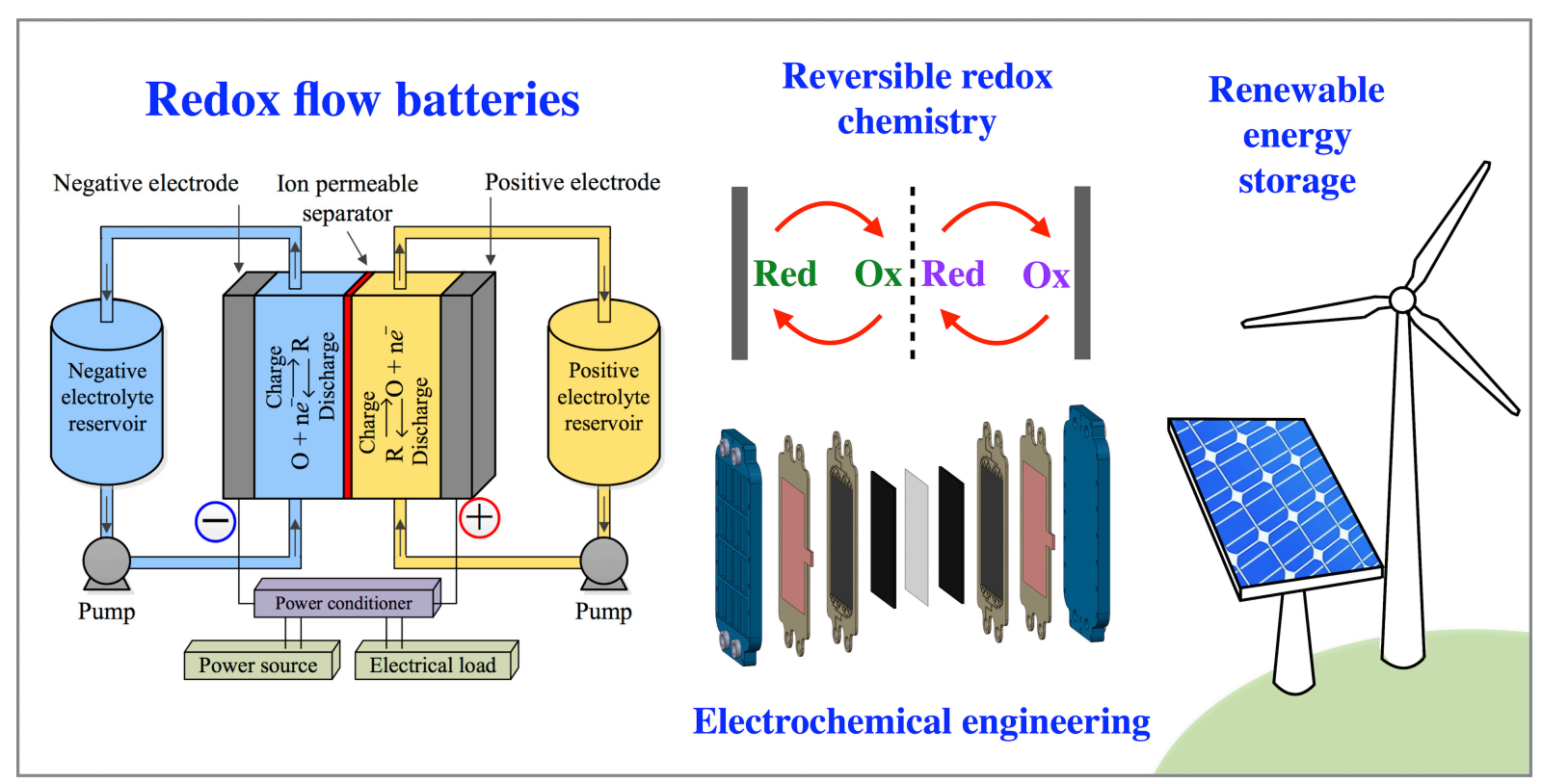




\section{Contents}

1. Introduction 4

2. The history of RFB development 7

3. Important principles of RFBs 10

3.1 The concept of RFBs for energy storage 11

3.2 Components of an RFB system 12

3.3 Classification of RFBs 13

3.4 Ideal characteristics of redox flow batteries $\quad 14$

$\begin{array}{lr}3.5 \text { Electrode reactions } & 15\end{array}$

4. Fundamental electrochemistry 16

4.1 The cell potential 16

4.2 Faraday's laws and electrochemical change $\quad 19$

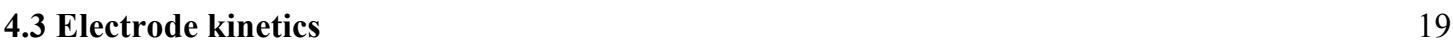

5. Fundamentals of electrochemical engineering 21

$\begin{array}{ll}\text { 5.1 Dimensionless group correlations } & 21\end{array}$

5.2 Reactor models and fractional conversion $\quad 24$

5.3 Expression of battery performance 26

5.4 Experimental studies of reaction environment 28

$\begin{array}{ll}\text { 5.5 Physicochemical balances for dynamic models } & 30\end{array}$

5.6 Modelling and simulation of RFBs $\quad 32$

6. Functional components of RFBs 36

6.1 Electrodes 36

6.2 Electrolytes $\quad 40$

6.3 Membranes and microporous separators $\quad 43$

6.4 Turbulence promoters $\quad 46$

7. Engineering aspects of electrolyte flow $\quad 47$

$\begin{array}{ll}\text { 7.1 Modes of electrolyte circulation } & 47\end{array}$

$\begin{array}{lr}\text { 7.2 Flow configuration at the electrodes } & 50\end{array}$

7.3 Electrolyte flow fields and manifold flow $\quad 51$

7.4 Pressure drop and pumping power $\quad 52$

8. Operational engineering and design aspects $\quad 54$

$\begin{array}{ll}\text { 8.1 Reactor design } & 54\end{array}$

8.2 Current distribution $\quad 56$

8.3 Inter-electrode gap and electrode thickness $\quad 57$

$\begin{array}{lr}\text { 8.4 Management of shunt currents } & 58\end{array}$

$\begin{array}{lr}8.5 \text { Electrical control } & 60\end{array}$

$\begin{array}{lr}\text { 8.6 Heat management } & 60\end{array}$

$\begin{array}{lr}\text { 8.7 Cross-mixing and electrolyte imbalance } & 62\end{array}$

9. Scale-up, construction and manufacture $\quad 63$

$\begin{array}{ll}9.1 \text { The process of scale-up } & 63\end{array}$

$\begin{array}{lr}\text { 9.2 Construction of cells and stacks } & 65\end{array}$

$\begin{array}{ll}9.3 \text { Construction of flow systems } & 67\end{array}$

10. Summary and future outlook 68

$\begin{array}{ll}\text { References } & 75\end{array}$ 


\section{Introduction}

Interest in redox flow batteries (RFBs) has grown considerably due to the increasing demand for static energy storage and the shortage of possible devices. The major drivers for this trend are the rapid growth market for intermittent solar, wind and tidal power and the promise of highly efficient power grids based on extended and versatile load-levelling capacity [1]. After decades of fundamental research and pilot-scale developments, medium and large-scale installations are being commercialized, creating an incipient and active RFB industry [2]. The development of practical RFBs has been slow and difficult. Many engineering challenges remain, even for successful systems, including the need to decrease capital costs, lower running costs and extend battery lifetime. Meanwhile, several promising systems have made only partial scale-up progress. The authors consider that this is partly due to inadequate consideration of engineering aspects of cell design, construction and performance, which has resulted in limited confidence in the technology.

RFB development has achieved important progress in electrolyte, electrode and membrane choice as well as the proposal, and reintroduction, of alternative chemistries. However, the academic field has largely evolved in an empirical fashion around the electrochemistry of established redox species while, in contrast to fields such as electrolysers and fuel cell design [3], little consideration has been given to the accepted principles of electrochemical engineering. More attention needs to be paid to the principles of green energy storage, for instance, the limitation of degradation or the minimization of critical materials [4]. Problems caused by this restricted approach include unsuccessful scale-up, poor maintenance, costly manufacture and limited performance efficiency. In particular, the majority of publications have been restricted to short term studies of small electrodes in the laboratory; very few contributions 
have considered pilot scale performance and the effect of cell design, electrode structure, reaction environment and operational conditions on performance.

In view of the demands of RFB technology, an increased focus is needed on engineering aspects, cell and stack design, reliable comparison figures of merit, monitoring, and modelling. RFBs are reversible electrochemical reactors, but many workers seem unaware of the established literature on electrochemical engineering and figures of merit describing their quantitative performance. Several leading books exist in the field [5-11] and useful theory for RFBs and their design can be found in well-established literature on filter-press cells and electrolysers. A sufficient knowledge of electrochemical engineering is essential to appreciate the critical features of cell design and operating conditions together with an ability to compare results from RFBs operated at different scales or predict performance under different operational conditions.

The present review aims to direct attention to the engineering aspects of RFBs, as this is a major present challenge to their extended commercial implementation. An electrochemical engineering approach to RFB design and scale-up is strongly encouraged and we also attempt to reduce the gap in technological and research awareness between the academic literature and the industry. This review is in line with the principles proposed by Arbabzadeh et al. [4] to direct research in energy storage, which highlight the need for: a) improved maintenance and operation and b) focus on the design of energy storage systems.

Numerous reviews have been published on RFBs, especially over the past decade; indeed, the authors are aware of more than 30 literature reviews since 1980. General reviews consider the main types of RFB and some performance figures, fundamental theory and main design 
considerations [12-15]. Several reviews describe the various RFB systems [16-20]. There are also more specialised reviews on RFBs, including: an early historical overview [21]; the perspective of other energy storage technologies [22,23]; membranes [24,25]; VRFB policy and funding [26]; non-aqueous systems and their membranes [27]; carbon-based electrodes [28]; an overview of selected engineering aspects [29]; regenerative fuel-cells [30]; challenges in the Zn-Ce RFB [31]; electrode materials and reaction mechanisms for the VRFB [32]; advances in VRFBs [33-35]; chemical characteristics of the redox species for RFBs [36,37]; $\mathrm{H}_{2}$-halogen systems [38]; vanadium electrolytes [39]; and recent organic RFBs [40]. Perceived technical challenges and research needs for RFBs were summarised by a group of experts for the U.S. Department of Energy [41]. Recent books and monograph chapters have also assessed the state of RFB technology. For instance, summaries on the development, characteristics and challenges of the VRFB [42,43], Zn-based [44], $\mathrm{Br}_{2}$-polysulfide [45], and $\mathrm{Zn}-\mathrm{Br}_{2}$ [46,47] systems, as well as RFBs in general [48]. The recent contribution by Chalamala et al. [29] focuses on some engineering considerations, explaining advances in flow field designs, mentioning key design features and the need for scalability. However, there is little reference to fundamental electrochemical engineering and reactor design, scale-up process, performancetime data or reaction environment.

The current growth in the number of publications has left several important aspects poorly treated in the literature:

a) Figures of merit describing performance (rate, voltage efficiency, charge efficiency, energy efficiency and state of charge).

b) Scale-up parameters (current density, electrolyte flow rate and velocity, electrode size, flow and mass transport and dimensionless groups). 
c) Reaction engineering (mass transfer, electrolyte flow and the distributions of current, potential and concentration).

d) Fractional conversion over the cell or in the tanks with time, current density or flow rate, conversion per-pass.

e) Membrane ionic conductivity, selectivity and transfer rates or ageing, i.e., time-dependent studies.

f) Type of cell geometry, manufacture method and characteristics.

g) Monitoring and diagnostics (including methods used and type of data collection).

h) Electrode characteristics (2-D vs. 3-D, coated vs. bulk, active area, porosity, electrocatalysis, roughness, etc.).

i) Electrode material (composition, electrocatalysis and electrocatalytic ability).

j) Electrode stability with time and conditions (degradation due to ageing, corrosion, or erosion).

k) Identification of rate determining or limiting electrode reaction (e.g., via monitoring of halfcell potentials).

1) Polarisation curves for both positive and negative electrode reactions under realistic chargedischarge operating conditions.

m) Identification and prevention of safety hazards and consideration of failure modes.

\section{The history of RFB development}

The concept of an RFB appeared as early as 1949 in a patent by Kangro [49], followed by a 1955 publication by Posner [50]. It has been suggested that the principle of RFBs could be traced back to 1884 in Renard's airship chlorine-chromium battery but this was a primary cell not reliant on electrolyte flow [51]. Zn-air hybrid RFBs with a flowing liquid electrolyte were first tested in 1966 [52]. Modern RFB developments were motivated by early work in the USA 
on prospective spaceflight power sources, carried out by the National Aeronautics and Space Administration (NASA) in the 1970s [53]. Publications on RFBs by NASA began in 1974 with the introduction of the Fe-Cr battery developed by Thaller et al. [53], followed by the Fe-Ti battery [54]. Other redox couples were investigated, including $\mathrm{Br}^{-} / \mathrm{Br}_{3}{ }^{-}, \mathrm{V}^{2+} / \mathrm{V}^{3+}$ and $\mathrm{V}^{4+} / \mathrm{V}^{5+}$ $[55,56]$. NASA also pioneered engineering aspects of RFBs, investigating electrode configurations [55], shunt currents [57], pumping losses [58], and cost analysis [59]. The FeCr RFB was extensively studied but problems related to the formation of $\mathrm{Cr}$ complexes and electrolyte crossover stopped its development at the time [60].

Research on alternative RFBs introduced, or returned to, several systems: $\mathrm{Zn}^{-\mathrm{Cl}_{2}}$ in 1974 [61], Zn-air [62] and $\mathrm{Zn}-\mathrm{Br}_{2}$ in 1977 [63], Zn-ferricyanide in 1979 [64], $\mathrm{H}_{2}-\mathrm{Br}_{2}$ in 1980 [65], all-iron in 1981 [66], Br-polysulfide in 1984 [67] and all-vanadium in 1985 [68]. The diverse oxidation states of vanadium and the availability and low cost of bromine and sulphide chemicals on the tonnage scale made such RFBs highly promising. Over the next two decades, this helped to provide a focus for much of the engineering efforts. Many recent RFB contributions appear to have ignored the importance of moderately priced, widely available, sustainable sourced commodity chemicals in RFB scale-up.

In the USA, Exxon and later Johnson Controls began the development of the $\mathrm{Zn}-\mathrm{Br}_{2}$ system in

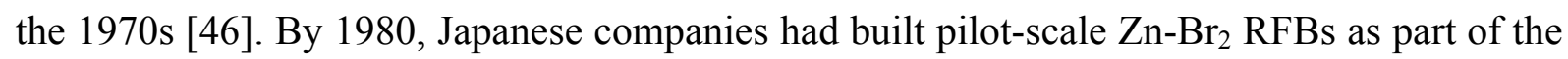
Moonlight Project, and a large facility was in operation by 1990 [69]. Interest in this system

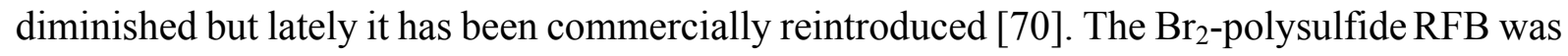
also the subject of much attention during the 1990s. Under the trade name of Regenesys, this RFB was developed into a load levelling installation with a capacity of $120 \mathrm{MW} \mathrm{h}[12,71]$. This system reached a high state of development, emphasising the engineering of cell stacks and the 
availability of large scale, low cost electrolytes. Nevertheless, further experience was required to improve confidence at the pilot-scale grid level. Numerous patents relevant to electrode materials, electrolytes, cell features and process operation were filed by the technical development team [72-76]. A corporate refocussing of energy interests in 2004 by the owners of this technology resulted in the cessation of development and prevented commercialisation. The technology rights were transferred to VRB Ltd but no further developments appear to have been made.

The all-vanadium battery has become the most studied RFB, promising widespread implementation [26]. This device uses vanadium ions in both sides of the separator, easing the problem of electrolyte cross-mixing and extending the lifetime of the battery. The initial developments made at the University of New South Wales in 1985 were later licenced to Kashima-Kita Electric Power Corp. (Mitsubishi) and the Japanese Electrotechnical Lab (ETL) [69], in cooperation with Sumitomo Electric Ltd. [77]. Pilot-plants were in operation by 1989 [69], based on technology previously developed for Fe-Cr systems. Kashima-Kita installed the first demonstration load levelling facility with a capacity of $800 \mathrm{~kW}$ h in 1997 [69]. A number of research institutes and companies have followed, including Pacific Northwest National Laboratory and UniEnergy Technologies in the USA, and Fraunhofer ICT and Gildermeister AG in Germany. Recently, Sumitomo has completed a $60 \mathrm{MW}$ h installation in Hokkaido [78] and rapid progress has been made by Rongke Power in China, with a $800 \mathrm{MW}$ h facility currently under construction [79], the largest RFB installation to date. A wide range of literature and patents has been produced, covering important improvements in the chemistry of VRFBs [14]. The main limitations of this RFB are the vanadium solubility, thermal precipitation of $\mathrm{V}^{5+}$ species, high electrolyte cost and the production capacity of vanadium salts [26], currently subject to geographical limitations and linked to steel production requirements. 
The renewed interest in RFBs after 2000 has produced a large number of new RFBs. Although several of them offer interesting new possibilities, others suffer from obvious flaws from an engineering and commercial perspective. $\mathrm{V}-\mathrm{Ce}$ [80] and V-polyhalide [81] were reported in 2002 and 2003, respectively. These RFBs seek to increase the potential and energy density of vanadium cells, albeit by complicating chemical compatibility. Other vanadium RFBs have since been proposed [14], including a $\mathrm{V}-\mathrm{Br}$ cell [33]. Concepts for impractical systems such as non-aqueous all-uranium [82] and all-neptunium [83] have also been considered. The soluble lead RFB was first published in 2004 [84]. Having the advantage of simplicity being one of the few undivided RFB cells, it still remains of interest today [85]. The Zn-Ce hybrid RFB was patented in 2004 [86]. It produces the highest cell potential for an aqueous RFB and continues to be developed [31]. A patent for a polyoxometallate mediated half-fuel cell, assigned to ACAL Energy, was filed in 2007 [87]. Other RFBs include the undivided Zn-Ni [88], Cdchloranil [89], $\mathrm{Cu}-\mathrm{PbO}_{2}$ [90], and $\mathrm{H}_{2}-\mathrm{Ce}$ [91]. $\mathrm{H}_{2}-\mathrm{Br}_{2}$ and $\mathrm{Fe}-\mathrm{Cr}$ have been reintroduced and scaled-up on the basis relatively high power density [92] and low cost [93], respectively. A VCe RFB coupled with hydrogen production has also been proposed [94] and a Zn-polyiodide RFB promises high volumetric energy density, due to the solubility of iodine species [95], but appears to offer no advantage over less expensive electrolytes and greater process experience with $\mathrm{Zn}-\mathrm{Br}_{2}$ cells. Other RFBs under development include non-aqueous systems [27], e.g., lithium-based [96-98], and quinone-based [99,100]. Electrochemical ion exchange (EIX), first developed for nuclear decontamination and water treatment [101], has been suggested for the storage of active species in RFBs [102]. Many variants and combinations of RFBs can be found in previous reviews.

\section{Important principles of RFBs}




\subsection{The concept of RFBs for energy storage}

RFBs are rechargeable devices that store energy in reversible redox couples dissolved in flowing electrolytes by means of electrochemical filter-press reactors. A typical divided RFB is represented in Figure 1. An ion exchange membrane that permits ionic transfer between halfcell electrodes while separating the positive and negative electrolytes divides each cell. Pumps are used to circulate the electrolytes between the stack and external reservoirs. In the case of undivided RFBs, the two redox couples are dissolved in the same electrolyte, requiring only one reservoir and no separator. During charge, electricity is used to drive the non-spontaneous redox reactions of the dissolved species, effectively storing energy into the electrolytes. During discharge, the reactions take place spontaneously in the reverse direction, releasing electricity.

It is important to realize that RFBs are electrochemical reactors applied to energy storage. A typical filter-press reactor (stack) of a RFB is shown in Figure 2. The stack is made up of a number of cell frames encasing bipolar electrodes hold together between rigid endplates (section 8.1). The rate of conversion of active redox species at the electrodes (charge or discharge), the stack voltage and the consumed/produced current are governed by the principles of electrochemical engineering. Figure 3 shows a scheme of the complex interrelated factors that determine the performance of RFBs. Design and scale-up of these devices has to take such relationships into account.

The main advantage of classical RFBs is that its power is independent from its energy capacity, as the latter depends on electrolyte volume and active species concentration. This statement is not valid in the case of hybrid RFBs. Along with the combination of other factors, such as their relatively low energy density and decreasing cost with larger scale, RFBs have proved suitable for medium and large-scale energy storage. RFBs are capable of operating at ambient 
temperature and pressure producing no pollution emissions, offering a safer alternative to Liion batteries and higher efficiency than electrolysis-fuel cell plants. Furthermore, there is no need to synchronize hundreds of individual batteries. Instead, two electrolytes might eventually need rebalancing. Important applications comprise grid load levelling, coupled with wind, tidal and solar power, and stand-alone, remote, backup or mobile power units. Substituting consumed electrolyte with charged electrolyte can also rapidly recuperate the stored energy, a concept that might be useful in specialised vehicles.

\subsection{Components of an RFB system}

The fundamental RFB unit is the electrochemical flow cell, normally divided by a membrane into two half-cells fed by their corresponding electrolytes. As shown in Figure 4, a number of individual cells build up to create bipolar stacks, the basic modules of a RFB system. The potential difference developed across each stack is the summation of that of the individual cells. In turn, the stacks are arranged (using convenient series and parallel electrical connections) into banks or arrays, which are fed by centrifugal pumps with electrolyte circulating to and from its reservoirs, and electrically connected to the power converter and control system. Large arrays of production engineered modules are possible $[103,104]$, as well as coupling to other energy storage/generation technologies in order to increase response time and capacity, e.g., using gas turbines [69] or thermal-hydro power [105]. The main components of such RFB energy storage systems are:

- Electrolyte flow and storage: electrolyte circuit (piping), pumps, switch valves, valve actuators and electrolyte reservoirs.

- Electrical connections and power conversion: electrical circuits, power electronics, power conditioner, AC/DC rectifier, transformer, AC breaker, cooling system, etc. 
- Control and monitoring: sensors for measurement of electrolyte flow rates, temperature, $\mathrm{pH}$, gas release, etc.; instruments for measuring stack potential difference and current; a control system and software for measurement and control.

Figure 5 shows an example of a RFB energy storage system in Yokohama Works (Japan) coupled to a solar farm [106]. The system developed by Sumitomo and installed in July 2012 consisted of five $1 \mathrm{MW}$ h vanadium RFBs, 16 electrolyte tanks, high-voltage unit, inverter, electrical controller and battery management unit.

\subsection{Classification of RFBs}

The main classification of RFBs is based on the phases of electrode and electrolyte. Figure 6 shows a scheme of the three types:

1. The classical (or true) RFB. No phase change occurs on the electrodes; all electroactive species remain soluble, e.g., the all-vanadium RFB. The electrodes are inert but must have effective electrocatalytic surfaces. Energy is stored only in the electrolytes. Common issues in these RFBs are sluggish kinetics, cross mixing of half-cell electrolytes and instability of reactants.

2. The type 1 hybrid RFB. At least one of the electrode reactions involves a phase change, such that some of the electroactive species are in the solid or gaseous phase. If electrodeposition takes place at an electrode, then the volume of the half-cells limits the storage capacity. Although their feasibility has been well demonstrated by the commercial $\mathrm{Zn}-\mathrm{Br}_{2}$ RFB [46], these systems can be prone to blocked manifolds due to detached solids/dendrites, edge effects at electrodes and flow inlet/exit effects [85]. In hybrid systems involving metal deposition e.g., 
Zn-Ce [107] and $\mathrm{Zn}-\mathrm{Br}_{2}$ [108], slow self-discharge can take place by deposit corrosion. It is also difficult to achieve compact deposits during mixed or mass transport controlled conditions. This category includes half-fuel RFBs, which can suffer from diffusion of liquid to the gascontaining half-cell and membrane blockage.

3. The type 2 hybrid RFB. Phase change at both of the electrodes in the cell. Both half-cell reactions involve phase changes at the electrode surfaces during charge and/or discharge, as in the soluble lead RFB [85], where lead ions in an acidic solution are reversibly converted to $\mathrm{PbO}_{2}$ on charge at the positive electrode and metallic lead at the negative one. The energy is stored as deposits in the two electrodes and the inter-electrode volume limits its capacity.

Further divisions of the classification result from cell design features and electrolyte characteristics: divided (by an ion exchange membrane or microporous separator) or undivided (without membrane); electrolyte manifolds (internal or external); electrode structure (2-D or porous 3-D), electrical connections (monopolar or bipolar); electrolyte type (aqueous or nonaqueous); and electrolyte phase (single phase or two phase, e.g., gas dispersions in liquid, slurries and suspensions).

\subsection{Ideal characteristics of redox flow batteries}

Any high-performance RFB should possess the following characteristics:

- High cell potential. Directly related to the energy storage capacity, it is achieved by a large potential difference between the electrode reactions and the minimization of overpotentials and ohmic losses.

- High cell current. Obtained by high electron transfer rates, large electrode areas and avoidance of mass transport limitations. 
- High energy efficiency. Major factors are high current efficiency (due to fast kinetics and avoidance of side reactions) together high voltage efficiency.

- Long life cycle. The electrodes, membranes and electrolytes should suffer from minimum decomposition, fouling or other changes that result in lower capacity over a large number of cycles.

- Practicality. Reactants and materials should be non-toxic, sustainable or easily recyclable, and widely available at low cost.

- High energy storage capability. The electroactive species must be highly soluble and all its oxidation states should be stable, i.e., remain in solution.

- Stable charge-discharge cycles. The conversion efficiency should be alike and close to $100 \%$ for the two electrode reactions, with minimum mixing of species through the membranes or separators.

Ideally, all unit cells in a RFB stack should experience a similar, uniform reaction environment, including electrolyte temperature, composition and flow together with a controlled current density.

\subsection{Electrode reactions}

A classical RFB should involve a pair of reversible redox couples realising a high potential difference, having high solubility and good stability. Potential values within the solvent potential window are necessary to minimize undesired side-reactions, such as hydrogen and oxygen evolution. For practical success, the chosen redox couples should be commodity chemicals, readily available and having moderate cost and low toxicity.

Many redox couples have been considered for RFBs. The main half-cell reactions and potentials for selected aqueous RFBs are shown in Table 1. Most are inorganic but there are also fast 
reacting electroactive organics, such as quinones, e.g., 9,10-anthraquinone-2,7-disulphonic acid (AQDS) or 2,6-dihydroxyanthraquinone (DHAQ), for the proposed anthraquinone- $\mathrm{Br}_{2}$ [99] and DHAQ-Fe [100] RFBs. Noack et al. have reviewed the properties of numerous redox couples proposed for RFBs [36]. Apart from cost, the most common limitations are the corrosion of electrode materials, precipitation, low solubility, cross-mixing and parasitic reactions. The susceptibility to electrode fouling by the co-products of reacting organic species should be addressed. The electrode kinetics in the VRFB have been extensively studied [32].

The active redox species are dissolved in a supporting electrolyte, the most common being sulphuric acid, sodium hydroxide and methanesulfonic acid. Neutral electrolytes could have additional advantages [111]. Mixed acid electrolytes have been considered in order to increase solubility and improve reaction kinetics, for instance adding hydrochloric to sulphuric acid in vanadium [112,113] and Zn-Ce [114] electrolytes. Another strategy is the use of additives in the form of electrochemical kinetics modifier ligands [115,116], conductivity-enhancing salts [46] and electroplating additives [117]. The $\mathrm{Zn}-\mathrm{Br}_{2} \mathrm{RFB}$ is based on halogen complexing agents $[46,47]$ and precipitation/crystallisation inhibitors can be deployed in VRFB electrolytes in to minimise thermal precipitation of solids [118-120]. Although ionic liquids allow access to redox couples outside the potential window of water [121], their use as solvents in RFBs is challenging, relatively few fulfilling the need for acceptable cost, stability and convenience in use. Many metals have relatively low solubility in ionic liquids while the solvent itself can be expensive (with few exceptions), viscous and prone to water absorption and oxidation in contact with air.

\section{Fundamental electrochemistry}

\subsection{The cell potential}


The equilibrium cell potential of a unit cell, $E_{c e l l}^{e}$, in galvanic (i.e. discharging or electricity generation) mode is given by the difference between the standard electrode potentials of the cathodic and anodic reaction, $E_{c}^{e}$ and $E_{a}^{e}$ :

$$
E_{\text {cell }}^{e}=E_{c}^{e}-E_{a}^{e}
$$

This is determined by the thermodynamics of the reaction and is related to the Gibbs free energy change, $\Delta G_{c e l l}$, which is the maximum thermodynamic energy available in the cell. $E_{e, c}$ and $E_{e, a}$ can, in an ideal, reversible system, be obtained from the Nernst equation in terms of the measurable concentrations of the species $c_{o x}$ and $c_{r e d}$ :

$$
E_{e}=E_{e}^{\circ}+\frac{2.3 R T}{z F} \log \frac{c_{o x}}{c_{\text {red }}}
$$

where $E_{e}$ is the equilibrium potential of the anodic or cathodic reaction and, $E_{e}^{\circ}$ is the formal potential of the redox couple.

In reality, the cell potential, $E_{\text {cell }}$ departs from equilibrium conditions since other potential losses are involved, including the overpotential at each electrode, the ohmic losses in the electrolytes, membrane/separators and electrode materials. The equation that determines the cell potential of any battery can be written as:

$$
E_{\text {cell }}=E_{\text {cell }}^{e}-\sum|\eta|-\sum|I| R
$$

where $\sum|\eta|$ is the total overpotential in the cell and $\sum|I| R$ the total ohmic loss. $E_{\text {cell }}^{e}$ is given by the choice of electrode reactions and their inherent thermodynamics, $\sum|\eta|$ by electrode kinetics 
(including charge transfer and mass transfer) and $\sum|I| R$ by Ohm's law. $\sum|\eta|$ is comprised of the activation overpotential, $\eta_{a c t}$, and the mass transport (concentration polarisation) overpotential, $\eta_{\text {conc }}$, for both electrode processes:

$\sum|\eta|=\left|\eta_{\text {act }}^{c}\right|+\left|\eta_{\text {act }}^{a}\right|+\left|\eta_{\text {conc }}^{c}\right|+\left|\eta_{\text {conc }}^{a}\right|$

The activation ovepotential $\eta_{a c t}$, is the additional voltage over and above the equilibrium value that needs to be added for the reaction to occur and can be minimised by catalysts and higher temperatures while high surface-area electrodes and high mass transport flow regimes usually mitigate $\eta_{\text {conc }}$, which is significant during reactant depletion at the electrodes.

$\sum|I| R$ accounts for the ionic and electronic resistance of all the components in the unit cell at the operation current, including the resistance of the anolyte, $I R_{\text {anol }}$, catholyte, $I R_{c a t h}$, separator, $I R_{\text {sep }}$, electrodes and their electrical connections, $I R_{\text {circ }}$ :

$\sum|I| R=I R_{\text {cath }}+I R_{\text {anol }}+I R_{\text {sep }}+I R_{\text {circ }}^{c}+I R_{\text {circ }}^{a}$

Ohmic losses in RFBs should not be underestimated. The number, thickness and electrical resistivity of separators, bipolar electrodes, and the interphases between electrodes, plates and current feeders/collectors render them much more important than in small, static batteries, having a significant contribution to the potential output of a stack of cells. A low electrical resistance between felt electrodes and bipolar plates is required or voltage efficiency is reduced, e.g., by high-resistance connections between a metallic current feeder and a carbon electrode [122]. 


\subsection{Faraday's laws and electrochemical change}

Faraday's laws relate the amount of active material in an RFB, $n$, undergoing an electrochemical reaction in each half-cell to the electrical charge, $q$, which can be integrated from the total electrical current, $I$, applied over a time interval, $t$ :

$$
\frac{d n}{d t}=\frac{\phi I}{z F}
$$

where $F$ is the Faraday constant $\left(96485 \mathrm{C} \mathrm{mol}^{-1}\right)$ and $z$ electron stoichiometry and $\phi$ is the current efficiency, considered due to competing side reactions at the electrodes.

The rated capacity of a battery is deliverable electrical charge expressed in A h units $(1 \mathrm{~A} \mathrm{~h}=$ $3600 \mathrm{~A} \mathrm{~s}$ ) for a given potential. This charge can be related to the content of active material in the device. If it is present in solution, as in RFBs, the relationship can be expressed in terms of its concentration, $c$, and the volume of the electrolyte, $V$ :

$$
q=c V z F
$$

If the material is solid, as in the half-cell of some hybrid RFBs, the mass and the ideal thickness of a uniform deposit of active material can be calculated from Faraday's law. In an RFB, $\Delta c$ is directly related to a change of SOC and, expressed as the fractional conversion, $X_{A}$, this change can be described by a reactor model (section 5.1).

\subsection{Electrode kinetics}

The rate control (charge transfer, mixed control or mass transport) of the electrode reactions in an RFB will determine the relationship between the electrode potentials and the 
developed/imposed current density. The type of rate control at the positive and negative electrodes can be different due to one reaction becoming subject to mass transport control before the other, implying a limiting electrode. Thus, it is important to obtain polarisation curves for each electrode. Preferably, the electrode reactions in a RFB should be under charge transfer control, where the system is less dependent on flow, although insufficient mass transport in the stack can produce voltage drops due to local depletion of reactant [123]. In practice, electrodes in electrochemical reactors operate under a degree of mixed control due to current, potential and flow distributions (sections 5.5 and 5.6). The total effective current, $I_{\text {tot }}$, for the desired reaction is then given by:

$$
\frac{1}{I_{\text {tot }}}=\frac{1}{I_{C T}}+\frac{1}{I_{L}}
$$

where $I_{C T}$ is the current due to charge transfer and $I_{L}$ is the limiting current under mass transport control.

The electrode kinetics under charge transfer control are given by the Butler-Volmer equation, but if the overpotential, $\eta$, has a significant value the resulting current density, $j$, can be approximated by the Tafel equation. The anodic Tafel equation can be expressed as:

$$
j=z F k c \exp \frac{\alpha z F \eta}{R T}
$$

where $\alpha$ is the charge transfer coefficient for the reaction and $k$ is the electron transfer rate constant. 
If the overpotential is sufficiently high, mass transport becomes the rate controlling step of the electrode process. A faster flow velocity or increased mixing/turbulence will increase current. In this case the limiting current, $I_{L}$, can be given by:

$$
I_{L}=z F k_{m} A c=K v^{x}
$$

where $k_{m}$ is the mass transport coefficient and $A$ the active electrode area. The limiting current can be related to the mean linear velocity of the electrolyte, $v$, by empirical constants such as $K$ and $x$. Typical values for $x$ in an empty rectangular channel are between 0.3 and $>0.5$ for laminar and turbulent flow regimes, respectively [124].

Although the electrode reactions in a RFB are not necessarily under full mass transport (constant current determined by design and current availability instead), the characterisation of the reaction environment under this condition is an advantageous tool in the assessment of electrode and cell design performance, which are very important during scale-up (section 9). As described in the next section, the mass transport coefficient, $k_{m}$, can be estimated via: 1 ) measurement of limiting currents, e.g., [125-127], or 2) approximation to a plug flow reactor model, e.g., [128-130]. In studies for RFBs, $k_{m}$ has been estimated from the rate of concentration decay in a $\mathrm{Br}_{2}$-polysulfide stack with parallel-plate electrodes [128]. Due to the difficulties in determining the active electrode area, the product $k_{m} A$ can be used, rather than $k_{m}$, as a figure of merit.

\section{Fundamentals of electrochemical engineering}

\subsection{Dimensionless group correlations}


The current output, voltage and efficiency of a RFB depend on electrolyte flow, mass transport, reactant conversion and electrode potential distribution. In order to design and size the unit flow cells and stacks, and to predict the conversion of the active species in the reservoirs over time, it is essential to quantitatively characterise the environment in which the electrode processes take place. The transformation in an electrochemical reactor can be established by a) macroscopic balances (global) and b) differential balances (microscopic scale) of mass, movement and heat $[7,8]$; the first are dependent on empirical data and the latter on analytical or numerical solutions (and problem statement). The relation between the involved variables provided a description of the system and can be studied in a simple manner through dimensional analysis $[7,8]$.

The mass transport environment can be conveniently normalized and characterized using dimensionless group correlations developed for rectangular channel, filter-press reactors [511]. These figures are highly useful in industrial development by allowing comparative studies of cell designs or electrode materials. The dimensionless group mass transport correlation for 2-D, planar electrodes in a rectangular electrolyte flow channel is given by the Sherwood number, $S h$ :

$$
S h=a R e^{b} S c^{c} L e^{e}
$$

where the coefficients $a, b$ and $c$ are determined experimentally ( $a \approx 2.5$ for planar electrodes under laminar flow [5]). The definitions of the dimensionless numbers are given in Table 2 . Together, they normalize for electrolyte properties, diffusion of the active species and dimensions of the flow cell. The Reynolds number, $R e$, describes fluid flow, and the Schmidt number, $S c$, electrolyte transport properties. Le describes the electrode and flow channel 
geometry. From the expanded form, $k_{m}$ at the electrode can be obtained as a function of the electrolyte mean linear velocity, $v$.

The dimensionless mass transport correlation for 3-D, porous electrodes usually takes the form [131]:

$$
S h=a R e^{b} S c^{c}
$$

In this case, if the expanded expression is multiplied by the volumetric electrode area, $A_{e}$, the volumetric mass transport coefficient, $k_{m} A_{e}$, can be obtained as a function of $v$ by an relationship [9,131]. $k_{m} A_{e}$ constitutes an electrode performance factor and it can be determined from limiting current measurements (equation 10) or from the fractional conversion fitted to a reactor model (next section). This expression is more practical than the actual value of $k_{m}$, as $A_{e}$ is difficult to obtain experimentally, especially when using large-size planar electrodes or porous materials, such as carbon felt. Furthermore, $k_{m} A_{e}$ can be applied to cell design in the estimation of the length and thickness of efficient electrodes for an acceptable potential loss and required fractional conversion $[7,8,132]$.

A set of diverse Pt/Ti porous electrodes for Ce-based RFBs has been studied in detail by determining their $k_{m} A_{e}$ via limiting current measurements [127]. As shown in Figure 7, a felt electrode produced $k_{m} A_{e}$ values of up to two orders of magnitude superior to that of a planar electrode. The performance factor was increased at electrodes with large $A_{e}$. Carbon felt electrodes were compared in this way for a $\mathrm{Br}_{2}$-polysulfide $\mathrm{RFB}$ [133]. Examples of mass transport studies in rectangular channel cells under controlled flow include segmented electrodes [134] and the relationship between mass transport and pressure drop $[135,136]$. 
Recently, Bisang et al. have used dimensional analysis to study various parallel plate filterpress reactors [137-139].

\subsection{Reactor models and fractional conversion}

A first approximation of the behaviour of RFBs can be obtained from isothermal electrochemical reactor models [5,6,140-142], according to their mode of operation and fluid flow conditions. Such models describe the fractional conversion of the redox reactive species (change in SOC) under mass transport control as a function of the volumetric flow, time and mass transport coefficient, typically within $5 \%$ of measured values. Deviations will be caused by operation outside mass transport and irregular flow, e.g., when the flow in the stack is nonideal, flowing by the sides of the electrode compartments [123]. The model can be established by following the fractional conversion (reactant concentration), $X_{A}$, or by determining $k_{m} A$ from limiting current measurements. The electrode area, $A$ is equivalent to the product $A_{e} V_{e}$.

The parallel plate filter-press reactors used in RFBs belong to the plug flow reactor (PFR) model type [5-10]; the electrolyte is assumed to flow continuously through the reactor without significant mixing in the direction of the flow, its concentration changing as a function of electrode length. PFRs can operate under three different electrolyte flow modes or regimes, as shown in Figure 8:

a) Single pass PFR. The electrolyte flows through the reactor between two separate reservoirs at a constant volumetric flow rate, e.g., in a RFB for black start applications.

b) PFR under batch recirculation. The electrolyte circulates continuously between the reactor and a mixed reservoir at a constant volumetric flow rate, as in most RFBs. This allows increasing the electrolyte volume and its residence time in the reactor. 
c) A cascade of PFRs. The electrolyte flows successively through two or more reactors hydraulically connected in series at a constant volumetric flow rate, for instance, in an array of cell stacks.

These models can be applied to individual cells, stacks or arrays of RFBs; their expressions are given in Table 3 [142]. Small laboratory RFB cells approximate to the batch reactor model (not a PFR, since it assumes perfect mixing) [130]. In the table, the reactant concentration is $c_{(\text {in })}$ at the reactor inlet manifold, $c_{(o u t)}$ at the reactor outlet manifold, $c_{i n(t)}$ at the inlet at time $t, c_{i n(0)}$ at the inlet at time zero, $c_{(t)}$ the concentration at time $t$ and $c_{(0)}$ the initial concentration. $N_{R}$ is the number of identical model reactors (e.g., individual cells in a stack) and $X_{A}$ the fractional conversion. The mean residence time in the tank, $\tau_{T}$, is given by:

$$
\tau_{T}=V_{T} / Q_{V}
$$

where $V_{T}$ is the volume of electrolyte in the tank and $Q_{V}$ the volumetric flow rate. Time $t$ divided by $\tau_{T}$ yields the number of electrolyte recycles.

Typical values of reactant fractional conversion for a single pass through an industrial-scale flow cell are between $1 \%$ and $10 \%$, while the conversion over a single large stack at low flow rate can be as high as $50 \%$ (the percentages also are relative to the overall volume). $X_{A}$ will determine the number of cells in the stack, as cells near the end of the stack (in cascade configuration) should not operate at low efficiency with depleted electrolyte, due to the rise of unwanted secondary reactions. 
Ponce de León et al. [128] have demonstrated the determination of the average $k_{m}$ in the $\mathrm{Br}$ polysulfide RFB from the slope of a log-log plot of the normalized conversion against time (change in SOC) for different flow rate values using a form of the PFR in batch recirculation model:

$$
\log \left(\frac{c_{\text {in }(t)}}{c_{\text {in }(0)}}\right)=2.3 \frac{t}{\tau_{T}}\left[1-\exp \left(-\frac{k_{m} A}{Q_{V}}\right)\right]
$$

The value of $k_{m}$ was correlated to the pressure drop across the stack in order to assess its overall performance. Ideally, high values of $k_{m}$ should be obtained with a low pressure drop, avoiding dependence on pumping power. The parameter $k_{m} A$ describes the performance of the stack and determines the reactant conversion; $k_{m} A$ is affected by electrode material and geometry (2-D, 3-D), cell design and flow rate. A vanadium RFB cell has been modelled as a plug flow reactor by Li et al. [143], allowing to determine the required flow rates as a function of the SOC and charging current.

\subsection{Expression of battery performance}

Figures of merit (FOMs) are used to quantify the performance of RFBs in order to compare different chemistries and cell designs, batteries at different scales or composition changes. FOMs should always be referred to the SOC, which has an important effect on the performance of the battery. The SOC represents the fraction of active species converted to their charged form. Typically, the SOC of the battery is referred to the concentration of the limiting electrolyte; strictly, each half-cell will show different degrees of conversion. SOC can be determined by spectroscopic UV-visible methods, as demonstrated for the all-vanadium RFB optical absorption [144] and transmission spectra [145]. The absorption-concentration relationship can be dissimilar for each electrolyte, e.g., linear for $\mathrm{V}^{3+} / \mathrm{V}^{3+}$ but non-linear for 
$\mathrm{V}^{4+} / \mathrm{V}^{5+}[146-148]$. Infrared spectroscopy can also be employed $[149,150]$. The redox potential of the electrolytes, measured in an open-circuit monitoring cell can also be used to determine the SOC, as in the all-vanadium RFB [144]. For the same system, modelling has permitted to estimate the SOC with high accuracy considering ageing in couple to on-line monitoring of open-circuit potential [151]. Volumetric titration can be easy to implement in laboratory studies, e.g., in the Zn-Ce RFB [152]. Electrolytic conductivity $[153,154]$ and viscosity-based [155] monitoring methods have also been considered.

Important performance indicators for electrochemical reactors have been considered in detail $[9,156]$. In the case of RFBs, the most important FOMs are related to the charge capacity, energy density and energy efficiency [12]. At constant current, the volumetric energy density, $E_{V}$ (units: $\mathrm{W} \mathrm{h} \mathrm{m}^{-3}$ ) is:

$$
E_{V}=\frac{I t E_{c e l l}}{V}
$$

where the total electrolyte volume in each half cell is considered.

Another important performance indicator is the electrochemical energy efficiency, $\eta_{e}<1$, which depends on the charge (coulombic) efficiency, $\eta_{C}$, and voltage efficiency, $\eta_{V}$ : Under constant current conditions

$$
\eta_{e}=\eta_{C} \eta_{V}
$$

The $\eta_{C}$ is predominantly affected by parasitic reactions, while $\eta_{V}$ by overpotentials and internal resistance. These efficiencies are maximized by appropriate cell design and operation. 


\subsection{Experimental studies of reaction environment}

It is essential to establish a good reaction environment within each flow cell compartment, including a sufficiently uniform distribution of: a) Reactant and product concentration (hence fractional conversion of reactant); b) Electrolyte velocity past the electrode surface (hence mass transport rate); and c) Potential (hence current) over the electrode surface.

Figure 9 summarises the aspects of the reaction environment in RFBs and their interrelationship. Characterization includes reaction kinetics, mass transfer, hydrodynamics, current and potential distribution (the latter two related to electrode resistivity and distance from electrical connection) [157]. Insufficient mass transport in the cell stack can produce significant potential drop due to consumption of redox species; the cell stack has to the designed accordingly, with free electrolyte flow, as electrolyte flow in large stacks can be non-ideal, either lower than expected, not completely developed or not using the total electrode area [123]. Flow visualization becomes a valuable device to study the flow in filter-press reactors, e.g., in the case of a commercial cell [158].

Few experimental studies of the reaction environment in RFBs exist in the literature, an important exception being the full-sized XL cell from Regenesys. Pilot-scale XL5 and XL10 cell stacks have been extensively characterised by Walsh and Ponce de León et al. [128,159] The obsolete, but instructive, XL module was conceived with production engineering in mind and benefitted from extensive studies of its reaction environment. Figure 10 shows an XL 200 module stack rated at $100 \mathrm{~kW}$ using composite carbon-polymer planar electrodes $\left(0.72 \mathrm{~m}^{2}\right)$ [160]. A $1.8 \mathrm{~mm}$ thick polymer mesh separated each electrode from the ion exchange membrane. The general reactor specification is summarised in Table 4. A drawing of a single 
electrode frame used for reaction environment studies is shown in Figure 11a), while Figure 11b) illustrates the cell stack arrangement. Mass transport studies of the XL stack were carried out with $1 \mathrm{~mol} \mathrm{dm}^{-3} \mathrm{Na}_{2} \mathrm{SO}_{4}$ in the 'polysulfide' compartment and ca. $0.9 \mathrm{~mol} \mathrm{dm}^{-3} \mathrm{NaBr}$ in 1 mol dm ${ }^{-3} \mathrm{Na}_{2} \mathrm{SO}_{4}$ in the 'bromine' compartment [159]. After applying $100 \mathrm{~A}$ (corresponding to a current density of $139 \mathrm{~mA} \mathrm{~cm}^{-2}$ ) for $60 \mathrm{~min}$., the positive and negative half-cells were shortcircuited, causing the reduction of dissolved bromine and the oxidation of hydrogen absorbed in the porous electrode. The PFR model in batch recycle given in equation (24) was used to estimate the global mass transport coefficient from the decay in the normalised concentration, $c_{i n(t)} / c_{i n(0)}$, of dissolved bromine at times $t$ and $0 v s$. the batch recirculation time, $t$. The term in square parenthesis is the fractional conversion in a single pass while $t / \tau_{T}$ represents the number of times that the electrolyte recycles through the tank.

The pressure drop was then measured between the inlet and outlet spiral manifolds and the 10 'bromine' compartments of the cell stack over a range of mean linear flow velocities between 0.13 and $6.5 \mathrm{~cm} \mathrm{~s}^{-1}$. Figure 12 shows the pressure drop in the stack $v s$. the mean linear flow velocity, which is given by the empirical relationship $\Delta p /$ bar $=0.13+\left(0.017 v / \mathrm{cm} \mathrm{s}^{-1}\right)^{1.9}$. The pressure drop through the electrode channels filled with turbulence promoters is relatively low in this RFB with planar electrodes and the losses take place predominantly at the spiral manifolds for the reduction of shunt currents. Note that the measured $\Delta p$ in the rectangular channels was higher than the predicted value. In comparison, $\Delta p$ can be up to 0.83 bars at 16 $\mathrm{cm} \mathrm{s}^{-1}$ in the well-studied FM01-LC flow reactor (planar electrode) [125]; 1.5 bar at $133 \mathrm{~cm}^{3}$ $\mathrm{s}^{-1}$ in a ElectroSynCell ${ }^{\circledR}$ industrial reactor (nickel foam electrodes) [161] and 2.2 bar at $20 \mathrm{~cm}$ $\mathrm{s}^{-1}$ in a single cell containing a carbon felt electrode [162]. 
The global mass transport coefficient, $k_{m}$, was then related to $\Delta p$ across the RFB stack. Figure 13 shows the values of mass transport coefficient and pressure drop at the same given mean linear flow velocity. At the nominal design mean linear flow velocity of $2 \mathrm{~cm} \mathrm{~s}^{-1}$, the 10 'bromine' compartments of the cell stack produced a $\Delta p$ of 0.21 bar [159]. Studies of XL5 (five bipolar electrode stack) reactors gave broadly similar results [128]. Flow dispersion vs. flow rate and residence time distribution (RTD) data for the same stack are shown in Figure 14. At lower flow rates, a second dispersion peak reveals the formation of a slow and a fast phase inside the reactor. In related works, Trinidad et al. have described the fitting of 8 different flow dispersion models to the FM01-LC reactor [163], while Bisang et al. have reported RTD in other parallel plate cells $[164,165]$.

These studies are unusual in considering: a) a reduced length stack of 5 or 10 bipolar electrodes from a large, industrial-scale reactor stack directly taken from a practical modular RFB stack, b) fluid flow and mass transport in such a small gap ( $c$ a. $2 \mathrm{~mm}$ ) production engineered cell, c) the decay of in-situ generated bromine concentration as a means of measuring mass transport, d) study of residence time distribution.

\subsection{Physicochemical balances for dynamic models}

Differential balances rationalise the complex and dynamic relationships among current and potential distribution, reaction kinetics, mass transport and ohmic potential drop in the electrolyte in terms of the fundamental physicochemical, fluid flow and electrochemical principles $[7,8,11]$. Their modelling and solution by computational methods provides a complete description of the ideal flux of redox species, fluid flow velocity, mass transport, reactant concentration and current and potential distribution in all points of the electrode compartment. The application of this approach to design optimization and prediction of 
behaviour in possible operational conditions in an essential tool in the development of modern electrochemical technology. A summary of important expressions and methodology is here given as an overall guide. A detailed treatment can be found in the book by Newman and Thomas-Alyea [11].

In RFBs and other electrochemical cells, the mass and charge transport properties of the active species under the electrode potential fields can be described by the Nernst-Planck equation:

$$
N=-z u F c \nabla \Phi-D \nabla c+c \mathbf{v}
$$

where $N$ is the total net flux density of a species, $u$ is its mobility, $z$ is its charge number, $c$ is its concentration and $D$ is its diffusion coefficient and $\Phi$ is the electrostatic potential. Different relationships are applied in models; for instance, the electrostatics are considered using the Poisson equation [166], while current and potential distribution due to Ohm's law are solved by the Laplace equation [11]. Local charge flow density is calculated by implementing Faraday's laws and the electroneutrality principle. Butler-Volmer or Tafel electrode kinetics can be considered depending on the desired level of accuracy required. These models apply appropriate mass balances and boundary conditions. Bouzek et al. have produced several detailed simulations of industrial electrochemical systems using this general approach [167].

Flowing electrolytes in RFBs can be modelled using the laminar, incompressible flow hydrodynamics described by the Navier-Stokes equation [11]:

$$
\frac{\partial \mathbf{v}}{\partial t}+\mathbf{v} \cdot \nabla \mathbf{v}=-\frac{1}{\rho} \nabla p+v \nabla^{2} \mathbf{v}+\mathrm{g}
$$


where $v$ is the kinemtic viscosity of the fluid, $\mathbf{v}$ is the mass-average velocity vector and $\mathrm{g}$ is the acceleration under gravity. Turbulent flow can be considered in CFD using the Reynolds averaged Navier-Stokes (RANS) equations considering the permeability of porous electrodes [157].

\subsection{Modelling and simulation of RFBs}

These aspects are considered in a concise and qualitative manner only. Models should relate RFB and operational conditions to performance, as evidenced by figures of merit including power, energy, charge capacity and energy, voltage or charge efficiency. Commonly, a RFB model should be capable of predicting and rationalising experimental findings on, for example: a) cell and stack potential $v s$. time and current density, b) performance efficiency as a function of time, under various operating conditions and c) the local distributions of electrolyte flow and current density with position and time within the cell. It is important that any optimisation of performance defines the criteria for optimisation (e.g., design simplicity, capital cost, running cost or energy efficiency) as well as the computational approach taken.

The types of model include techno-economic, multi-physics, the electrical network, technoeconomic and chemical engineering approaches. First principles and commercial software, (e.g., Comsol, Simulink) may be utilised, the first offering flexibility and rigour, albeit at the expense of time, manpower, limited generality and rapid redundancy. 1-, 2- and 3-dimensional static and dynamic treatments may be applied. Approximate, practical and skeletal models, ranging to extensive multi-parameter rigorous ones, have been considered. As summarized by Klotz [168], electrochemical models can also be classified into the so called, white (exact physical description), grey (combination of physical description and empirical relations) and black box (behaviour reproduction) types. 
A flow chart indicating the strategy, organisation and operation of the model is useful but seldom given. Examples of such charts are provided by Viswanathan et al. [169] in their costperformance model and by $\mathrm{Xu}$ and Zhao [170] in their timely review of fundamental models for flow batteries. For example, Figure 15 indicates a flow chart to summarise the approach taken by Bayanov [171].

Traditionally, there have been few examples of practical models validated by operational experience and experimental validation but there is evidence of much recent effort, especially for the all vanadium RFB. Examples include cell voltage vs. time during a charge-discharge cycle and soluble lead concentration distributions $[172,173]$. Other approaches include technoeconomic ones for Br-polysulfide $[174,175]$ and dynamic models for the all-vanadium RFB, taking into account diffusion, thermal simulation and shunt currents [176-179]. Simulation of the cost of RFBs for power grid regulation has also been achieved [180].

Common types of RFBs being treated by mathematical models include (selected):
a) The all vanadium cell, e.g., $[171,173,176,181]$
b) Zinc-bromine cell [182-184].
c) Bromine-polysulfide cells $[174,175]$.
d) Soluble lead batteries [185].
e) Hydrogen-bromine cell [186-188].

Vanadium RFBs are by far the most commonly encountered RFBs [26] and modelling has been considered by several groups: a general multiphysics dynamic approach considering electrolyte flow through homogeneous porous electrodes coupled to electrochemical kinetics and mass 
transport [172]. The model successfully predicted cell voltage vs. time and localised distributions of vanadium concentrations, current and potential within a unit cell [173]. Later extensions to this model considered non-isothermal conditions [189], hydrogen evolution [190] and oxygen evolution [191] during charge. The model was demonstrated for experimental charge-discharge data and its use in monitoring was highlighted [144]. Other important contributions include:

a) A dynamic model of ion diffusion and loss [176].

b) Thermal modelling and self-discharge [177].

c) The effect of shunt current on efficiency and temperature [179].

d) A multi-physics and energetic model [192].

e) Optimization of the operating point [193].

f) Capital cost sensitivity [194].

g) A simplified model [195].

h) Shunt current in a cell stack [196].

i) Aging model prediction [197].

Few of these, however, consider ageing effects or practical problems such as irreversible electrode poisoning or electrical contact problems between the feeder and a porous electrode. In general, RFB models have not taken into account membrane degradation, which has a much longer history in models for PEM fuel cells [198], as does heat and water transport/balance in fuel cells [199].

It is important to appreciate that models for rectangular flow channels in filter press cells are relevant to the fluid flow, mass transport, fluid dispersion and current distribution in RFBs. 
Examples include the current distribution [200] and reaction environment in FM01-LC cells [201], and the development of a model for characterization of fluid dispersion [202].

PEMFC design principles such as flow-field designs to RFBs with promising results [203], and electrolyte flow has been modelled for these electrode designs [204-206]. Nevertheless, the very different reaction environment conditions in a liquid electrolyte RFB, as well as pressure drop and electrode connection requirements must be considered.

The driving forces for adopting a mathematical model of an RFB can include:

a) Prediction of performance to aid battery and process design, before use.

b) Rationalisation of the effect of variables in experimental performance.

c) Minimisation of the number or complexity of laboratory experiments.

d) Extension of performance expectation at a different scale of operation.

Practical, trustworthy models are forged from a knowledge of experimental data across various scales; all models require experimental verification, preferably from an independent source.

Recently, Kodym et al. [167] have demonstrated how the development of multi-dimensional models and the availability of computational power have made possible the macroscopic modelling of stacks of parallel plate electrochemical reactors, which is applicable to RFB modules. As highlighted by Watt-Smith et al. [144] the use of detailed, physics-based modelling to rationalise and understand trends in data and to optimize performance has been demonstrated to be a realistic prospect. Such models would be particularly useful during the process of scale-up, reducing the financial burden on physical experimentation, and accelerating process development and providing greater confidence for commercialisation. The 
modelling multi-area power systems involving RFB has suggested that optimal automatic generation control regulators (OARs) can significantly increase the stability of the power supply [105].

\section{Functional components of RFBs}

\subsection{Electrodes}

Electrodes for RFBs have to meet challenging demands. They should have fast kinetics (electrocatalysis) and high selectivity towards the reactions of interest while maintaining their integrity and the stability of the supporting electrolyte [207]. Ideally, RFB electrodes should have the following properties: a) high electroactive area, b) low electrical resistivity, c) reasonable cost (preferably commodity over specialised electrodes), d) chemical stability (typically in highly acidic or alkaline medium), e) resistance to oxidation, f) ability to operate at high current densities (usually $<500 \mathrm{~mA} \mathrm{~cm}^{-2}$ ), g) adequate mechanical strength and elastic modulus, and h) long cycling life. Porous electrodes should be able to operate free of blockages and planar electrodes must be impermeable and their surface allow hydraulic sealing. Low resistivity of the electrode material reduces ohmic drop and keeps uniform potential and current distribution. Typical values and structures for achieving high performance are considered in detail elsewhere [208]. The electrode materials used in RFBs can be classified under the following categories: a) composite (carbon-based or metallic), b) electrocatalyst coating (coated or uncoated), c) structural geometry (2-D or 3-D), d) thermal or chemical treatment (treated or untreated), and e) flow mode (flow-by or flow-across).

The electrodes of RFBs are typically composite graphite-polymer plates plus porous electrode materials, e.g., carbon felt, compressed onto their surfaces. Bipolar electrodes have reversible cathode and anode sides with only the end electrodes in the stack electrically connected, 
allowing the current to flow perpendicularly to the electrode surface through the electrolyte. SEM images of a carbon-polymer composite bipolar plate are shown in Figure 16a). Microscopically, these materials are relatively heterogeneous. The polymer addition can confer robustness and flexibility without sacrificing too much electrical conductivity. Electrical connection to the felt is usually achieved by mechanical pressure, which determines the electrical resistance of the interphase and has to take into account the compressibility of the electrode. Uniformity of the felt materials is critical for long-term battery operation. Thermal bonding of the felt to the bipolar plates can help to obtain robust connections, but may result in polymer flow on the electrode surface and poor conductivity. Degradation of conductive resin adhesives used to bond porous materials onto conductive backing plates is problematic and thermal/pressure bonding is normally preferred.

Carbon-based electrodes are widely used in RFBs due to their reasonable cost, conductivity and chemical stability. A number of different carbon-based materials have been evaluated and used in many RFBs [28]. The high surface area of 3-D carbon and graphite felts helps to obtain fast reaction kinetics while maintaining relatively large overpotentials for gas evolution parasitic reactions [209]. Polyacrylonitrile (PAN)-based felts have been used in the all-vanadium system (Figure 16b) [28], and other carbon felt electrodes have seen use in the undivided Zn-Ce [210], $\mathrm{Fe}-\mathrm{Cr}$ [211], $\mathrm{V}-\mathrm{Br}_{2}$ [212], and Br-polysulfide systems [133]. It has been noted that surface hydroxyl, carbonyl and carboxyl groups affect the behaviour of these electrodes although it is not clear if the main cause for this is a modification of charge transfer and the kinetics of vanadium species [213] or an increase of their wettability [214]. Similar materials such as carbon paper have shown some suitability for all-vanadium RFBs [203] and have been used in the $\mathrm{H}_{2}-\mathrm{Br}_{2}$ system [92]. Carbon cloth was previously considered for the VRFB [215]. A disadvantage of these carbon materials is their oxidation and embrittlement during prolonged 
use. This can be further studied in RFBs by using accelerated electrode degradation methods [216]. The effect of fibre diameter on the reaction kinetics of porous electrodes has been modelled [188], showing that small diameter fibres are preferable for slow kinetics and vice versa. Electrode blockage by fibres coming off a poorly prepared or damaged felt electrode is a possibility.

In other systems, planar (2-D) carbon bipolar electrodes are more suitable, but at the cost of a reduced electrode surface area. The Br-polysulfide RFB used low-cost activated carbonpolymer composite electrodes [217]. In hybrid systems with metal deposition planar graphitized carbon polymers are advantageous and PVA, PVDF and HDPE-based materials have been used, e.g., in Zn-ferricyanide [218], Zn-Ce [219] and soluble lead [85] RFBs. In order to overcome the capacity limitation imposed by the flat surface, reticulated vitreous carbon

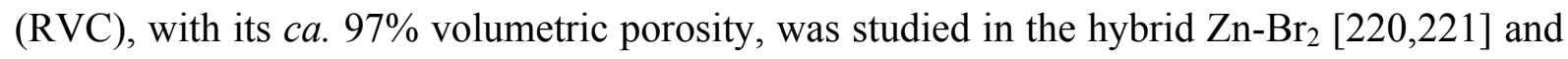
soluble lead [85,222] RFBs, although uniform coatings in the hybrid electrode were notoriously difficult to achieve. Due to the higher permeability of this 3-D porous material, RVC might be useful in RFBs with semisolid electrolytes [223]. RVC was also preliminarily evaluated for the VRFB [224]. Studies with glassy carbon discs have shown that oxygen functional groups could have a negative effect on the kinetics of vanadium species at RVC [225].

Catalytic coatings and different activation treatments can improve the performance of carbonbased electrodes. Carbon felts for the vanadium RFB have been modified with noble metals (Pt, Pd, Te, Mn, In, Au, Ir) [226,227], metal oxides $\left(\mathrm{RuO}_{2}\right.$ [228], $\left.\mathrm{Mn}_{3} \mathrm{O}_{4}[229]\right)$, non-metallic catalysts (mesocellular carbon foam [230], Bi [231]) and activated by thermal treatment [232] and acids [233]. The Fe-Cr RFB used carbon felts treated with gold and lead [211]. Goldmodified carbon felt has also been evaluated for the V-Ce RFB [234], although gold is corroded 
by $\mathrm{Ce}(\mathrm{IV})$ in acid solution. Modification of the surface by metal coatings also improves the electrical conductivity of felts [227]. Graphite bipolar plates coated with metallic $\mathrm{Ni}$ and $\mathrm{Cd}$ in the positive and negative sides were a requirement in the Zn-ferricyanide RFB [218]. More recently, nanomaterial-based composite electrodes, e.g., carbon nanotubes [235-237] and graphene [238] have been implemented and a method for bipolar plate production has been patented [239]. Metallic substrates coated with diamond-like carbon doped in various ways have also been studied as bipolar plates for RFBs [240].

Metallic electrodes have found less use in RFBs due to their restricted compatibility with many electrolytes and redox species, which can lead to irreversible reactions, oxidation or dissolution of the electrodes. Metal electrodes are also more expensive and heavier than their carbon-based counterparts, making their incorporation into RFB stacks less attractive. Nevertheless, micromesh and metal felt of foam could overcome this limitation. Some metallic electrodes used in RFBs include platinized titanium for the Zn-Ce (Figure 16c) [127], and nickel foam for the Br-polysulfide RFBs [241]. Cadmium-coated nickel and titanium coated with Ir and Ta oxides have also been considered for the Zn-air [242] and all-vanadium [243] RFBs, respectively.

Catalytic metal oxide electrodes have also received attention. Dimensionally stable anodes (DSA) are massively produced for the chlor-alkali industry and thus have been evaluated in various RFBs, despite their relatively high cost. In early studies, DSA was found to underperform in the Fe-Ti RFB in comparison to graphite foil [244] and to be compatible to Pt in the $\mathrm{Zn}-\mathrm{Br}_{2} \mathrm{RFB}$ [245]. DSA displays high stability and catalytic activity for vanadium conversion [246] and recent work has demonstrated that similar materials such as Ti coated with $\mathrm{IrO}_{2}$ and $\mathrm{Ta}_{2} \mathrm{O}_{5}$ can be used as positive electrodes in the VRFB [243], yielding higher 
energy efficiency although with increase in $\mathrm{H}_{2}$ evolution. DSA was also evaluated in the V-Ce RFB [247], were it showed a limited ability to reduce Ce(IV) ions. Ru-Co and Ru-Mn alloy oxides can be used as low-cost alternatives to precious metals in $\mathrm{H}_{2}-\mathrm{B}_{2}$ and $\mathrm{H}_{2}-\mathrm{Cl}_{2}$ systems [248].

Increasing attention has been given to the architecture of electrode materials in the field of static batteries [249]. Hybrid porous structures, hierarchical materials and templated composites are possible. For instance, composite electrodes embedded with percolating sulphur networks have enabled higher performance in a Li-polysulphide RFB [250]. A related example is a nanostructured thin film (NSTF)-PtCoMn electrode for fuel cells, which consists of catalytic nanowhiskers deposited on a membrane [251].

\subsection{Electrolytes}

The physical and chemical properties of the electrolytes also influence reactor design and the performance of a RFB. Ideal electrolytes should have: a) a high concentration of redox species, b) chemical and thermal stability, c) low viscosity, d) high ionic conductivity, e) reasonable cost and abundance, f) safety in use, g) suitability for long storage and h) the facility for chemical analysis to monitor state of charge. These properties are mostly determined by the chemical properties of the system; still, some compromise can be achieved at certain concentrations, whilst using additives or acid mixtures may enhance some of these properties. High concentration of active species translates into higher energy capacity and higher volumetric energy density, increasing current output and reducing secondary reactions. Saturated solutions can be used in some systems, but in others care must be taken not to reach the solubility limits to prevent precipitation. The concentration and physical properties of the electrolytes change with the SOC, so it is advisable to consider the interactive effects of these 
changes. Electrode contamination with the products of corrosion in a failed stack is a possibility that should be prevented. The importance of analysing redox species in the electrolytes, preferably by a continuous, non-destructive technique, is often overlooked in early studies.

Electrolyte viscosity is an important physical parameter as it is considered in the mass transport characterization of a RFB. High mass transport rates and thus higher energy efficiency are easier to achieve with low viscosity electrolytes, as descried by the Reynolds number. Likewise, the diffusion coefficient of the active species is related to the viscosity by the Einstein-Stokes relationship. Stacks and flow systems involving manageable pressure drop and pumping requirements can only be obtained if the electrolytes have reasonable viscosities. The ionic conductivity of the electrolytes has an effect on the cell potential, especially saturated solutions, which can have relatively high resistivity [252]. Shunt currents and their mitigation will be determined by the conductivity of electrolytes (section 8.4).

Most RFBs are based on strong acidic or alkaline electrolytes. For example, vanadium electrolytes often consist of $\mathrm{H}_{2} \mathrm{SO}_{4}$ solutions, sometimes with a small concentration of $\mathrm{H}_{3} \mathrm{PO}_{4}$ in order to increase stability [14]. Similar $\mathrm{H}_{2} \mathrm{SO}_{4}$ electrolytes are used in variants, e.g., V-Ce [80]. $\mathrm{HCl}$ solutions have been used in other systems, such as Fe-Ti [54] $\mathrm{Fe}-\mathrm{Cr}$ [53], all-iron [66], and all-copper [253] RFBs. The management of the corrosion and high vapour pressure of $\mathrm{HCl}$ can be problematic. Methanesulfonic acid electrolytes have a lower vapour pressure and help to prevent dendritic deposits in the hybrid soluble-Pb [85] and $\mathrm{Zn}-\mathrm{Ce}$ [31] RFBs. In principle, this acid could also be used in all-vanadium RFBs [254]. Mixtures of sulfuric and methanesulfonic acids have been proposed for the all-vanadium [255] and $\mathrm{Zn}-\mathrm{Ce}$ [114,256] RFBs, as well as sulfuric-hydrochloric mixtures for the all-vanadium system [112]. Acid 
mixtures have showed improvement in kinetics, but care must be taken in order to avoid metastable solutions or unnecessary complicated chemistries.

Alkaline electrolytes are commonly used in hybrid RFBs, such as the Zn-air [62], Znferricyanide [64] and Zn-Ni [257]. Alkaline solutions help to reduce hydrogen evolution at low potentials but dendritic growths and carbonation of the electrolyte can be a problem. $\mathrm{KOH}$ electrolyte can be used in a quinone-ferricyanide system [100], which has the advantage of low cost. However, in the original Zn-ferricyanide scale-up study, ferricyanide species crystalized and solid management was required [218]. Further progress in ferricyanide systems will need careful consideration of speciation conditions, especially when HCN gas could be evolved in the unlikely event of the electrolyte becoming acid. Other electrolytes involve complex halide species, such as the Br-polysulfide [12,71], $\mathrm{Zn}-\mathrm{Br}_{2}$ (polybromide ions) [46,47], V-polyhalide $\left(\mathrm{Br}_{2} \mathrm{Cl}^{-}\right.$ions) [81] and $\mathrm{Zn}$-polyiodide [95]. In general, complexing agents are required so that halide produced during charge remains in the solution as a heavy complex, avoiding toxic halogen gas evolution.

Non-aqueous electrolytes have also received attention due to their wider potential window that could enable higher cell potentials than those possible in aqueous solvents [27,36]. Examples include acetonitrile [258,259] and propylenecarbonate [260] support electrolytes. At the moment, none of these systems has been scaled-up and the relatively low conductivity of these media needs to be addressed. Non-aqueous electrolytes will only be implemented if low cost targets can reached [261], together with adequate safety, storage and transport. Other media, such as ionic liquids, will prove challenging due to their limited availability, rheological properties, susceptibility to water absorption, restricted stability and cost. 
Complex electrolytes based on suspensions of percolating conductive particles have also attracted interest for RFBs [262]. Aqueous 'slurry electrodes' have been explored for the Znair [263] and all-iron RFB [264], but more recent versions of the same concept are nanofluids and semi-solid 'flowing electrodes' containing nanostructured carbon materials. Non-aqueous Li-based RFBs with such features have been proposed [265]; incorporated materials also include carbon black [266] and magnetic nanoparticles [267]. Multi-walled carbon nanotubes have been demonstrated as flow electrodes for $\mathrm{VO}^{2+} / \mathrm{VO}_{2}{ }^{+}$redox couple [262], while superporous carbon has enabled semi-solid Li-air RFB non-aqueous electrolytes [223]. Different concepts for Zn hybrid RFBs can also be found, for instance a system based on a suspension of Ag doped polyaniline [268] and a system based on polymerized 2,2,6,6-tetramethylpiperidinylN-oxyl (TEMPO) present as micelles [269]. Rheological limitations and hindered electron transfer at the solid-suspension interface [270] are the main limitations of these systems, not to mention the need for testing under realistic operational charge-discharge regimes.

\subsection{Membranes and microporous separators}

Separators are a crucial component for most RFBs, providing a physical barrier between the dissimilar electrolytes while allowing the transport of the charge carrier ions and preventing the contact between adjacent electrodes in RFBs with zero-gap architecture. Ion exchange membranes (IEM) are the widely used. Their main disadvantage is their cost, making up as much as $40 \%$ of the total [17]. Micro and nanoporous separators provide a promising low-cost alternative [271] to IEMs at the expenses of an inferior performance [272]. Separators increase the design complexity of stacks, double the size of the flow system, and introduce high cost and limit the lifetime of the devices. Hence there are considerable incentives in developing highperformance RFB undivided systems. 
IEMs must have high ionic conductivity to minimize ohmic loss and high ion selectivity to avoid electrolyte cross-mixing. Chemical stability under strong acid or alkaline electrolytes containing strong oxidants $\left(\mathrm{VO}_{2}{ }^{+}, \mathrm{Br}_{3}{ }^{-}, \mathrm{Ce}^{4+}\right)$ is necessary, as membrane degradation can determine the operational lifetime of a RFB. IEMs should also have the mechanical strength to withstand (undesirable) differential pressure and the compression against porous electrodes. Membranes are usually bonded to the frames of individual cells by compression or plastic welding as seen in section 9.2.

Characterization and performance evaluation of IEMs under operational conditions is essential. The two main properties required for cell stack design are the potential drop and the area resistance. The latter is the product of ionic resistance across the membrane and its projected area in $\Omega \mathrm{cm}^{2}$ units (a scalable dimension). This can be measured using a 4-electrode membrane test cell. Other important properties include: a) ion exchange capacity, b) ionic conductivity, c) ion permeability d) leakage, e) electrolyte uptake, f) swelling ratio, and g) dimensional stability [27]. Chemical stability and resistance to oxidation studies are also required to assess the degradation of the membrane. There is surprisingly little data regarding membrane ageing under long-term operating conditions. Stability studies taking place during weeks of continuous cycling [273] can give some useful preliminary data but this time scale is still inadequate. Membrane degradation can be taken into account in RFB simulation, as it has been done for fuel cells [198].

Numerous commercial, modified and custom fabricated IEMs, both cationic and anionic, have been considered for RFB applications [24,25,27]. They can be grouped into: a) pore filled, b) perfluorinated, c) modified perfluorinated, d) partially perfluorinated and e) non-fluorinated [24]. In general, cationic membranes provide better ionic conductivity (due to the high proton 
mobility), chemical stability and mechanical strength than the anionic membranes [274], although some anionic membranes have shown considerably lower permeability to vanadium species, such as quaternary ammonium poly(fluorenyl ether)-based membranes [275]. In terms of chemical stability and resistance to oxidation, cationic perfluorinated membranes are superior to those based on hydrocarbon backbones [276].

Despite their high cost, Nafion ${ }^{\circledR}$ cation-exchange membranes continues to be the most cited cell divider in RFBs and a performance benchmark for the development of alternative materials. Commercially available and widely used in fuel cells [277], these perfluorocarbon membranes have an acceptable combination of high conductivity and chemical resistance. Alternative trademarks for ion exchange membranes include Aciplex ${ }^{\circledR}$, Flemion ${ }^{\circledR}$ and Fumatech ${ }^{\circledR}[15]$. Extruded Nafion $^{\circledR} 117$ has a typical area resistance of $0.16 \Omega \mathrm{cm}^{2}$ [278] and high chemical stability [279]. However, reactive species and water have relatively high diffusivity and permeability in Nafion ${ }^{\circledR}$ materials [280]. Indeed, electrolyte cross-mixing remains a problem in most RFBs.

In order to reduce the permeability of IEMs to redox species as well as their cost, several strategies have been investigated. For instance, alternative low-cost membranes based on poly(fluorenyl ether ketone) [281], sulfonated poly(sulfone) [282] and sulfonated poly(arylene thioether) [283] have shown similar conductivity and lower permeability to vanadium species than Nafion ${ }^{\circledR}$, yielding higher coulombic efficiencies in all-vanadium RFB cells. In-situ sol-gel synthesis of $\mathrm{SiO}_{2}[284,285]$ and $\mathrm{TiO}_{2}$ [286] nanoparticles as well as catalyst-coated membranes [287] and simultaneous polymerization with chlorosulfonyl groups [288] have reduced the permeability of Nafion ${ }^{\circledR}$ albeit increasing the area resistance. Increased selectivity and reduced water transfer can be obtained with higher degree of crosslinking [212], or layer-by-layer films 
preparation, e.g., alternating Nafion and polyethylenimine [289]. It has been claimed that the VANADion $^{\circledR}$ dual-layered separator consisting on a $20 \mu \mathrm{m}$ thick Nafion ${ }^{\circledR}$ polymer layer coupled to a microporous material could effectively reduce the cost of the separator with the usual benefits of lower area resistance and higher ion permeability [290].

Microporous separators offer a low-cost alternative to IEMs sometimes at comparable performance. The preparation and performance of these separators have been reviewed [271]. Most of them are polymer-ceramic composites, e.g., Daramic ${ }^{\circledR}$. The challenge posed by microporous separators is their high permeability, which results in electrolyte cross-mixing; as a result, pressure differentials will significantly affect the mass transport trough the separators [291], requiring pressure balancing control or more frequent electrolyte rebalancing.

\subsection{Turbulence promoters}

The performance of RFBs using planar flow-by electrodes (e.g., $\mathrm{Zn}-\mathrm{Br}_{2}, \mathrm{Br}$-polysulfide) can be improved by placing inert 'turbulence promoters' in form of polymeric (expanded and woven) meshes or nets within the electrode channels. These structures increase mass transport by rising the mean linear electrolyte velocity, mixing and turbulence, resulting in higher limiting current densities for a given flow rate in simple and low-cost manner [292]. These meshes can also help to achieve uniform flow distribution at the electrode surface [134]. The pressure drop caused by the turbulence promoters is low [136], although it can become more important with smaller electrode gaps. Turbulence promoters also separate and maintain a uniform gap between membranes and electrodes. The effect of turbulence promoters in small laboratory cells decreases due to the prevalence of manifold flow [293]. 
The mass transport enhancement factor, $\gamma$, has typical values $<10[292,294]$ and dimensionless group correlations can be used for their evaluation. Ralph et al. [294] studied the performance of several turbulence promoters in an attempt to relate their mass transport enhancement to their geometry and characteristic dimensions. It was found that their performance is related to the surface area in the opposing direction to the flow and that a profiled mesh with sharper edges gives superior results. Flow dispersion studies can also be used to study the effect of mesh turbulence promoters [164]. More recently, CFD simulations have provided a better understanding of turbulence promoters and the relation to their geometry [295-297]. It has been confirmed that the profiled mesh produces greater wall shear and that its orientation has an important effect [297]. Also larger angles of the mesh filaments increase mass transport [296], while different geometries can be evaluated taking into account the pressure drop effects [295].

Under the same principles as inert turbulence promoters, mass transport is also increased at metallic expanded mesh [298] and foam electrodes [161]. Additionally, it has been demonstrated that electrodes with nanostructured surfaces can significantly increase mass transport in flow cells [126].

\section{Engineering aspects of electrolyte flow}

\subsection{Modes of electrolyte circulation}

RFBs typically operate under batch recirculation mode, with the array of stacks hydraulically fed in parallel while the stacks among separated hydraulic arrays are electrically connected in series [299]. Unit cells in the stacks are, in turn, hydraulically feed in parallel by internal manifolds in the stack (Figure 17) or external tubes. There are several other ways in which electrolytes of a RFB can circulate through the unit cells and among the array of stacks and the tanks. Their advantages and disadvantages are here described. 
RFBs can be constructed for batch recirculation or simple batch operation, the first being the most suitable and generally used configuration.

- Batch recirculation. Two main tanks are needed for a divided RFB, which is economical. Each of the electrolytes circulates between the stacks and a single tank. A uniform concentration is maintained in the tanks, which changes gradually during charge and discharge cycles. These systems approximate to the plug flow reactor in batch recirculation model.

- Batch mode. This can be used only for black start applications. The electrolytes flow from holding to receptor tanks, passing through the modules. Having dedicated tanks for the charged and consumed electrolytes, the number of tanks in a divided system increases to four. Residence time in the modules is limited, reducing the conversion efficiency. These systems approximate to the single pass plug flow reactor model.

Independently of the mode of operation, arrays of several stacks can be disposed in two ways in terms of their hydraulic connections:

- Stacks arranged in parallel. This is the most common configuration; the individual stacks in the arrays are connected to the tanks in parallel. All the modules operate with the same inlet concentration of active species and similar flow rates of electrolytes, albeit with multiple fluid feeds to the cells in a stack. Such an array of modules can be approximated to a plug flow reactor model. This configuration is more common in medium-size RFB.

- Stacks arranged in cascade. The modules are connected hydraulically in series and the electrolytes flow successively through each of them. In this case, the concentration of the active species is different for each module. The progressive fractional conversion can be estimated by modelling the array as a cascade of plug flow reactors in order to ensure that 
the final modules in the array are not underperforming [123]. This configuration has been implemented in large systems with planar electrodes in order to reduce the size and cost of the piping system and of the electrical connections.

Regarding the internal flow within a stack, i.e., through the unit cells, this can be arranged in two manners:

- Unit cells fed by electrolyte in parallel. This is the most advantageous configuration. Internal manifolds or external tubes simultaneously fed the unit cells in the stack, seeking to achieve the same volumetric flow rate in each of them. Shunt current management is required. The electrolyte flows from bottom to top in order to displace gas bubbles. These stacks can be modeled as a plug flow reactor with the combined electrode area of all the half-cells.

- Unit cells can be fed by electrolyte in series or cascade mode. This configuration is not recommended [5]. The electrolyte flows successively through all the unit cells, meaning that one element of volume passes through each of them, gradually changing the concentration. This results in a higher pressure drop and less uniform flow. Depending on the stack orientation, the flow can alternate its vertical direction, producing problems with trapped gas. In theory, shunt currents can be minimized [300].

For the stacks (and cells) fed in cascade there are also two possibilities for the relative direction of the flow of the positive and negative electrolytes [34,300]:

- Electrolytes flowing in the same direction ('co-current'). This is a simple common solution. Both electrolytes enter through their respective inlet manifolds and flow in the same direction (relative to the longitudinal axis of the module). The conversion of the redox species through the rest of the cells increases in the same direction. 
- Electrolytes flowing in opposite directions ('counter-current'). The inlet manifolds (one for each electrolyte) of the module are placed in opposite sides, meaning that a charged and a consumed electrolyte flow through the first and last cells. It has been claimed that this configuration can reduce potential variation and water transfer while increasing the charge efficiency [300].

\subsection{Flow configuration at the electrodes}

There are three basic electrode configurations in relation to the electrolyte flow in parallel plate flow cells. In the 'flow-by' and 'flow-through' configurations, the electrical current is perpendicular and parallel to the fluid flow [301], respectively. The 'flow-through' mode is only possible with porous electrodes. An additional, less used, configuration for porous electrodes is called 'flow-across'. In this case, the overall direction of fluid flow in the cell is perpendicular to the current, but it turns parallel as it passes momentarily across the porous electrode [6]. The flow-by configuration has economic [301] and practical [132] advantages over the flow-through configuration, and has been used in most RFBs.

Flow-by porous electrodes greatly increase active surface area and enhance mass transport in comparison to planar electrodes, e.g., in the case of felt [302,303] and mesh electrodes [304]. An illustration on the significant difference provided by porous electrodes can be found in the Zn-Ce RFB [127]. Porous electrodes are compressed against the bipolar plates to ensure good electrical connection and so that no space is left between the felt and the membrane. Planar flow-by electrodes (e.g., $\mathrm{Zn}-\mathrm{Br}_{2}, \mathrm{Br}$-polysulfide, soluble $\mathrm{Pb}$ ), on the other hand, have lower surface areas, limiting conversion rates and mass transport while producing higher local current density at the surface. A static, inert turbulence promoter is generally placed in the flow channel to keep a uniform electrode-membrane separation. 
Several modifications to the electrolyte paths in filter-press cells (flow cell architecture) can be implemented in order to increase the mass transport through porous electrodes and have been used for many years in electrosynthesis reactors [6]. Inspired by fuel cell design, the 'flowacross' configuration and other variants have recently been applied to RFBs by machining serpentine [203,305] and interdigitated [306] flow fields in the bipolar plates adjacent to felt electrodes. These flow fields can also be cut from the felt electrodes [307], and perforated carbon paper electrodes have also been considered [308]. A study in a small cell has found that these configurations increase the flow across the porous electrode resulting in a significant increase of performance while reducing pressure drop over the cell [306]. Nevertheless, significantly larger ohmic losses are produced due to reduced electrical contact area and thick bipolar plate requirement, while results with large electrodes remain to be shown. Models for this configurations have been developed [204,305,309-311]. In view of the promising possibility of higher operational current density, more research is needed on the practical implementation of such features. As shown by Reed et al. [307], interdigitated flow fields have allowed an all-vanadium stack to operate at $320 \mathrm{~mA} / \mathrm{cm}^{2}$ with an energy efficiency of $75 \%$.

\subsection{Electrolyte flow fields and manifold flow}

The design of flow frames, unit cells and cell stacks evolves around controlled hydrodynamics. Simulation and modelling of flow fields end electrolyte manifolds within the cells by CFD or any other computational tool becomes then attractive for the design process as explained in section 5.6. Uniform, disperse electrolyte flow should be ensured so that the reactant supply and mass transport are high enough and to maintain uniform current and potential distribution at the electrodes. Otherwise, stagnant zones can appear in the reactors [312], reducing the conversion efficiency and resulting in localized high current densities. The flow regime 
(laminar, transitional or turbulent) at the electrode compartments is in practice non-ideal and discontinuous over the electrode length/volume, showing high mixing and sometimes turbulence even at relative low mean linear flow velocities. This is one of the reasons why turbulent flow equations are considered in flow cell modelling [200]. It has to be noted that undesired side-reactions such as gas evolution can significantly alter the flow regime [312]. Useful estimations of Reynolds number describe the flow in the cells in ideal, well-developed conditions.

Flow dispersers are placed next to the manifolds in order to spread flow and reduce jets. These are found, for example, as engraved ribs or obstacles. For instance, micro-pillars placed at the entrance of flow fields can increase flow dispersion [313]. These features are less needed with porous electrodes of low permeability. Flow develops in the cell at some distance from the inlet manifolds [314], especially in the case of open channels. Therefore, areas close to internal manifolds are fitted with 'calm zones', i.e., a section of the channel without electrode that allows flow development. Frías-Ferrer et al. [315] established a geometrical dimensionless parameter to express the effect of manifold jets and flow development on mass transport, giving a measure of the predominance of manifold flow with decreasing cell size. This effect is dominant in laboratory-scale flow cells [293], hence the need of using larger cells for meaningful pilot-scale developments. The same group developed a model of fluid dispersion for reactors with carbon felt electrodes [202]. CFD has also been applied to study manifold jet effects on mass transport in flow cells [316]. These studies focused on internal manifolds commonly used in RFBs as they decrease the thickness of flow frames.

\subsection{Pressure drop and pumping power}


Pump operation has an energetic cost that reduces the overall efficiency of a RFB, the required power being a product of the flow rate and pressure drop, $\Delta p$. In well-designed systems, these losses can be minimised to $2-4 \%$ and calculation of pumping energy requirements is routinely performed in chemical engineering. The pumping demands in a cell or stack will increase, at a given flow rate, due to low cross sectional area, tortuous manifolds, long channels, viscous electrolytes, and the presence porous electrodes or turbulence promoters in the flow channel. Accordingly, these features are designed to compromise pressure drop and flow velocity with performance. Still, sufficient pressure drop is needed to maintain a good mass transfer rate, reactant supply and product removal together with effective gas removal, where necessary. Using low viscosity electrolytes, maintaining moderate flow velocity, low turbulence and avoiding height differences in the flow circuit can also minimize pumping loses. Controlled intermittent pump operation has also been suggested [317] but this can raise safety concerns due to overcharging and gas build-up.

The pressure drop in RFB stacks can be determined by considering the measured Darcy's friction factor or permeability of the electrode material, as well as the pressure drop occurring at the internal manifolds. As shown in Figure 12, purely theoretical estimations, such as Darcy's pressure drop for empty square channels in laminar flow, can underestimate the real conditions in practical set ups. Flow optimization and pressure drop has been related to Darcy's friction factor in all-vanadium RFBs [318]. Ye et al. present a summary of some of these expressions for RFBs [319]. Modelling enables the optimization of pressure drop in RFBs, e.g., in terms of electrode and channel dimensions [319]. Experimental approaches involve the measurement of $\Delta p$ in flow cells and description via empirical relationships [135]. For porous electrodes, the Ergun equation gives a precise correlation between the pressure and flow rate within a wide range of Reynolds numbers [320,321]. Two relationships can be used as indication of the design 
quality of RFB cells (or porous electrode materials): $\Delta p$ vs. $v$ [125] and $k_{m} A_{e} v s . \Delta p$ [135]. These are economically important, indicating how much pumping power is needed to achieve a certain mean linear flow rate at the electrodes and its related electrochemical performance. This is shown in Figure 13, for the XL Br-polysulfide stack. Another example on the study of the pressure drop at electrodes for Ce-based RFBs can be found in a recent work [322].

\section{Operational engineering and design aspects}

\subsection{Reactor design}

Designing an electrochemical reactor is an interdisciplinary activity that encompasses knowledge of electrochemistry, chemical engineering, material science, chemistry and computational modelling and simulation. As a first approach, electrode size and number of cells in the stack are set by the desired fractional conversion at a given flow rate under ideal conditions [7-9]. Useful estimations are obtained from dimensional analysis and reactor models (section 5.1) before using simulation to provide a detailed dynamic optimisation (section 5.6). Associated components are designed around the electrode and stack requirements.

The parallel plate, or filter-press reactor, in the bipolar configuration is the obvious geometry for RFBs [6]. Figure 2 shows a typical cell stack consisting of a number of membrane-divided cells compressed between two endplates. This modular design provides ease of construction, convenient membrane-electrode assembly, wide range of materials, and mass production of its repetitive components. Parallel plate disposition of the electrodes helps to obtain uniform potential and current distribution, while the bipolar configuration makes the reactor more compact and eliminates the need for an electrical busbar to connect them [323]. Filter-press reactors have also the advantage of being scalable by increasing the area of the electrodes, the number of cells in a stack, or the number of stacks. Its main drawback is the difficulty to achieve 
uniform flow through the electrode compartments and perfect hydraulic sealing. Shunt currents can decrease their performance and require careful design to minimize them.

The general principles of electrochemical reactor design apply in the case of RFBs [9], including adequate capital and operational costs, reliability, simplicity and appropriate reaction engineering. A RFB cell stack involves a series of design options that will determine its complexity, cost and performance. Often, these features are mutually excluding and thus a compromise has to be made. The most important design options are presented in a decision tree in Figure 18. For instance, the need for cell division is determined by the chemistry of the system while electrolyte manifolds can be internal flow fields in the cell bodies or external rubber tubing. Parallel electrolyte feed is usually preferred to minimize complexity and pressure drop. The electrodes can be 2-D or 3-D, typically determining the conversion cell frame design. The reactor can be commercially supplied or manufactured in-house.

Perhaps the most critical design aspect of the stacks is the design of cell frames or cell bodies that incorporate flow manifolds and flow distributors. The geometry and dimensions of these components determine the fluid flow of electrolyte towards the electrode, having an important effect on the mass transport conditions. The stack design also comprises the rigid endplates, accessory elements such as manifolds, current feeder/collectors, electrical connections, gaskets and means for stack compression, generally tie-bars.

Recent trends in RFB stack design include the grouping of cells into sub-stacks separated by intermediate current collector plates within the same compressor end-plates, e.g., in [239], the placement of more than one electrode within each cell frame [324,325]. Such measures are intended to reduce number of cells having common manifolds to minimise shunt currents and 
pressure drop, while reducing the volume and material of the modules. Interdigitated flow fields are increasingly being incorporated in stacks, improving the electrochemical performance of VRFBs while reducing pressure drop [307].

\subsection{Current distribution}

A uniform current distribution is required to ensure an even reaction rate over the entire electrode surface. When parts of the electrode experience significantly higher or lower current secondary reactions can prevail and localized corrosion of the electrode can occur. Several factors influence the current distribution including: a) the geometry of the electrodes, b) their electrical conductivity, c) the kinetics of the electrochemical reactions and d) the changing concentration of the electroactive species. Three types of current density distribution have been widely recognized depending on which of the parameters listed above dominates the electrochemical process [11]; primary current distribution depends on the electrode geometry while secondary current distribution takes into account the rate of the electrochemical reaction. The tertiary current distribution considers the influence of the mass transfer on the electrochemical reaction. The experimental current distribution is more complex than the ideal cases because over time the surface of the electrode changes with the electrochemical reaction making variations in the electroactive sites on the surface. The concentration of the electroactive species also decreases along the electrodes towards the exit manifolds and over time as the electrolyte circulates through the cell from the reservoir in a RFB, affecting the current distribution.

The numerical simulation of current distribution in RFBs allows predicting the performance of different cell designs and the behaviour of different chemical systems, in advance of the scale up stage. For instance, a one-dimensional numerical model was developed for the $\mathrm{Br}$ - 
polysulfide RFB in order to predict the current distribution, among other important parameters, and validated against experimental data [174]. In the soluble lead RFB, a simulation of the current distribution used a 2-dimensional stationary model when a 3-dimensional honeycomb $\mathrm{PbO}_{2}$ electrode was sandwiched between 2 planar electrodes. The authors reported that the current distribution in the $\mathrm{PbO}_{2}$ electrode depends mostly on the geometrical effects and not on the hydrodynamics [326]. Another mathematical model for this system incorporates the current distribution to study a number of limiting cases. The authors concluded that the anodic reaction and the ion transport controlled the battery performance [327]. Current distribution for other systems such as the Zn-ferricyanide [328], the all-iron flow battery [264] and the vanadium RFBs [234,305] propose different mathematical models.

\subsection{Inter-electrode gap and electrode thickness}

The length of the separation between planar electrodes and the thickness of porous electrodes have a significant contribution to potential loss during charge and discharge cycles. In the case of RFBs with parallel plate electrodes (e.g., $\mathrm{Zn}-\mathrm{Br}_{2}$ ), larger gaps increase the electrical resistance due to the flowing electrolytes. As a result, inter-electrode gaps are always minimized aiming, for example, to keep them under $3 \mathrm{~mm}$. In some RFBs using $0.67 \mathrm{~m}^{2}$ flow-by planar electrodes, the inter-electrode gap was 1.8 - $2.1 \mathrm{~mm}$ [159]. In such cases, the contact between membranes and electrodes is typically prevented by placing polymer meshes between the electrodes, which can simultaneously work as turbulence promoters (section 6.5). Small interelectrode gaps are also important in laboratory scale flow cells. The need for small electrodemembrane haps has been corroborated for the $\mathrm{Zn}-\mathrm{Ce}$ system by using the cell potential equation [252]. In hybrid RFBs relying on metal electrodeposition, the volume of the electrode channel defined by the inter-electrode gap will ultimately limit the charge capacity. 
The 'zero gap' architecture with porous electrodes greatly reduces the effect of electrode separation. In this case mesh, felt, or other porous electrode, is pressed up against the membrane. The inter-electrode space will be limited to the thickness of the membrane, e.g., the vanadium RFBs using carbon felt electrodes. Great care must be taken to avoid rupture of the membrane during the compression of the stack and the compression factor of the felt must be taken into account. If a compressible electrode is used in only one half-cell, a spacer mesh must be used in the other side to avoid deformation of the membrane. However, the thickness of the porous electrode in the 'zero gap' architecture becomes critical, as the solution potential trough the porous matrix experiences an exponential decay [132,329].

\subsection{Management of shunt currents}

Without proper measures, bipolar filter-press reactors used as RFBs can suffer from efficiency loss due to shunt ('bypass', 'leakage' or 'stray') currents. Such electrical currents flow when there is an alternative, low resistance path to the current passing through the bipolar electrodes [330]. In the most usual scenario, these currents travel through the common electrolyte inside the manifolds connecting individual cells. Significant shunt currents may: a) overdrive the end electrodes, since they experience an above average current density, b) induce non-uniform current and potential distributions, resulting in underperformance in the central section of the stack, c) interfere with instrumentation or cause corrosion of metallic components. For these reasons, shunt currents should aim to be $<1 \%$ of the cell stack current, meaning $<10$ A for a 1 kA cell. Such currents can be calculated from the potential differences measured between probes placed in the feed manifolds or pipes of the cells in the stack [331], or measured using magnetic field detectors [330]. Provided an efficient conversion per pass, stacks with a small number of unit cells can diminish the effect of shunt currents. 
Mathematical models for shunt currents are available, allowing the calculation of potential losses and current distribution along cell stacks by comparing the battery to a circuit of resistors. The model developed by Kaminski and Savinell [332] can be used with confidence; a modified version has been successfully used on several industrial cells and a similar relationship empirically confirmed by one of us (FCW) on several industrial RFB installations. Other detailed models can be found in the work of White et al. [333], Rangarajan et al. [334] and, more recently, by Henquín et al. [335] The scheme by Yang et al. was specifically developed for batteries [336]. Dimensionless group treatments for the scale-up of shunt currents can also be found [337], along with a simple method to estimate the shunt currents from current potential curves [338]. Shunt current models have been used to optimize modules of VRFBs, e.g. $[319,339]$.

Strategies for prevention of shunt currents are based on the extension of the electrolyte paths in order to increase their electrical resistance. These include tortuous inlet/outlet manifolds and long external polymeric tubes. Tortuous or labyrinthine manifolds have been designed in different patterns, for instance, spirals in the Regenesys Br-polysulfide RFB [74]. The required length for high-resistivity electrode paths can be calculated from the conductivity of the electrolyte, as illustrated in a simulated VRFB stack [196]. Modelling of the relationship between pumping loss and shunt current in tubes connecting cells and modules has also been performed [319]. Much less practical methods of reducing shunt currents are: the decrease of electrolyte inlet/outlet diameter [340], the use of shower heads [319], and the flushing of inert gas through manifolds [317]. In theory, cascade hydraulic feeding of the individual cells within a stack can prevent shunt currents [300], but this configuration generally not recommended. Implementation of these features should minimize the increase in pressure drop. 


\subsection{Electrical control}

Integrated power electronics are the main control component of a RFB and are usually supplied by electrical firms. They determine the battery regime, i.e., constant current, constant cell voltage, constant electrode potential or variable and the mode of operation. These include load following, voltage control, frequency regulation, power system stabilization, constant voltage reactive current and constant $\mathrm{AC}$ power [103]. Constant current is usually preferred, for simplicity. The power conditioner consists of transformer, DC/AC inverter/rectifier, circuit breakers and its own control unit.

These systems can be complex as they need to manage the grid or load requirements, the available power input (both being highly variable), switch pump power, monitor state of charge, electrolyte levels, temperature, flow velocity, safety measures, etc. The voltage and current passing through the modules are constantly monitored and so the frequency and voltage of the power grid. The system comprises sensors, data acquisition units, power conditioner, control computer and, more importantly, control software. These elements work together to achieve optimal energy storage, forming a battery management system (BMS) [106]. Operation algorithms are developed for specific applications, for instance, stabilization of the power grid connected to a wind farm [299], or the use of optimal automatic generation control regulators (OARs) in the connection of a RFB to the grid [105]. Automation also plays an important role, especially for mobile, remote or backup power systems. Large utility-scale load leveling plants are monitored from a central software control, which includes safety protocols. For instance, electrical current must be automatically shut down in the event of accidental draining of a stack.

\subsection{Heat management}


An increase in temperature during the operation of RFBs is produced by: a) Joule heating of the electrolyte due to the passage of electric current through the resistive components in reactors, b) pump and electrolyte flow friction and c) the spontaneous exothermic charge/discharge/self-discharge reactions. Temperature change can affect the RFB performance in various ways, for instance, thermal precipitation of $\mathrm{V}^{5+}$ usually takes place at $40{ }^{\circ} \mathrm{C}$ [341]. Modeling and simulation are the most convenient way to predict the heating of the RFB and the effects on its performance [176-179,189]. Experience has shown that, in utility scaled systems Joule heating can generate between 10 to $30{ }^{\circ} \mathrm{C}$ above room temperature, if not managed [123]. Pumping and fluid flow friction though the hydraulic system can increase the temperature by an additional 2 to $10{ }^{\circ} \mathrm{C}$. Heat and pump power loss have been considered in a model for the vanadium RFB [342]. The change of temperature follows a constant rise after the start of the operation reaching a plateau when equilibrium with heat dissipation is reached. A maximum of $45{ }^{\circ} \mathrm{C}$ was typically observed without thermal control in the Regenesys RFB. Diffusion of active species across the membrane result in a self-discharge reaction in the VRFB [177], and stack temperatures of up to $55^{\circ} \mathrm{C}$ can be predicted as a result when the pumps are turned off, depending on the type of separator and stack amount of insulation.

Energy lost as heat per unit time, $P_{h}$, can be estimated from the electrical resistance, $R$ of the modules using the Joule heating expression:

$$
P_{h}=I^{2} R
$$

The amount of produced heat can also be estimated from the energy loss as given by the energy efficiency of the RFB [108]. Self-discharge, shunt current and Joule heating contributions have been modeled for a VRFB using separators with high vanadium ion permeability [179]. In this 
case, and at $50 \%$ SOC, it is claimed that $76 \%$ of heat generation was due to self-discharge, Joule heating being comparatively low at $14 \%$.

Heat exchangers are an integral part of utility-scale RFBs, e.g., in the all vanadium [299] and $\mathrm{Zn}-\mathrm{Br}_{2}$ [108] systems, and electrolyte flow can be exploited for the thermal management. Cooling towers were required in the 120 MW h utility-scale Regenesys RFB [103]. Typically, heat exchangers are fabricated with titanium or glass, which increase costs. Alternatives, such as long polymer tubing, have been considered for RFBs [108]. In principle, heat transfer coefficient of stacks and electrolyte reservoirs (insulated or not) can be controlled [179], and it has been suggested that the area/volume relationship of electrolyte reservoirs could be adjusted to aid thermal management [178].

\subsection{Cross-mixing and electrolyte imbalance}

Gradual electrolyte cross-mixing occurs via the transport of reactive species, acid and water though the membrane. Water uptake and transport takes place in ion exchange membranes due to electro-osmotic drag [343]. Active species, such as $\mathrm{V}^{2+}$ and $\mathrm{V}^{3+}$, transport water between the two half-cells of RFBs, in response to concentration gradients [344,345]. Between 3 and 4 moles of water per mole of ion can be expected [9]. Even though ions and water travel in opposite directions during charge and discharge [280], these combined mechanisms produce dilution and concentration changes that result in electrolyte imbalance and loss of performance. Rebalancing the electrolyte can be achieved by 'watering', adding chemical oxidants/reducers to the electrolytes or by deliberate electrolyte mixing [154]. The use of rebalancing electrochemical flow cells is also possible [346]. Another approach consists in passing the electrolyte through a column packed with a catalyst in order to change the concentration of an electrolyte [94]. More drastic methods have been incorporated into the design of some RFBs, 
e.g., in the early $\mathrm{Zn}$-ferricyanide system $\mathrm{H}_{2}$ evolved at the $\mathrm{Zn}$ electrode was directed to the positive electrolyte in order to reduce ferricyanide ions [218]. It has been suggested that alternating cationic and anionic membranes in a stack could reduce imbalance [300], although one of the membranes will most likely underperform in a particular RFB. Undivided systems, e.g., the Zn-Ni RFB [88], would be largely immune to electrolyte imbalance.

\section{Scale-up, construction and manufacture}

\subsection{The process of scale-up}

The scale-up process of a RFB takes a laboratory concept trough several stages of development to achieve an efficient and cost-effective commercial device. Scale-up relies heavily on dimensional analysis and simulation, ensuring adequate electrode geometry, reaction kinetics, current distribution, fluid flow, etc. [347]. Scale-up can be performed via three different approaches, based on increasing complexity and precision, and also reflecting the chronological development in the field: a) black box approach, b) parametric studies, and c) modelling and simulation. As shown in Figure 19, the scale-up process comprises three main stages [9].

Fundamental electrochemistry studies include the study of electrode reactions in three-electrode cells, evaluating electrolyte compositions and electrode materials using cyclic and linear voltammetry, which provide a preliminary (non-scalable) assessment of the system. Laminar flow RDE can be used to determine ideal kinetic parameters, and diffusion coefficients of the redox species at battery concentrations. RFBs can have rough or 3-D surfaces under nonlaminar flow, meaning that mass transport characterization is better performed in actual flow cells. Four-electrode cells can be used to study the electrode materials and membrane properties. For RFBs involving metal deposition, studies with conventional [348] and rotating 
[349,350] Hull cells can be useful to assess the effect of current density and mass transport on the deposit morphology.

During the development of electrochemical technology, the concept is scaled-up to laboratory flow cells and pilot stacks, which are designed taking into account the effects of potential and current distribution and the electrolyte flow regime. This stage determines if the system is feasible. Examples of the increasing size of modules during RFB development are shown in Figure 10. Polarisation and charge-discharge tests are performed with unit flow cells containing electrode sizes of $100 \mathrm{~cm}^{2}$ (not smaller) and currents $<10$ A. Note that over 40 years of experience have indicated appropriate sizes of flow cells to pursue meaningful charge-discharge data at reliable mass transport-fluid flow. Peristaltic pumps are commonly used at this stage, but pulsating flow should be avoided with pulse dampeners, otherwise wave-like current output can be obtained [127].

The size of the unit cell is then increased to pilot-scale, typically with electrodes between 100 and $10,000 \mathrm{~cm}^{2}$ and currents from 10 to $1,000 \mathrm{~A}$. This allows obtaining realistic figures of merit. Design of flow distributors, cell frames and evaluation of fluid flow (by flow visualization, for example) and pressure drop usually starts in this step, involving the modelling of the reaction environment. Pilot-scale cells and stacks should be easy to modify and include sensors to monitor electrode potentials, temperature, shunt currents, pressure, etc. The hydraulic sealing of the stack is one of the major challenges to be solved. Problems encountered may include changes in the dimensions of the cell and stack components, reproducibility of inter-electrode gaps and non-uniform flow distribution. Long-term operation testing (performing thousands of charge-discharge cycles) provides data on the ageing of electrode materials and overall reactor 
integrity. A reliable SOC monitoring method, flow and control systems are also implemented. Based on these considerations and operational performance, typical costs can be estimated.

Finally, the design and construction of the commercial RFB takes place, including modules, ancillary systems and process control. Testing of final prototypes is performed and safety factors, operation procedures and maintenance indications are developed. Customers will ultimately determine commercial success. Thus, RFB systems should be released over firm market considerations and competitive costs. Marketing and education of costumers is especially needed to expand market share and attention should be given to niche applications. Constant improvement, performance monitoring, customer satisfaction, and failure analysis become essential aspects.

\subsection{Construction of cells and stacks}

As shown in Figure 4, each individual flow cell is formed by two adjacent polymer cell frames (electrode frames, flow frames) with the separator placed between the electrodes. The space between the bipolar plate and the separator creates the flow channel, which can be occupied by a porous electrode. The cell frames encase the bipolar plates hermetically and incorporate part of the internal electrolyte manifolds and flow pathways/distributors that direct the flow towards the electrode. The flow distributors can be separated inserts, while the frame manifolds can have tortuous paths, e.g., spirals, for shunt current minimization [74]. In RFBs with metal deposition, the frame can cover more of the bipolar plate surface in one side so as to minimise concentration of current in the edges of the electrode [108]. The membrane is kept in place by mechanical compression or, more reliably, welded to the polymer frames [72]. 
Hydraulic sealing among the cells is accomplished by the controlled deformation of the frames during compression, substituting gaskets, although more developed alternatives include a clipin architecture of the cell frames [73], and vibration welding of cell stacks [108]. Fluoroelastomer/glass fibre composites are being researched in small cells for improving sealing [351], and the use of epoxy composites to bind electrode and frames are being explored [352]. Figure 19 shows an ion exchange membrane fitted to a unit cell during the assembly of a stack. Corrosion of the cell stack or its metallic components can be a cause of failure. Thus, materials for the polymeric frame should have relatively low cost and high chemical resistance, e.g., HDPE, PVDF. End-plates, electrical connections and probes must be protected from corrosion.

Classical fabrication techniques for the polymeric frames (electrode frames, flow frames) include CNC machining and, more efficiently, injection moulding. Mass production greatly decreases cost, but only once the design has been optimized and proved reliable. Emerging additive manufacture technologies, e.g., 3-D printing fast prototyping, can aid during the design stage of electrochemical flow cells [353]. In the future, advanced 3-D printing of cell bodies and electrodes could lead towards specialised integrated and assembled RFBs, thanks to the ability to print multiple materials (including electrodes and membranes) and produce complete flow cells rather than their components [353].

Dimensional tolerances, compressibility of felt electrodes and deformation of cell frames with changes of temperature become vital to avoid electrolyte and salt leaks, especially with increasing number of cells. In fact, the assembly torque can have influence on the electrochemical response of the stack. This effect have been studied in a laboratory flow battery [313]. More modelling and prediction can be done in regard to the stack compression. For 
instance, in the field of PEM fuel cells, studies are available for sealing force prediction and temperature [354] and degradation of silicon gaskets [355]. In some cases, carbon felt electrodes have received a wetting treatment before or after the assembly of the stack in order to ensure uniform flow and removal of air bubbles. The end electrodes are electrically connected to a current feeder/collector by mechanical compression. The resistance of this electrical connection will change orders of magnitude depending on compression force or by the formation of passivation films at the connection interphase. Failure of the end plate electrodes can occur due to localised stress and cracking from non-uniform compression. Commercial pressure-sensitive sheets can be used to evaluate uniformity of compression, e.g., in [313].

\subsection{Construction of flow systems}

The tanks used in RFBs are usually fabricated in, or lined with, chemically resistant polymers, their cost and complexity increasing considerably with scale. Connecting multiple medium-size tanks can reduce costs in a large system and the addition of tanks can easily expand the capacity of the battery. Usually, the electrolyte stored in large tanks is mixed by continuous recirculation of part of the pump flow. Tanks and stacks should be placed at the same level to avoid unnecessary pumping demands. Ground level, underground, and even expandable rubber tanks inside concrete cisterns have been used [77]. 'Fresh' electrolyte flow in a black start in an energy storage system conveniently employs a tank above the level of cell stacks, permitting gravity feed of electrolyte from 'header tanks'. A 'black start' involves start-up of an RFB system in the absence of external electrical energy.

Hybrid RFB systems with a gaseous fuel require adequate compressors, tubing, valves and vessels. Half-fuel cell RFBs using pure $\mathrm{O}_{2}$ or $\mathrm{H}_{2}$ usually need costly technical and safety 
measures, while air-based RFBs could be easier to design and operate. Any system involving $\mathrm{H}_{2}$ must prevent any possibility of explosive mixtures by having appropriate ventilation means. The risk of highly energetic $\mathrm{H}_{2}$-halogen explosive mixtures should not be underestimated. Some RFBs with liquid electrolytes, e.g., the Br-polysulfide RFB [123], have incorporated a gas extraction and monitoring system to cope with the possibility of release of hazardous gases and cell stack designs have included manifolds to vent gaseous products of side reactions [31].

\section{Summary and future outlook}

Currently, the all-vanadium RFB remains the most promising and extensively researched system for utility energy storage, followed by the $\mathrm{Zn}-\mathrm{Br}_{2}$ system. Further engineering optimizations permitting confident scale-up will result in more extended commercial implementation, although these systems can soon reach their intrinsic performance limitations. Current needs include the improvement and cost reduction of membranes and mass production of stacks. New advances can be expected from the implementation of inexpensive tailored organic redox couples, especially those soluble in aqueous electrolytes. Some of them are widely available reagents and, potentially, of natural sustainable origin. Nevertheless, these systems have yet to prove stability on long-term testing, acceptable management of electrolyte cross-mixing and prevention of electrode fouling. Custom-made electrode and flow cell engineering will be required for these RFBs during their future scale-up efforts. In parallel, mathematical modelling has become more accessible, enabling a better understating of the complex relationships between performance, reaction environment, fluid-flow, operational conditions and charge/discharge regimes. However, these models should be validated or built upon the experimental characterization/monitoring of RFB systems. 
Many of the RFBs proposed in the recent academic literature consist of unpractical systems in terms of electrolyte/electrode stability, safety, operational current density and energy efficiency, as well as cost and availability of reagents/electrode materials. Many unjustified claims of high performance, green or novel RFBs can be found in the journals. This situation reflects a lack of understanding of the fundamental theory of flow cells and the research needs of RFBs for energy storage, particularly in the academic field.

The authors believe that insufficient consideration of engineering aspects of redox flow battery design has limited their performance, hindered scale-up and resulted in restricted confidence in large-scale, long-term, low-maintenance operation.

Important aspects of good engineering practice to include in all RFB studies include:

1. Primary and secondary electrode reactions, including their current density vs. electrode potential characteristics and rate controlling factors. This includes suitable electrocatalyst coatings, if needed, and active electrode area.

2. The effect of electrolyte flow rate on mass transport rate, pressure drop and performance.

3. Adequate evaluation of constructional materials, including feeders, electrodes, membranes, and turbulence promoters' short-term and longer-term stability.

4. A controlled, uniform reaction environment within each cell, including suitable flow-, concentration- and current density- distributions.

5. A clear knowledge of the factors controlling performance and cost, both initially and ongoing as well as those governing scaling.

6. A clear statement of thermodynamic, polarisation and ohmic cell voltage components, together with their evolution in time and their relationship to current density. 
Important RFB aspects that need more consideration in the literature include:

1. Scale-up parameters, including current density, electrolyte flow rate and linear velocity and electrode size.

2. Type of cell, including geometry and manufacture.

3. Reaction engineering, including mass transfer, flow-, current, potential and concentration distributions.

4. Fractional conversion over the cell or in the electrolyte tanks with time, current density and electrolyte flow rate.

5. Electrode characteristics, including active area, volumetric porosity, surface state, electrocatalysis and roughness.

6. Improved electrode materials, including their production and coating by electrocatalysts.

7. Electrode stability with time and conditions, degradation due to ageing, corrosion, erosion, etc.

8. Membrane ionic conductivity, selectivity and transfer rates plus ageing effects.

9. Figures of merit describing performance, including rate, efficiency and state of charge after at known numbers of charge-discharge history cycles.

10. Monitoring and control, methods and practice.

11. Construction of cell bodies, including electrode and flow frames, their sealing and compression.

12. Fast prototyping, design process aided by $3-\mathrm{D}$ printing and $\mathrm{CNC}$ including increased speed. 13. Modes of failure, and means of prevention.

\section{Acknowledgements}

This review has been informed by FCW's experience of laboratory, pilot and full-scale RFB development over many years together with discussions at conferences including the ISE 
Course on 'Potential and Current Distributions in Electrochemical Systems', Edinburgh, 27 August 2006 and the introductory lecture 'Progress \& Challenges in the Development of Flow Battery Technology' delivered by FCW to the First International Flow Battery Forum, IFBF 2010, Vienna, 15-16, June 2010; 'Scale-up, operation and manufacture of redox flow batteries' delivered by Ian Whyte, to IFBF 2010, Vienna, 15-16, June 2010; 'Flow battery design, scaleup, and manufacture' given by I. Whyte, IFBF 2011, Edinburgh, 3 May 2011. LFA also acknowledges discussions with colleagues working on RFB development, in particular during IFBF 2015, Glasgow, 16-17 June 2015 and IFBF 2016, Karlsruhe, 7-9 June 2016. The authors thank Muthu Krishna for his useful comments. LFA gratefully acknowledges the support of CONACYT and SEP scholarships. FCW, CPDL and LFA acknowledge enabling of this research EPSRC Centre for Doctoral Training in Energy Storage and its Applications (EP/L016818/1). No new data were created during the preparation of this critical review. 


\section{List of symbols}

A Active electrode area $\mathrm{m}^{2}$

$\begin{array}{lll}A_{e} & \text { Electrode area per unit electrode volume } \mathrm{m}^{-1}\end{array}$

$B \quad$ Breadth of rectangular flow channel m

c Reactant concentration $\quad \mathrm{mol} \mathrm{m}^{-3}$

$d_{e} \quad$ Equivalent diameter of a rectangular flow channel m

$D$ Diffusion coefficient of an aqueous species $\mathrm{m}^{2} \mathrm{~s}^{-1}$

E Electrode potential $v s$. a reference electrode V

$E^{\ominus} \quad$ Standard electrode potential $\quad$ V

$E^{\circ} \quad$ Standard electrode potential $\quad$ V

$E_{\text {cell }}$ Cell potential $\quad \mathrm{V}$

$E_{\text {cell }}^{e} \quad$ Equilibrium cell potential $\quad \mathrm{V}$

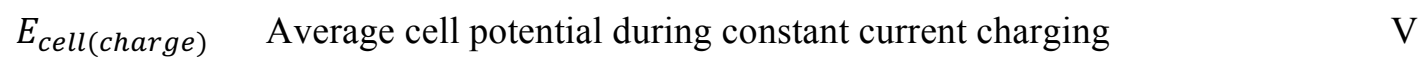

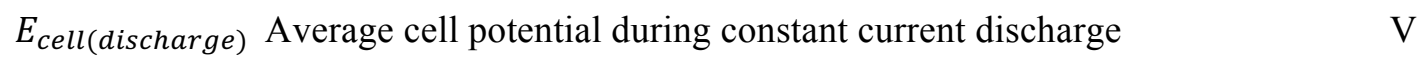

$\begin{array}{lll}E_{V} & \text { Volumetric energy density } \quad \mathrm{W} \mathrm{h} \mathrm{m}^{-3}\end{array}$

F Faraday constant $\quad \mathrm{C} \mathrm{mol}^{-1}$

$g \quad$ Acceleration due to gravity $\mathrm{m} \mathrm{s}^{2}$

G Molar Gibbs free energy $\quad \mathrm{J} \mathrm{mol}^{-1}$

I Current A

$I_{C T} \quad$ Current due to charge transfer $\quad \mathrm{A}$

$I_{L} \quad$ Limiting current due to convective-diffusion $\quad \mathrm{A}$

$j$ Current density $\quad \mathrm{A} \mathrm{m}^{-2}$

$j$. Exchange current density $\quad \mathrm{A} \mathrm{m}^{-2}$

$k \quad$ First order apparent rate constant $\quad \mathrm{s}^{-1}$

$k_{a} \quad$ Anodic charge transfer rate constant $\quad \mathrm{s}^{-1}$

$k_{m} \quad$ Mass transfer coefficient $\mathrm{m} \mathrm{s}^{-1}$

$k_{m} A_{e} \quad$ Volumetric mass transfer coefficient $\quad \mathrm{s}^{-1}$

$L \quad$ Length of rectangular flow channel m

$n \quad$ Amount of a species mol

$N_{R} \quad$ Number of identical reactors Dimensionless

$N \quad$ Net flux density of the species $\quad \mathrm{mol} \mathrm{m}^{-2} \mathrm{~s}^{-1}$

$p$ Pressure $\mathrm{N} \mathrm{m}^{-2}$

$P_{h} \quad$ Energy lost as heat $\quad \mathrm{J}$

$q \quad$ Electrical charge $\quad \mathrm{C}$

$q_{(\text {charge })} \quad$ Electrical charge during charge $\quad \mathrm{C}$ 


\begin{tabular}{|c|c|c|}
\hline \multicolumn{2}{|c|}{$q_{(\text {discharge })} \quad$ Electrical charge during discharge } & \multirow{2}{*}{$\begin{array}{l}\mathrm{C} \\
\mathrm{A} \mathrm{h} \mathrm{m}^{-3}\end{array}$} \\
\hline$q_{V}$ & Volumetric charge capacity & \\
\hline$Q_{V}$ & Volumetric flow rate of electrolyte & $\mathrm{m}^{3} \mathrm{~s}^{-1}$ \\
\hline$R$ & Electrical resistance & ohm \\
\hline$R e$ & Reynolds number & Dimensionless \\
\hline \multirow[t]{2}{*}{$S$} & Separation between electrode and membrane (divided cell) & \\
\hline & or between electrodes (undivided cell) & $\mathrm{m}$ \\
\hline$S c$ & Schmidt number & Dimensionless \\
\hline$S h$ & Sherwood number & Dimensionless \\
\hline$t$ & Time & $\mathrm{s}$ \\
\hline$T$ & Temperature & $\mathrm{K}$ \\
\hline$u$ & Mobility of the active species & $\mathrm{m}^{2} \mathrm{~mol} \mathrm{~J} \mathrm{~J}^{-1}$ \\
\hline$v$ & Mean linear flow velocity of electrolyte & $\mathrm{m} \mathrm{s}^{-1}$ \\
\hline $\mathbf{v}$ & Mass average velocity vector & Dimensionless \\
\hline$V$ & Volume & $\mathrm{m}^{3}$ \\
\hline$V_{e}$ & Volume of electrode & $\mathrm{m}^{3}$ \\
\hline$V_{R}$ & Reactor electrolyte volume & $\mathrm{m}^{3}$ \\
\hline$V_{T}$ & Volume of electrolyte in the tank & $\mathrm{m}^{3}$ \\
\hline$x$ & Distance along electrode & $\mathrm{m}$ \\
\hline$X_{A}$ & Fractional conversion of the reactant & $\mathrm{m}$ \\
\hline$Y_{S T}$ & Space-time yield & $\mathrm{mol} \mathrm{m}^{-3} \mathrm{~s}^{-1}$ \\
\hline$z$ & Electron stoichiometry & Dimensionless \\
\hline
\end{tabular}

\section{Greek}

$\alpha_{a} \quad$ Anodic charge transfer coefficient

Dimensionless

$\alpha_{c} \quad$ Cathodic charge transfer coefficient

Dimensionless

$\eta \quad$ Overpotential $\left(\eta=E-E_{e}\right)$

$\mathrm{V}$

$\gamma \quad$ Mass transport enhancement factor

Dimensionless

$v \quad$ Kinematic viscosity of the electrolyte

$\mathrm{cm}^{2} \mathrm{~s}^{-1}$

$\phi \quad$ Current efficiency

Dimensionless

$\Phi \quad$ Electrostatic potential

$\mathrm{V}$

$\tau_{R} \quad$ Mean residence time in the reactor

S

$\tau_{T} \quad$ Mean residence time in the tank

$\mathrm{S}$

$\eta_{V} \quad$ Voltage efficiency

Dimensionless

$\eta_{e} \quad$ Energy efficiency

Dimensionless 
$\eta_{C} \quad$ Charge (coulombic) efficiency

Dimensionless

$\eta_{p} \quad$ Power efficiency

Dimensionless

\section{Abbreviations}

2-D; 3-D Two-dimensional; three-dimensional

CFD Computational flow dynamics

HDPE High density polyethylene

IEM Ion exchange membrane

NSTF Nanostructured thin film

PEMFC Proton exchange membrane fuel cell

PFR Plug flow reactor

PVDF Poly(vinylidenefluoride)

PVC Poly(vinylchloride)

RDE Rotating disc electrode

RFB Redox flow battery

RTD Residence time distribution

RVC Reticulated vitreous carbon

SOC State of charge

VRFB Vanadium redox flow battery

\section{Subscripts and superscripts}

$\begin{array}{ll}a & \text { Anode } \\ \text { act } & \text { Activation (charge transfer control) } \\ c & \text { Cathode } \\ \text { conc } & \text { Concentration (mass transfer control) } \\ \text { cell } & \text { Cell } \\ e & \text { At equilibrium } \\ E & \text { Electrode } \\ \text { in } & \text { Inlet manifold } \\ \text { out } & \text { Outlet manifold } \\ \text { ox } & \text { Oxidized form } \\ R & \text { Reactor } \\ \text { red } & \text { Reduced form } \\ T & \text { Tank } \\ (0) & \text { At time zero } \\ (t) & \text { At time } t\end{array}$




\section{References}

[1] U.S. Department of Energy, Grid energy storage, (2013). http://energy.gov/oe/downloads/grid-energystorage-december-2013 (accessed March 9, 2016).

[2] Flow Battery -Energy Storage News, Energystoragenews.org. www.energystoragenews.org/category/16/flow-battery/ (accessed April 3, 2015).

[3] S. Bebelis, K. Bouzek, A. Cornell, M.G.S. Ferreira, G.H. Kelsall, F. Lapicque, C. Ponce de León, M.A. Rodrigo, F.C. Walsh, Highlights during the development of electrochemical engineering, Trans. IChemE. 91 (2013) 1998-2020. doi:10.1016/j.cherd.2013.08.029.

[4] M. Arbabzadeh, J.X. Johnson, G.A. Keoleian, P.G. Rasmussen, L.T. Thompson, Twelve principles for green energy storage in grid applications, Environ. Sci. Technol. 50 (2015) 1046-1055. doi:10.1021/acs.est.5b03867.

[5] D.J. Pickett, Electrochemical Reactor Design, 2nd ed., Elsevier, Amsterdam, 1979.

[6] D. Pletcher, F.C. Walsh, Industrial Electrochemistry, 2nd ed., Chapman and Hall, London, 1990.

[7] F. Coeuret, Introducción a la Ingeniería Electroquímica, Editorial Reverté, Barcelona, 1992.

[8] F. Coeuret, A. Storck, Eléments de Génie Électrochimique, 2nd ed., Éditions TEC et DOC / Lavoisier, Paris, 1993.

[9] F.C. Walsh, A First Course on Electrochemical Engineering, The Electrochemical Consultancy, Romsey, 1993.

[10] V.M. Schmidt, Elektrochemische Verfahrenstechnik, John Wiley \& Sons, 2003.

[11] J. Newman, K.E. Thomas-Alyea, Electrochemical Systems, 3rd ed., John Wiley \& Sons, Hoboken NJ, 2004.

[12] C. Ponce de León, A. Frías-Ferrer, J. González-García, D.A. Szánto, F.C. Walsh, Redox flow cells for energy conversion, J. Power Sources. 160 (2006) 716-732. doi:10.1016/j.jpowsour.2006.02.095.

[13] A.Z. Weber, M.M. Mench, J.P. Meyers, P.N. Ross, J.T. Gostick, Q. Liu, Redox flow batteries: a review, J. Appl. Electrochem. 41 (2011) 1137-1164. doi:10.1007/s10800-011-0348-2.

[14] M. Skyllas-Kazacos, M.H. Chakrabarti, S.A. Hajimolana, F.S. Mjalli, M. Saleem, Progress in flow battery research and development, J. Electrochem. Soc. 158 (2011) R55-R79. doi:10.1149/1.3599565.

[15] P. Leung, X. Li, C. Ponce de León, L. Berlouis, C.T.J. Low, F.C. Walsh, Progress in redox flow batteries, remaining challenges and their applications in energy storage, RSC Adv. 2 (2012) 1012510156. doi:10.1039/c2ra21342g.

[16] T. Nguyen, R.F. Savinell, Flow batteries, Electrochem Soc Interface. (2010) 54-56.

[17] W. Wang, Q. Luo, B. Li, X. Wei, L. Li, Z. Yang, Recent progress in redox flow battery research and development, Adv. Funct. Mater. 23 (2012) 970-986. doi:10.1002/adfm.201200694.

[18] M.H. Chakrabarti, S.A. Hajimolana, F.S. Mjalli, M. Saleem, I. Mustafa, Redox flow battery for energy storage, Arab. J. Sci. Eng. 38 (2012) 723-739. doi:10.1007/s13369-012-0356-5.

[19] P. Alotto, M. Guarnieri, F. Moro, Redox flow batteries for the storage of renewable energy: A review, Renew. Sust. Energ. Rev. 29 (2014) 325-335. doi:10.1016/j.rser.2013.08.001.

[20] G.L. Soloveichik, Flow batteries: Current status and trends, Chem. Rev. 115 (2015) 11533-11558. 
doi:10.1021/cr500720t.

[21] M. Bartolozzi, Development of redox flow batteries. A historical bibliography, J. Power Sources. 27 (1989) 219-234. doi:10.1016/0378-7753(89)80037-0.

[22] Z. Yang, J. Zhang, M.C.W. Kintner-Meyer, X. Lu, D. Choi, J.P. Lemmon, J. Liu, Electrochemical energy storage for green grid, Chem. Rev. 111 (2011) 3577-3613. doi:10.1021/cr100290v.

[23] G.L. Soloveichik, Battery technologies for large-scale stationary energy storage, Annu. Rev. Chem. Biomol. Eng. 2 (2011) 503-527. doi:10.1146/annurev-chembioeng-061010-114116.

[24] X. Li, H. Zhang, Z. Mai, H. Zhang, I. Vankelecom, Ion exchange membranes for vanadium redox flow battery (VRB) applications, Energy Environ. Sci. 4 (2011) 1147. doi:10.1039/c0ee00770f.

[25] H. Prifti, A. Parasuraman, S. Winardi, T.M. Lim, M. Skyllas-Kazacos, Membranes for redox flow battery applications, Membranes. 2 (2012) 275-306. doi:10.3390/membranes2020275.

[26] G. Kear, A.A. Shah, F.C. Walsh, Development of the all-vanadium redox flow battery for energy storage: A review of technological, financial and policy aspects, Int. J. Energy Res. 36 (2011) 11051120. doi:10.1002/er.1863.

[27] S.-H. Shin, S.-H. Yun, S.-H. Moon, A review of current developments in non-aqueous redox flow batteries: Characterization of their membranes for design perspective, RSC Adv. 3 (2013) 9095. doi:10.1039/c3ra00115f.

[28] M.H. Chakrabarti, N.P. Brandon, S.A. Hajimolana, F. Tariq, V. Yufit, M.A. Hashim, M.A. Hussain, C.T.J. Low, P.V. Aravind, Application of carbon materials in redox flow batteries, J. Power Sources. 253 (2014) 150-166. doi:10.1016/j.jpowsour.2013.12.038.

[29] B.R. Chalamala, T. Soundappan, G.R. Fisher, M.R. Anstey, V.V. Viswanathan, M.L. Perry, Redox flow batteries: an engineering perspective, Proc. IEEE. 102 (2014) 976-999.

doi:10.1109/JPROC.2014.2320317.

[30] Y.V. Tolmachev, M.A. Vorotyntsev, Fuel cells with chemically regenerative redox cathodes (review), Russ. J. Electrochem. 50 (2014) 403-411. doi:10.1134/S1023193514020050.

[31] F.C. Walsh, C. Ponce de León, L. Berlouis, G. Nikiforidis, L.F. Arenas-Martínez, D. Hodgson, D. Hall, The development of $\mathrm{Zn}$-Ce hybrid redox flow batteries for energy storage and their continuing challenges, ChemPlusChem. 80 (2015) 288-311. doi:10.1002/cplu.201402103.

[32] K.J. Kim, M.-S. Park, Y.-J. Kim, J.H. Kim, S.X. Dou, M. Skyllas-Kazacos, A technology review of electrodes and reaction mechanisms in vanadium redox flow batteries, J. Mater. Chem. A. (2015) 123. doi:10.1039/C5TA02613J.

[33] M. Skyllas-Kazacos, G. Kazacos, G. Poon, H. Verseema, Recent advances with UNSW vanadiumbased redox flow batteries, Int. J. Energy Res. 34 (2010) 182-189. doi:10.1002/er.1658.

[34] Á. Cunha, J. Martins, N. Rodrigues, F.P. Brito, Vanadium redox flow batteries: a technology review, Int. J. Energy Res. 39 (2015) 889-918. doi:10.1002/er.3260.

[35] M. Ulaganathan, V. Aravindan, Q. Yan, Recent advancements in all-vanadium redox flow batteries, Adv. Mater. 3 (2015) 1500309. doi:10.1002/admi.201500309/pdf.

[36] J. Noack, N. Roznyatovskaya, T. Herr, P. Fischer, The chemistry of redox-flow batteries, Angew. Chem. Int. Ed. 54 (2015) 2-36. doi:10.1002/anie.201410823/pdf.

[37] F. Pan, Q. Wang, Redox species of redox flow batteries: A review, Molecules. 20 (2015) 2049920517. doi:10.3390/molecules201119711. 
[38] K.T. Cho, M.C. Tucker, A.Z. Weber, A review of hydrogen/halogen flow cells, Energy Technology. 4 (2016) 655-678. doi:10.1002/ente.201500449.

[39] M. Skyllas-Kazacos, L. Cao, M. Kazacos, N. Kausar, A. Mousa, Vanadium electrolyte studies for the vanadium redox battery-A review, ChemSusChem. 9 (2016) 1521-1543.

doi:10.1002/cssc.201600102.

[40] J. Winsberg, T. Hagemann, T. Janoschka, M.D. Hager, U.S. Schubert, Redox-flow batteries: From metals to organic redox-active materials, Angew. Chem. Int. Ed. 55 (2016) 2-28. doi:10.1002/anie.201604925.

[41] A.Z. Weber, Flow cells for energy storage workshop summary report, Washington DC, 2012. http://energy.gov/sites/prod/files/2014/03/f12/flow_cells_2012_workshop_report.pdf (accessed August 15, 2016).

[42] C. Menictas, M. Skyllas-Kazacos, T.M. Lim, Redox flow batteries for medium- to large-scale energy storage, in: Z. Melhem (Ed.), Electricity Transmission, Distribution and Storage Systems, Woodhead Publishing, 2013: pp. 398-441.

[43] M. Skyllas-Kazacos, J.F. MCann, Vanadium redox flow batteries (VRBs) for medium-and large-scale energy storage, in: C. Menictas, M.S. Kazacos, T.M. Lim (Eds.), Advances in Batteries for Mediumand Large-Scale Energy Storage, Woodhead Publishing, 2014: pp. 329-378.

[44] X. Li, C. Ponce de León, F.C. Walsh, R.G.A. Wills, D. Pletcher, Zinc-based flow batteries for medium- and large-scale energy storage, in: C. Menictas, M. Skyllas-Kazacos, T.M. Lim (Eds.), Advances in Batteries for Medium- and Large-Scale Energy Storage, Elsevier, 2014: pp. 293-311.

[45] H. Zhang, Polysulfide-bromine flow batteries (PBBs) for medium- and large-scale energy storge, in: C. Menictas, M. Skyllas-Kazacos, T.M. Lim (Eds.), Advances in Batteries for Medium- and LargeScale Energy Storage, Elsevier, 2014: pp. 317-326.

[46] Butler, P. C., P.A. Eidler, P.G. Grimes, S.E. Klassen, R.C. Miles, Zinc/bromine batteries, in: D. Linden, T.B. Reddy (Eds.), Handbook of Batteries, McGraw-Hill, 2001.

[47] G.P. Rajarathnam, A.M. Vassallo, The Zinc/Bromine Flow Battery, Springer, Singapore, 2016. doi:10.1007/978-981-287-646-1.

[48] G. Tomazic, M. Skyllas-Kazacos, Redox flow batteries, in: P.T. Moseley, J. Garche (Eds.), Electrochemical Energy Storage for Renewable Sources and Grid Balancing, Elsevier, 2015: pp. 309336 .

[49] W. Kangro, Verfahren zur Speicherung von elektrischer Energie, German patent 914,264, 1949.

[50] A.M. Posner, Redox fuel cell, Fuel. 34 (1955) 330-338.

[51] C. Renard, Les Piles Légères (Piles Chlorochromiques) du Ballon Dirigeable "La France," G. Masson, Paris, 1890. http://gallica.bnf.fr/ark:/12148/bpt6k1108811.r=.langEN (accessed September 19, 2016).

[52] M.A. Vertes, E.G. Katsoulis, J.E. Oxley, K. Alfredson, Zinc/air high energy density rechargeable energy storage system, AD-639609, Leesona Corp, Great Neck, NY, 1966.

[53] L.H. Thaller, Electrically rechargeable redox flow cells, TM-X71540, NASA, 1974.

[54] M. Reid, R.F. Gahn, Factors affecting the open-circuit voltage and electrode kinetics of some iron/titanium redox flow cells, TM X-73669, NASA, 1977.

[55] J. Giner, L. Swette, K. Cahill, Screening of redox couples and electrode materials, CR-134705, NASA, 1976. 
[56] Redox flow cell development and demonstration project, calendar year 1977, TM-79067, NASA, 1979.

[57] P.R. Prokopius, Model for calculating electrolytic shunt path losses in large electrochemical energy conversion systems, TM X-3359, NASA, 1976.

[58] N. Hagedorn, M.A. Hoberecht, L.H. Thaller, NASA Redox cell stack shunt current, pumping power, and cell performance tradeoffs, TM-82686, NASA, 1982.

[59] K. Michaels, G. Hall, Cost projections for redox energy storage systems, CR-165260, NASA, 1980.

[60] N.H. Hagedorn, NASA Redox storage system development project final report, TM-83677, NASA, 1984.

[61] P. Carr, P.C. Symons, D.J. Aller, Energy Development Associates, Operational zinc chlorine based on a water store, US Patent 4,146,680 A, 1979.

[62] A.J. Appleby, J. Jacquelin, J.P. Pompon, Charge-discharge behavior of the C.G.E. circulating zinc-air vehicle battery, SAE Technical Paper 770381 (1977). doi:10.4271/770381.

[63] H.S. Lim, A.M. Lackner, R.C. Knechtli, Zinc-bromine secondary battery, J. Electrochem. Soc. 124 (1977) 1154-1157. doi:10.1149/1.2133517.

[64] G.B. Adams, Lockheed Missiles \& Space Company, Inc., Electrically rechargeable battery, US Patent, 4,180,623 A, 1979.

[65] R.S. Yeo, D.T. Chin, A hydrogen-bromine cell for energy storage applications, J. Electrochem. Soc. 127 (1980) 549-555. doi:10.1149/1.2129710.

[66] L.W. Hruska, R.F. Savinell, Investigation of factors affecting performance of the iron-redox battery, J. Electrochem. Soc. 128 (1981) 18-25. doi:10.1149/1.2127366.

[67] R.J. Remick, P.G.P. Ang, Institute Of Gas Technology, Electrically rechargeable anionically active reduction-oxidation electrical storage-supply system, US Patent 4,485,154 A,1984.

[68] M. Skyllas-Kazacos, M. Rychick, R. Robins, All-vanadium redox battery, US Patent 4,786,567 A, 1988.

[69] T. Shigematsu, Redox flow battery for energy storage, SEI Technical Review. 73 (2011) 4-13.

[70] Redflow Limited - Energy Storage Solutions, http://redflow.com/ (accessed December 30, 2016).

[71] P. Morrissey, Regenesys: a new energy storage technology, Int. J. Ambient Energy. 21 (2000) 213220. doi:10.1080/01430750.2000.9675376.

[72] P.E. Williams, T.A. Mitchell, D.G. Clark, Laser cutting and joining a fluorinated polymer membrane to a polymer frame, Canadian Patent 2,338,208 A1, 2000.

[73] D.G. Clark, S.H. Joseph, S.E. Male, Regenesys Technologies Ltd, Method for the fabrication of electrochemical cells, European Patent 0,870,342 B1, 2002.

[74] D.G. Clark, S.H. Joseph, H.S. Oates, Regenesys Technologies Ltd, Electrochemical cell, US Patent 6,524,452, 2003.

[75] S.E. Male, P.J. Mitchell, P.J. Morrissey, Regenesys Technologies Ltd, Electrolyte rebalancing system, European Patent 1,192,680 B1, 2003.

[76] D.G. Clark, S.H. Joseph, H.S. Oates, National Power Plc, Flow-frame for forming a sub-assembly for use in an electrochemical cell, Canadian Patent 2,343,228 C, 2008. 
[77] N. Tokuda, M. Furuya, Y. Kikuoko, Y. Tsutui, T. Kumamoto, T. Kanno, Development of a redox flow (RF) battery for energy storage, in: Pccon-02, IEEE, Osaka, 2002: pp. 1144-1149. doi:10.1109/PCC.2002.998133.

[78] Sumitomo Electric Industries, Ltd., Press release: Selected to be subsidized by the governmental program for urgent demonstration project of large-scale energy storage systems, Sumitomo Electric Industries, Ltd. (2013). http://global-sei.com/news/press/13/prs088_s.html (accessed April 1, 2016).

[79] 200MW/800MWh Energy Storage Station to be Built with RONGKE POWER's Vanadium Flow Battery - UniEnergy Technologies, Uetechnologies.com. http:/www.uetechnologies.com/news/71200mw-800mwh-energy-storage-station-to-be-built-with-rongke-power-s-vanadium-flow-battery (accessed February 3, 2017).

[80] B. Fang, S. Iwasa, Y. Wei, T. Arai, M. Kumagai, A study of the Ce(III)/Ce(IV) redox couple for redox flow battery application, Electrochim. Acta. 47 (2002) 3971-3976.

[81] M. Skyllas-Kazacos, Novel vanadium chloride/polyhalide redox flow battery, J. Power Sources. 124 (2003) 299-302. doi:10.1016/S0378-7753(03)00621-9.

[82] T. Yamamura, Y. Shiokawa, H. Yamana, H. Moriyama, Electrochemical investigation of uranium $\beta$ diketonates for all-uranium redox flow battery, Electrochim. Acta. 48 (2002) 43-50. doi:10.1016/S0013-4686(02)00546-7.

[83] K. Hasegawa, A. Kimura, T. Yamamura, Y. Shiokawa, Estimation of energy efficiency in neptunium redox flow batteries by the standard rate constants, J. Phys. Chem. Solids. 66 (2005) 593-595. doi:10.1016/j.jpcs.2004.07.018.

[84] A. Hazza, D. Pletcher, R. Wills, A novel flow battery: A lead acid battery based on an electrolyte with soluble lead(II) Part I. Preliminary studies, Phys. Chem. Chem. Phys. 6 (2004) 1773-1778. doi:10.1039/B401115E.

[85] R.G.A. Wills, J. Collins, D. Stratton-Campbell, C.T.J. Low, D. Pletcher, F.C. Walsh, Developments in the soluble lead-acid flow battery, J. Appl. Electrochem. 40 (2009) 955-965. doi:10.1007/s10800009-9815-4.

[86] R.L. Clarke, B. Dougherty, S. Harrison, P.J. Millington, S. Mohanta, Cerium batteries, US Patent application 2004/0202925 A1, 2004.

[87] A.M. Creeth, J.-G. Liu, Acal Energy Ltd, A.M. Creeth, J.-G. Liu, Fuel cells, 2007.

[88] J. Cheng, L. Zhang, Y.-S. Yang, Y.-H. Wen, G.-P. Cao, X.-D. Wang, Preliminary study of single flow zinc-nickel battery, Electrochem. Commun. 9 (2007) 2639-2642. doi:10.1016/j.elecom.2007.08.016.

[89] Y. Xu, Y. Wen, J. Cheng, G. Cao, Y. Yang, Study on a single flow acid Cd-chloranil battery, Electrochem. Commun. 11 (2009) 1422-1424. doi:10.1016/j.elecom.2009.05.021.

[90] J. Pan, Y. Sun, J. Cheng, Y. Wen, Y. Yang, P. Wan, Study on a new single flow acid $\mathrm{Cu}-\mathrm{PbO}_{2}$ battery, Electrochem. Commun. 10 (2008) 1226-1229. doi:10.1016/j.elecom.2008.06.008.

[91] H.M.H. Dewage, B. Wu, A. Tsoi, V. Yufit, G.J. Offer, N. Brandon, A novel regenerative hydrogen cerium fuel cell for energy storage applications, J. Mater. Chem. A. 3 (2015) 9446-9450. doi:10.1039/C5TA00571J.

[92] K.T. Cho, P. Ridgway, A.Z. Weber, S. Haussener, V. Battaglia, V. Srinivasan, High performance hydrogen/bromine redox flow battery for grid-scale energy storage, J. Electrochem. Soc. 159 (2012) A1806-A1815. doi:10.1149/2.018211jes.

[93] B. Adams, Megawatt-hour, Fe-Cr redox flow battery system ARRA demonstration, Staff Workshop an Exploration of Advancements in Energy Storage in California Since the American Recovery and 
Reinvestment Act. http://www.energy.ca.gov/research/notices/2014-12-

01_workshop/presentations/Bret_Adams_EnerVault.pdf (accessed April 1, 2016).

[94] V. Amstutz, K.E. Toghill, F. Powlesland, H. Vrubel, C. Comninellis, X. Hu, H.H. Girault, Renewable hydrogen generation from a dual-circuit redox flow battery, Energy Environ. Sci. 7 (2014) 23502358. doi:10.1039/C4EE00098F.

[95] Bin Li, Z. Nie, M. Vijayakumar, G. Li, J. Liu, V. Sprenkle, W. Wang, Ambipolar zinc-polyiodide electrolyte for a high-energy density aqueous redox flow battery, Nature Communications. 6 (2015) 6303. doi:10.1038/ncomms7303.

[96] F.R. Brushett, J.T. Vaughey, A.N. Jansen, An all-organic non-aqueous lithium-ion redox flow battery, Adv. Energy Mater. 2 (2012) 1390-1396. doi:10.1002/aenm.201200322.

[97] Y. Yang, G. Zheng, Y. Cui, A membrane-free lithium/polysulfide semi-liquid battery for large-scale energy storage, Energy Environ. Sci. 6 (2013) 1552-1558. doi:10.1039/C3EE00072A.

[98] Y. Zhao, H.R. Byon, High-performance lithium-iodine flow battery, Adv. Energy Mater. 3 (2013) 1630-1635. doi:10.1002/aenm.201300627.

[99] B. Huskinson, M.P. Marshak, C. Suh, S. Er, M.R. Gerhardt, C.J. Galvin, X. Chen, A. Aspuru-Guzik, R.G. Gordon, M.J. Aziz, A metal-free organic-inorganic aqueous flow battery, Nature. 505 (2014) 195-198. doi:10.1038/nature12909.

[100] K. Lin, Q. Chen, M.R. Gerhardt, L. Tong, S.B. Kim, L. Eisenach, A.W. Valle, D. Hardee, R.G. Gordon, M.J. Aziz, M.P. Marshak, Alkaline quinone flow battery, Science. 349 (2015) 1529-1532. doi:10.1126/science.aab3033.

[101] P.M. Allen, N.J. Bridger, C.P. Jones, M.D. Neville, A.D. Turner, Electrochemical Ion Exchange, in: P.A. Williams, M.J. Hudson (Eds.), Recent Developments in Ion Exchange, Springer Netherlands, Dordrecht, 1990: pp. 213-218. doi:10.1007/978-94-009-0777-5_20.

[102] K. Cammann, Towards a new generation of redox-flow-batteries (RFBs). Mediator-supported RFBs based on solid electron exchanger columns, (2015). Personal communication (November 19, 2015).

[103] A. Price, S. Bartley, S. Male, G. Cooley, A novel approach to utility scale energy storage, Power Eng. J. 13 (1999) 122-129. doi:10.1049/pe:19990304.

[104] The DOE Global Energy Storage Database, Office of Electricity Delivery \& Energy Reliability, Sandia National Laboratories (2017). http://www.energystorageexchange.org/projects (accessed February 14, 2017).

[105] Y. Arya, N. Kumar, Optimal AGC with redox flow batteries in multi-area restructured power systems, Jestech. (2016) 1-16. doi:10.1016/j.jestch.2015.12.014.

[106] H. Nakahata, N. Ayai, T. Shibata, Development of smart grid demonstration systems, SEI Technical Review. 76 (2013) 8-13.

[107] P.K. Leung, C. Ponce de León, F.J. Recio, P. Herrasti, F.C. Walsh, Corrosion of the zinc negative electrode of zinc-cerium hybrid redox flow batteries in methanesulfonic acid, J. Appl. Electrochem. 44 (2014) 1025-1035. doi:10.1007/s10800-014-0714-y.

[108] N. Clark, P.A. Eidler, P. Lex, Development of zinc/bromine batteries for load leveling applications: Phase 2 final report, Sandia National Laboratories, Albuquerque NM, 1999.

[109] P. Lex, B. Jonshagen, The zinc/bromine battery system for utility and remote area applications, Power Eng. J. 13 (1999) 142-148. doi:10.1049/pe:19990307.

[110] C.C. Liu, R.T. Galasco, R.F. Savinell, Operating performance of an Fe-Ti stationary redox battery in 
the presence of lead, J. Electrochem. Soc. 129 (1982) 2502-2505. doi:10.1149/1.2123592.

[111] X. Wei, G.-G. Xia, B. Kirby, E. Thomsen, Bin Li, Z. Nie, G.G. Graff, J. Liu, V. Sprenkle, W. Wang, An aqueous redox flow battery based on neutral alkali metal ferri/ferrocyanide and polysulfide electrolytes, J. Electrochem. Soc. 163 (2016) A5150-A5153. doi:10.1149/2.0221601jes.

[112] L. Li, S. Kim, W. Wang, M. Vijayakumar, Z. Nie, B. Chen, J. Zhang, G. Xia, J. Hu, G.G. Graff, Z. Yang, A stable vanadium redox-flow battery with high energy density for large-scale energy storage, Adv. Energy Mater. 1 (2011) 394-400. doi:10.1002/aenm.201100008.

[113] S. Kim, M. Vijayakumar, W. Wang, J. Zhang, B. Chen, Z. Nie, F. Chen, J. Hu, Z. Yang, Chloride supporting electrolytes for all-vanadium redox flow batteries, Phys. Chem. Chem. Phys. 13 (2011) 18186-18193. doi:10.1039/C1CP22638J.

[114] G. Nikiforidis, W.A. Daoud, Effect of mixed acid media on the positive side of the hybrid zinc-cerium redox flow battery, Electrochim. Acta. 141 (2014) 255-262. doi:10.1016/j.electacta.2014.06.142.

[115] Y.W.D. Chen, K.S.V. Santhanam, A.J. Bard, Solution redox couples for electrochemical energy storage I. Iron (III)-iron (II) complexes with O-phenanthroline and related ligands, J. Electrochem. Soc. 128 (1981) 1460-1467. doi:10.1149/1.2127663.

[116] P. Modiba, M. Matoetoe, A.M. Crouch, Electrochemical impedance spectroscopy study of Ce(IV) with aminopolycarboxylate ligands for redox flow batteries applications, J. Power Sources. 205 (2012) 1-9. doi:10.1016/j.jpowsour.2012.01.004.

[117] P.K. Leung, C. Ponce de León, C.T.J. Low, F.C. Walsh, Zinc deposition and dissolution in methanesulfonic acid onto a carbon composite electrode as the negative electrode reactions in a hybrid redox flow battery, Electrochim. Acta. 56 (2011) 6536-6546. doi:10.1016/j.electacta.2011.04.111.

[118] A. Mousa, M. Skyllas-Kazacos, Effect of additives on the low-temperature stability of vanadium redox flow battery negative half-cell electrolyte, ChemElectroChem. 2 (2015) 1742-1751.

[119] S. Roe, C. Menictas, M. Skyllas-Kazacos, A high energy density vanadium redox flow battery with 3 M vanadium electrolyte, J. Electrochem. Soc. 163 (2015) A5023-A5028. doi:10.1149/2.0041601jes.

[120] N. Kausar, A. Mousa, M. Skyllas-Kazacos, The effect of additives on the high-temperature stability of the vanadium redox flow battery positive electrolytes, ChemElectroChem. 3 (2016) 276-282.

[121] M. Armand, F. Endres, D.R. MacFarlane, H. Ohno, B. Scrosati, Ionic-liquid materials for the electrochemical challenges of the future, Nature Materials. 8 (2009) 621-629. doi:10.1038/nmat2448.

[122] G. Nikiforidis, L. Berlouis, D. Hall, D. Hodgson, Impact of electrolyte composition on the performance of the zinc-cerium redox flow battery system, J. Power Sources. 243 (2013) 691-698. doi:10.1016/j.jpowsour.2013.06.045.

[123] Regenesys utility scale energy storage, Module test programme, DTI, URN 04/1049 (2004). http://webarchive.nationalarchives.gov.uk/20070603164510/http://www.dti.gov.uk/renewables/public ations/pdfs/kel00246moduletestprogramme.pdf (accessed February 2, 2015).

[124] F.C. Walsh, D. Pletcher, Electrochemical engineering and cell design, in: D. Pletcher, Z.-Q. Tian, D. Williams (Eds.), Developments in Electrochemistry: Science Inspired by Martin Fleischmann, John Wiley \& Sons, 2014: pp. 95-111.

[125] M. Griffiths, C. Ponce de León, F.C. Walsh, Mass transport in the rectangular channel of a filter-press electrolyzer (the FM01-LC reactor), AIChE J. 51 (2005) 682-687. doi:10.1002/aic.10311.

[126] F.J. Recio, P. Herrasti, L. Vázquez, C. Ponce de León, F.C. Walsh, Mass transfer to a nanostructured nickel electrodeposit of high surface area in a rectangular flow channel, Electrochim. Acta. 90 (2013) 507-513. doi:10.1016/j.electacta.2012.11.135. 
[127] L.F. Arenas, C. Ponce de Leon, F.C. Walsh, Mass transport and active area of porous Pt/Ti electrodes for the $\mathrm{Zn}$-Ce redox flow battery determined from limiting current measurements, Electrochim. Acta. 221 (2016) 154-166. doi:10.1016/j.electacta.2016.10.097.

[128] C. Ponce de León, G.W. Reade, I. Whyte, S.E. Male, F.C. Walsh, Characterization of the reaction environment in a filter-press redox flow reactor, Electrochim. Acta. 52 (2007) 5815-5823. doi:10.1016/j.electacta.2007.02.080.

[129] F.C. Walsh, D. Pletcher, I. Whyte, J.P. Millington, Electrolytic removal of cupric ions from dilute liquors using reticulated vitreous carbon cathodes, J. Chem. Technol. Biotechnol. 55 (1992) 147-155.

[130] P. Trinidad, F.C. Walsh, Batch oxidation of cerous ions in a divided FM01-LC filter-press reactor, Icheme Symposium Series. 145 (1999) 281-290.

[131] D. Pletcher, F.C. Walsh, Three-dimensional electrodes, in: D. Gernders, N. Weinberg (Eds.), Electrochemistry for a Cleaner Environment, The Electrosynthesis Company, New York, 1992: pp. $51-100$.

[132] S. Langlois, F. Coeuret, Flow-through and flow-by porous electrodes of nickel foam Part III: theoretical electrode potential distribution in the flow-by configuration, J. Appl. Electrochem. 20 (1990) 740-748. doi:10.1007/BF01094300.

[133] H. Zhou, H. Zhang, P. Zhao, B. Yi, A comparative study of carbon felt and activated carbon based electrodes for sodium polysulfide/bromine redox flow battery, Electrochim. Acta. 51 (2006) 63046312. doi:10.1016/j.electacta.2006.03.106.

[134] C.J. Brown, D. Pletcher, F.C. Walsh, J.K. Hammond, D. Robinson, Local mass transport effects in the FM01 laboratory electrolyser, J. Appl. Electrochem. 22 (1992) 613-619. doi:10.1007/BF01092609.

[135] C.J. Brown, F.C. Walsh, D. Pletcher, Mass transfer and pressure drop in a laboratory filterpress electrolyser, Trans. IChemE. 73 (1995) 196-205.

[136] C.J. Brown, D. Pletcher, F.C. Walsh, J.K. Hammond, D. Robinson, Studies of space-averaged mass transport in the FM01-LC laboratory electrolyser, J. Appl. Electrochem. 23 (1993) 38-43. doi:10.1007/BF00241573.

[137] A.N. Colli, R. Toelzer, M.E.H. Bergmann, J.M. Bisang, Mass-transfer studies in an electrochemical reactor with a small interelectrode gap, Electrochim. Acta. 100 (2013) 78-84. doi:10.1016/j.electacta.2013.03.134.

[138] A.N. Colli, J.M. Bisang, Validation of theory with experiments for local mass transfer at parallel plate electrodes under laminar flow conditions, J. Electrochem. Soc. 160 (2013) E5-E11. doi:10.1149/2.015302jes.

[139] A.N. Colli, J.M. Bisang, The effect of a perpendicular and cumulative inlet flow on the mass-transfer distribution in parallel-plate electrochemical reactors, Electrochim. Acta. 137 (2014) 758-766.

[140] A. Walker, A.A. Wragg, The modelling of concentration-time relationships in recirculating electrochemical reactor systems, Electrochim. Acta. 22 (1977) 1129-1134. doi:10.1016/00134686(77)80051-0.

[141] P. Trinidad, F.C. Walsh, D. Gilroy, Conversion expressions for electrochemical reactors which operate under mass transport controlled reaction conditions, Part I: batch reactor, PFR and CSTR, Int. J. Engng. Ed. 14 (1998) 431-441.

[142] F.C. Walsh, P. Trinidad, D. Gilroy, Conversion expressions for electrochemical reactors which operate under mass transport controlled reaction conditions-Part II: Batch recycle, cascade and recycle loop reactors, Int. J. Engng. Ed. 21 (2005) 981-992. 
[143] Y. Li, M. Skyllas-Kazacos, J. Bao, A dynamic plug flow reactor model for a vanadium redox flow battery cell, J. Power Sources. 311 (2016) 57-67. doi:10.1016/j.jpowsour.2016.02.018.

[144] M.J. Watt-Smith, P. Ridley, R.G.A. Wills, A.A. Shah, F.C. Walsh, The importance of key operational variables and electrolyte monitoring to the performance of an all vanadium redox flow battery, $\mathrm{J}$. Chem. Technol. Biotechnol. 88 (2012) 126-138. doi:10.1002/jctb.3870.

[145] L. Liu, J. Xi, Z. Wu, W. Zhang, H. Zhou, W. Li, X. Qiu, State of charge monitoring for vanadium redox flow batteries by the transmission spectra of $\mathrm{V}(\mathrm{IV}) / \mathrm{V}(\mathrm{V})$ electrolytes, J. Appl. Electrochem. 42 (2012) 1025-1031. doi:10.1007/s10800-012-0477-2.

[146] X. Gao, R.P. Lynch, L. Martin J, D.N. Buckley, Spectroscopic study of vanadium electrolytes in vanadium redox flow battery (VRFB), ECS Trans. 45 (2013) 25-36. doi:10.1149/04526.0025ecst.

[147] D.N. Buckley, X. Gao, R.P. Lynch, N. Quill, M.J. Leahy, Towards optical monitoring of vanadium redox flow batteries (VRFBs): An investigation of the underlying spectroscopy, J. Electrochem. Soc. 161 (2014) A524-A534. doi:10.1149/2.023404jes.

[148] N. Quill, C. Petchsingh, R.P. Lynch, X. Gao, D. Oboroceanu, D.N. Eidhin, M. O'Mahony, C. Lenihan, D. N. Buckley, Factors affecting spectroscopic state-of-charge measurements of positive and negative electrolytes in vanadium redox flow batteries, ECS Trans. 64 (2015) 23-39. doi:10.1149/06418.0023ecst.

[149] S. Rudolph, U. Schröder, I.M. Bayanov, K. Blenke, D. Hage, High resolution state of charge monitoring of vanadium electrolytes with IR optical sensor, J. Electroanal. Chem. 694 (2013) 17-22.

[150] W. Duan, R.S. Vemuri, J.D. Milshtein, S. Laramie, R.D. Dmello, J. Huang, L. Zhang, D. Hu, M. Vijayakumar, W. Wang, J. Liu, R.M. Darling, L. Thompson, K. Smith, J.S. Moore, F.R. Brushett, X. Wei, A symmetric organic - based nonaqueous redox flow battery and its state of charge diagnostics by FTIR, J. Mater. Chem. A. (2016).

[151] Z. Wei, T.M. Lim, M. Skyllas-Kazacos, N. Wai, K.J. Tseng, Online state of charge and model parameter co-estimation based on a novel multi-timescale estimator for vanadium redox flow battery, Applied Energy. 172 (2016) 169-179. doi:10.1016/j.apenergy.2016.03.103.

[152] G. Nikiforidis, L. Berlouis, D. Hall, D. Hodgson, An electrochemical study on the positive electrode side of the zinc-cerium hybrid redox flow battery, Electrochim. Acta. 115 (2014) 621-629. doi:10.1016/j.electacta.2013.09.081.

[153] M. Skyllas-Kazacos, M. Kazacos, State of charge monitoring methods for vanadium redox flow battery control, J. Power Sources. 196 (2011) 8822-8827.

[154] S. Corcuera, M. Skyllas-Kazacos, State-of-charge monitoring and electrolyte rebalancing methods for the vanadium redox flow battery, Eur. Chem. Bull. 1 (2012) 511-519.

[155] Q. Xu, T.S. Zhao, C. Zhang, Effects of SOC-dependent electrolyte viscosity on performance of vanadium redox flow batteries, Applied Energy. 130 (2014) 139-147. doi:10.1016/j.apenergy.2014.05.034.

[156] F.C. Walsh, Normalised performance indicators for electrochemical reactors used in environmental control: the normalised volumetric power consumption, Bull. Electrochem. 8 (1992) 471-474.

[157] F.F. Rivera, C. Ponce de Leon, F.C. Walsh, J.L. Nava, The reaction environment in a filter-press laboratory reactor: the FM01-LC flow cell, Electrochim. Acta. 161 (2015) 436-452. doi:10.1016/j.electacta.2015.02.161.

[158] C. Bengoa, A. Montillet, P. Legentilhomme, J. Legrand, Flow visualization and modelling of a filterpress type electrochemical reactor, J. Appl. Electrochem. 27 (1997) 1313-1322. doi:10.1023/A:1018456609059. 
[159] C. Ponce de León, I. Whyte, G.W. Reade, S.E. Male, F.C. Walsh, Mass transport and flow dispersion in the compartments of a modular 10 cell filter-press stack, Aust. J. Chem. 61 (2008) 797-804. doi: $10.1071 / \mathrm{CH} 07161$.

[160] F.C. Walsh, Electrochemical technology for environmental treatment and clean energy conversion, Pure Appl. Chem. 73 (2001) 1819-1837. doi:10.1351/pac200173121819.

[161] A. Montillet, J. Comiti, J. Legrand, Application of metallic foams in electrochemical reactors of filterpress type part I: flow characterization, J. Appl. Electrochem. 23 (1993) 1045-1050.

[162] J. González-García, V. Montiel, A. Aldaz, J.A. Conesa, J.R. Pérez, G. Codina, Hydrodynamic behavior of a filter-press electrochemical reactor with carbon felt as a three-dimensional electrode, Ind. Eng. Chem. Res. 37 (1998) 4501-4511. doi:10.1021/ie980144a.

[163] P. Trinidad, C. Ponce de León, F.C. Walsh, The application of flow dispersion models to the FM01LC laboratory filter-press reactor, Electrochim. Acta. 52 (2006) 604-613. doi:10.1016/j.electacta.2006.05.040.

[164] A.N. Colli, J.M. Bisang, Evaluation of the hydrodynamic behaviour of turbulence promoters in parallel plate electrochemical reactors by means of the dispersion model, Electrochim. Acta. 56 (2011) 7312-7318. doi:10.1016/j.electacta.2011.06.047.

[165] E.R. Henquín, J.M. Bisang, Performance of a multipurpose research electrochemical reactor, Electrochim. Acta. 56 (2011) 5926-5933. doi:10.1016/j.electacta.2011.04.115.

[166] J.O.M. Bockris, A.K.N. Reddy, Modern Electrochemistry: An Introduction to an Interdisciplinary Area, Plenum Press, New York, 1970.

[167] R. Kodým, M. Drakselová, P. Pánek, M. Němeček, D. Šnita, K. Bouzek, Novel approach to mathematical modeling of the complex electrochemical systems with multiple phase interfaces, Electrochim. Acta. 179 (2015) 538-555. doi:10.1016/j.electacta.2015.01.039.

[168] D. Klotz, Characterization and Modeling of Electrochemical Energy Conversion Systems by Impedance Techniques, Dr.-Ing. dissertation, KIT Scientific Publishing (2012).

[169] V. Viswanathan, A. Crawford, D. Stephenson, S. Kim, W. Wang, B. Li, Greg Coffey, E. Thomsen, G. Graff, P. Balducci, M. Kintner-Meyer, V. Sprenkle, Cost and performance model for redox flow batteries, J. Power Sources. 247 (2014) 1040-1051. doi:10.1016/j.jpowsour.2012.12.023.

[170] Q. Xu, T.S. Zhao, Fundamental models for flow batteries, Prog. Energ. Combust. 49 (2015) 40-58. doi:10.1016/j.pecs.2015.02.001.

[171] I.M. Bayanov, R. Vanhaelst, The numerical simulation of vanadium RedOx flow batteries, J. Math. Chem. 49 (2011) 2013-2031. doi:10.1007/s10910-011-9872-x.

[172] A.A. Shah, M.J. Watt-Smith, F.C. Walsh, A dynamic performance model for redox-flow batteries involving soluble species, Electrochim. Acta. 53 (2008) 8087-8100. doi:10.1016/j.electacta.2008.05.067.

[173] A.A. Shah, R. Tangirala, R. Singh, R.G.A. Wills, F.C. Walsh, A dynamic unit cell model for the allvanadium flow battery, J. Electrochem. Soc. 158 (2011) A671-A677. doi:10.1149/1.3561426.

[174] D.P. Scamman, G.W. Reade, E.P.L. Roberts, Numerical modelling of a bromide-polysulphide redox flow battery. Part 1: Modelling approach and validation for a pilot-scale system, J. Power Sources. 189 (2009) 1220-1230. doi:10.1016/j.jpowsour.2009.01.071.

[175] D.P. Scamman, G.W. Reade, E.P.L. Roberts, Numerical modelling of a bromide-polysulphide redox flow battery. Part 2: Evaluation of a utility-scale system, J. Power Sources. 189 (2009) 1231-1239. doi:10.1016/j.jpowsour.2009.01.076. 
[176] A. Tang, J. Bao, M. Skyllas-Kazacos, Dynamic modelling of the effects of ion diffusion and side reactions on the capacity loss for vanadium redox flow battery, J. Power Sources. 196 (2011) 1073710747. doi:10.1016/j.jpowsour.2011.09.003.

[177] A. Tang, J. Bao, M. Skyllas-Kazacos, Thermal modelling of battery configuration and self-discharge reactions in vanadium redox flow battery, J. Power Sources. 216 (2012) 489-501. doi:10.1016/j.jpowsour.2012.06.052.

[178] A. Tang, S. Ting, J. Bao, M. Skyllas-Kazacos, Thermal modelling and simulation of the all-vanadium redox flow battery, J. Power Sources. 203 (2012) 165-176. doi:10.1016/j.jpowsour.2011.11.079.

[179] A. Tang, J. McCann, J. Bao, M. Skyllas-Kazacos, Investigation of the effect of shunt current on battery efficiency and stack temperature in vanadium redox flow battery, J. Power Sources. 242 (2013) 349-356. doi:10.1016/j.jpowsour.2013.05.079.

[180] J.A. Mellentine, W.J. Culver, R.F. Savinell, Simulation and optimization of a flow battery in an area regulation application, J. Appl. Electrochem. 41 (2011) 1167-1174. doi:10.1007/s10800-011-0326-8.

[181] A.K. Sharma, M. Vynnycky, C.Y. Ling, E. Birgersson, M. Han, The quasi-steady state of allvanadium redox flow batteries: A scale analysis, Electrochim. Acta. 147 (2014) 657-662. doi:10.1016/j.electacta.2014.09.134.

[182] T.I. Evans, R.E. White, A review of mathematical modeling of the zinc/bromine flow cell and battery, J. Electrochem. Soc. 134 (1987) 2725-2733. doi:10.1149/1.2100277.

[183] G.D. Simpson, R.E. White, An algebraic model for a zinc/bromine flow cell, J. Electrochem. Soc. 136 (1989) 2137-2144. doi:10.1149/1.2097226.

[184] E. Manla, A. Nasiri, C.H. Rentel, M. Hughes, Modeling of zinc bromide energy storage for vehicular applications, IEEE Trans. Ind. Electron. 57 (2010) 624-632. doi:10.1109/TIE.2009.2030765.

[185] A.A. Shah, X. Li, R.G.A. Wills, F.C. Walsh, A mathematical model for the soluble lead-acid flow battery, J. Electrochem. Soc. 157 (2010) A589-A599. doi:10.1149/1.3328520.

[186] M.D.R. Kok, J.T. Gostick, Multiphysics simulation of the bromine cathode: Cell architecture and electrode optimization, ECS Trans. 69 (2015) 21-35. doi:10.1149/06901.0021 ecst.

[187] X. You, Q. Ye, T. Van Nguyen, P. Cheng, 2-D model of a $\mathrm{H}_{2} / \mathrm{Br}_{2}$ flow battery with flow-through positive electrode, J. Electrochem. Soc. 163 (2016) A447-A457. doi:10.1149/2.0361603jes.

[188] M.D.R. Kok, A. Khalifa, J.T. Gostick, Multiphysics simulation of the flow battery cathode: Cell architecture and electrode optimization, J. Electrochem. Soc. 163 (2016) A1408-A1419. doi:10.1149/2.1281607jes.

[189] H. Al-Fetlawi, A.A. Shah, F.C. Walsh, Non-isothermal modelling of the all-vanadium redox flow battery, Electrochim. Acta. 55 (2009) 78-89. doi:10.1016/j.electacta.2009.08.009.

[190] A.A. Shah, H. Al-Fetlawi, F.C. Walsh, Dynamic modelling of hydrogen evolution effects in the allvanadium redox flow battery, Electrochim. Acta. 55 (2010) 1125-1139.

doi:10.1016/j.electacta.2009.10.022.

[191] H. Al-Fetlawi, A.A. Shah, F.C. Walsh, Modelling the effects of oxygen evolution in the all-vanadium redox flow battery, Electrochim. Acta. 55 (2010) 3192-3205. doi:10.1016/j.electacta.2009.12.085.

[192] C. Blanc, A. Rufer, Multiphysics and energetic modeling of a vanadium redox flow battery, in: 2008 IEEE International Conference on Sustainable Energy Technologies (ICSET), IEEE, Singapore, 2008: pp. 696-701. doi:10.1109/ICSET.2008.4747096.

[193] C. Blanc, A. Rufer, Optimization of the operating point of a vanadium redox flow battery, in: 2009 
IEEE Energy Conversion Congress and Exposition. ECCE 2009, IEEE, 2009: pp. 2600-2605. doi:10.1109/ECCE.2009.5316566.

[194] M. Zhang, M. Moore, J.S. Watson, T.A. Zawodzinski, R.M. Counce, Capital cost sensitivity analysis of an all-vanadium redox-flow battery, J. Electrochem. Soc. 159 (2012) A1183-A1188. doi:10.1149/2.041208jes.

[195] D. You, H. Zhang, J. Chen, A simple model for the vanadium redox battery, Electrochim. Acta. 54 (2009) 6827-6836. doi:10.1016/j.electacta.2009.06.086.

[196] C. Yin, S. Guo, H. Fang, J. Liu, Y. Li, H. Tang, Numerical and experimental studies of stack shunt current for vanadium redox flow battery, Applied Energy. 151 (2015) 237-248. doi:10.1016/j.apenergy.2015.04.080.

[197] G. Merei, S. Adler, D. Magnor, D.U. Sauer, Multi-physics model for the aging prediction of a vanadium redox flow battery system, Electrochim. Acta. 174 (2015) 945-954.

doi:10.1016/j.electacta.2015.06.046.

[198] A.A. Shah, K.H. Luo, T.R. Ralph, F.C. Walsh, Recent trends and developments in polymer electrolyte membrane fuel cell modelling, Electrochim. Acta. 56 (2011) 3731-3757.

doi:10.1016/j.electacta.2010.10.046.

[199] T.V. Nguyen, R.E. White, A water and heat management model for proton-exchange-membrane fuel cells, J. Electrochem. Soc. 140 (1993) 2178-2186. doi:10.1149/1.2220792.

[200] T. Pérez, C. Ponce de León, F.C. Walsh, J.L. Nava, Simulation of current distribution along a planar electrode under turbulent flow conditions in a laboratory filter-press flow cell, Electrochim. Acta. 154 (2015) 352-360. doi:10.1016/j.electacta.2014.11.166.

[201] F.F. Rivera, C. Ponce de Leon, J.L. Nava, F.C. Walsh, The filter-press FM01-LC laboratory flow reactor and its applications, Electrochim. Acta. 163 (2015) 338-354.

doi:10.1016/j.electacta.2015.02.179.

[202] J. González-García, A. Frías-Ferrer, V. Montiel, A. Aldaz, J.A. Conesa, Development of a model for the characterization of fluid dispersion in electrochemical reactors, J. Hydroinform. 4 (2002) 281-295.

[203] D.S. Aaron, Q. Liu, Z. Tang, G.M. Grim, A.B. Papandrew, A. Turhan, T.A. Zawodzinski, M.M. Mench, Dramatic performance gains in vanadium redox flow batteries through modified cell architecture, J. Power Sources. 206 (2012) 450-453. doi:10.1016/j.jpowsour.2011.12.026.

[204] T. Jyothi Latha, S. Jayanti, Hydrodynamic analysis of flow fields for redox flow battery applications, J. Appl. Electrochem. 44 (2014) 995-1006. doi:10.1007/s10800-014-0720-0.

[205] T. Jyothi Latha, S. Jayanti, Ex-situ experimental studies on serpentine flow field design for redox flow battery systems, J. Power Sources. 248 (2014) 140-146. doi:10.1016/j.jpowsour.2013.09.084.

[206] C. Yin, Y. Gao, S. Guo, H. Tang, A coupled three dimensional model of vanadium redox flow battery for flow field designs, Energy. 74 (2014) 886-895. doi:10.1016/j.energy.2014.07.066.

[207] A.M. Couper, D. Pletcher, F.C. Walsh, Electrode materials for electrosynthesis, Chem. Rev. 90 (1990) 837-865. doi:10.1021/cr00103a010.

[208] F.C. Walsh, C. Ponce de León, Progress in modern electrochemical cell designs for labortory and pilot scale, Electrochim. Acta. (2015).

[209] R. Schweiss, Influence of bulk fibre properties of PAN-based carbon felts on their performance in vanadium redox flow batteries, J. Power Sources. 278 (2015) 308-313.

doi:10.1016/j.jpowsour.2014.12.081. 
[210] P.K. Leung, C. Ponce de León, F.C. Walsh, An undivided zinc-cerium redox flow battery operating at room temperature (295 K), Electrochem. Commun. 13 (2011) 770-773.

doi:10.1016/j.elecom.2011.04.011.

[211] D.A. Johnson, M.A. Reid, Chemical and electrochemical behavior of the $\mathrm{Cr}(\mathrm{III}) / \mathrm{Cr}$ (II) half-cell in the iron-chromium redox energy storage system, J. Electrochem. Soc. 132 (1985) 1058-1062. doi:10.1149/1.2114015.

[212] H. Vafiadis, M. Skyllas-Kazacos, Evaluation of membranes for the novel vanadium bromine redox flow cell, J. Membrane Sci. 279 (2006) 394-402. doi:10.1016/j.memsci.2005.12.028.

[213] H. Fink, J. Friedl, U. Stimming, Composition of the electrode determines which half-cell's rate constant is higher in a vanadium flow battery, J. Phys. Chem. C. (2016) acs.jpcc.5b12098. doi:10.1021/acs.jpcc.5b12098.

[214] M.-A. Goulet, M. Skyllas-Kazacos, E. Kjeang, The importance of wetting in carbon paper electrodes for vanadium redox reactions, Carbon. 101 (2016) 390-398.

[215] H. Kaneko, K. Nozaki, Y. Wada, T. Aoki, A. Negishi, M. Kamimoto, Vanadium redox reactions and carbon electrodes for vanadium redox flow battery, Electrochim. Acta. 36 (1991) 1191-1196. doi:10.1016/0013-4686(91)85108-J.

[216] A.M. Pezeshki, R.L. Sacci, G.M. Veith, T.A. Zawodzinski, M.M. Mench, The cell-in-series method: A technique for accelerated electrode degradation in redox flow batteries, J. Electrochem. Soc. 163 (2016) A5202-A5210. doi:10.1149/2.0251601jes.

[217] G.J.W. Radford, J. Cox, R.G.A. Wills, F.C. Walsh, Electrochemical characterisation of activated carbon particles used in redox flow battery electrodes, J. Power Sources. 185 (2008) 1499-1504. doi:10.1016/j.jpowsour.2008.08.020.

[218] N.J. Magnani, R.P. Clark, J.W. Braithwaite, D.M. Bush, Butler, P. C., J.M. Freese, K.R. Grothaus, K.D. Murphy, P.E. Shoemaker, Exploratory battery technology development and testing report for 1985 SAND86-1266, Sandia National Laboratories, 1987.

[219] G. Nikiforidis, L. Berlouis, D. Hall, D. Hodgson, A study of different carbon composite materials for the negative half-cell reaction of the zinc cerium hybrid redox flow cell, Electrochim. Acta. 113 (2013) 412-423. doi:10.1016/j.electacta.2013.09.061.

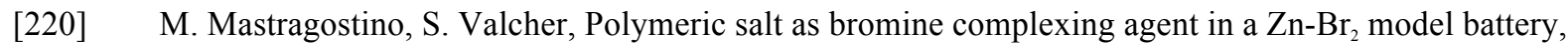
Electrochim. Acta. 28 (1983) 501-505. doi:10.1016/0013-4686(83)85034-8.

[221] C.D. Iacovangelo, F.G. Will, Parametric study of zinc deposition on porous carbon in a flowing electrolyte cell, J. Electrochem. Soc. 132 (1985) 851-857. doi:10.1149/1.2113972.

[222] A. Banerjee, D. Saha, T.N. Guru Row, A.K. Shulka, A soluble-lead redox flow battery with corrugated graphite sheet and reticulated vitreous carbon as positive and negative current collectors, Bull. Mater. Sci. 36 (2013) 163-170. doi:10.1007/s12034-013-0426-7.

[223] I. Ruggeri, C. Arbizzani, F. Soavi, A novel concept of semi-solid, Li redox flow air $\left(\mathrm{O}_{2}\right)$ battery: A breakthrough towards high energy and power batteries, Electrochim. Acta. 206 (2016) 291-300. doi:10.1016/j.electacta.2016.04.139.

[224] S. Zhong, M. Skyllas-Kazacos, Electrochemical behaviour of vanadium(V)/vanadium(IV) redox couple at graphite electrodes, J. Power Sources. 39 (1992) 1-9. doi:10.1016/0378-7753(92)85001-Q.

[225] L. Cao, M. Skyllas-Kazacos, D.-W. Wang, Effects of surface pretreatment of glassy carbon on the electrochemical behavior of V(IV)/V(V) redox reaction, J. Electrochem. Soc. 163 (2016) A1164A1174. doi:10.1149/2.0261607jes. 
[226] B. Sun, M. Skyllas-Kazakos, Chemical modification and electrochemical behaviour of graphite fibre in acidic vanadium solution, Electrochim. Acta. 36 (1991) 513-517. doi:10.1016/00134686(91)85135-T.

[227] W.H. Wang, X.D. Wang, Investigation of Ir-modified carbon felt as the positive electrode of an allvanadium redox flow battery, Electrochim. Acta. 52 (2007) 6755-6762. doi:10.1016/j.electacta.2007.04.121.

[228] C. Fabjan, J. Garche, B. Harrer, L. Jörissen, C. Kolbeck, F. Philippi, G. Tomazic, F. Wagner, The vanadium redox-battery: an efficient storage unit for photovoltaic systems, Electrochim. Acta. 47 (2001) 825-831. doi:10.1016/S0013-4686(01)00763-0.

[229] K.J. Kim, M.-S. Park, J.-H. Kim, U. Hwang, N.J. Lee, G. Jeong, Y.-J. Kim, Novel catalytic effects of $\mathrm{Mn}_{3} \mathrm{O}_{4}$ for all vanadium redox flow batteries, Chem. Commun. 48 (2012) 5455-5457.

doi:10.1039/C2CC31433A.

[230] S. Jeong, S. An, J. Jeong, J. Lee, Y. Kwon, Effect of mesocelluar carbon foam electrode material on performance of vanadium redox flow battery, J. Power Sources. 278 (2015) 245-254.

doi:10.1016/j.jpowsour.2014.12.074.

[231] Z. González, A. Sánchez, C. Blanco, M. Granda, R. Menéndez, R. Santamaría, Enhanced performance of a Bi-modified graphite felt as the positive electrode of a vanadium redox flow battery, Electrochem. Commun. 13 (2011) 1379-1382. doi:10.1016/j.elecom.2011.08.017.

[232] B. Sun, M. Skyllas-Kazacos, Modification of graphite electrode materials for vanadium redox flow battery application-I. Thermal treatment, Electrochim. Acta. 37 (1992) 1253-1260. doi:10.1016/0013-4686(92)85064-R.

[233] B. Sun, M. Skyllas-Kazacos, Chemical modification of graphite electrode materials for vanadium redox flow battery application — part II. Acid treatments, Electrochim. Acta. 37 (1992) 2459-2465. doi:10.1016/0013-4686(92)87084-D.

[234] P.K. Leung, M.R. Mohamed, A.A. Shah, Q. Xu, M.B. Conde-Duran, A mixed acid based vanadiumcerium redox flow battery with a zero-gap serpentine architecture, J. Power Sources. 274 (2015) 651658. doi:10.1016/j.jpowsour.2014.10.034.

[235] W. Li, J. Liu, C. Yan, Multi-walled carbon nanotubes used as an electrode reaction catalyst for $\mathrm{VO}_{2}^{+} / \mathrm{VO}^{2+}$ for a vanadium redox flow battery, Carbon. 49 (2011) 3463-3470.

doi:10.1016/j.carbon.2011.04.045.

[236] P. Han, Y. Yue, Z. Liu, W. Xu, L. Zhang, H. Xu, S. Dong, G. Cui, Graphene oxide nanosheets / multiwalled carbon nanotubes hybrid as an excellent electrocatalytic material towards $\mathrm{VO}^{2+} / \mathrm{VO}^{2+}$ redox couples for vanadium redox flow batteries, Energy Environ. Sci. 4 (2011) 4710-4717. doi:10.1039/C1EE01776D.

[237] G. Wei, C. Jia, J. Liu, C. Yan, Carbon felt supported carbon nanotubes catalysts composite electrode for vanadium redox flow battery application, J. Power Sources. 220 (2012) 185-192. doi:10.1016/j.jpowsour.2012.07.081.

[238] H.-M. Tsai, S.-J. Yang, C.-C.M. Ma, X. Xie, Preparation and electrochemical activities of iridiumdecorated graphene as the electrode for all-vanadium redox flow batteries, Electrochim. Acta. 77 (2012) 232-236.

[239] S. Maeda, J. Sugawara, H. Hayami, Sumitomo Electric Industries, Ltd., Bipolar plate for redox flow battery, US patent application 20130037760 A1, 2013.

[240] B. Caglar, J. Richards, P. Fischer, J. Tuebke, Conductive polymer composites and coated metals as alternative bipolar plate materials for all-vanadium redox-flow batteries, Adv. Mat. Lett. 5 (2014) 299-308. 
[241] P. Zhao, H. Zhang, H. Zhou, B. Yi, Nickel foam and carbon felt applications for sodium polysulfide/bromine redox flow battery electrodes, Electrochim. Acta. 51 (2005) 1091-1098. doi:10.1016/j.electacta.2005.06.008.

[242] Y.-H. Wen, J. Cheng, S.-Q. Ning, Y.-S. Yang, Preliminary study on zinc-air battery using zinc regeneration electrolysis with propanol oxidation as a counter electrode reaction, J. Power Sources. 188 (2009) 301-307. doi:10.1016/j.jpowsour.2008.11.054.

[243] S. Chandrabose Raghu, M. Ulaganathan, T.M. Lim, M. Skyllas-Kazacos, Electrochemical behaviour of titanium/iridium(IV) oxide: Tantalum pentoxide and graphite for application in vanadium redox flow battery, J. Power Sources. 238 (2013) 103-108. doi:10.1016/j.jpowsour.2013.03.084.

[244] R.F. Savinell, C.C. Liu, R.T. Galasco, S.H. Chiang, J.F. Coetzee, Discharge characteristics of a soluble iron-titanium battery system, J. Electrochem. Soc. 126 (1979) 357-360.

doi:10.1149/1.2129043.

[245] J. Van Zee, R.E. White, An analysis of a back fed porous electrode for the $\mathrm{Br}_{2} / \mathrm{Br}^{-}$redox reaction, J. Electrochem. Soc. 130 (1983) 2003-2011. doi:10.1149/1.2119510.

[246] M. Rychcik, M. Skyllas-Kazacos, Evaluation of electrode materials for vanadium redox cell, J. Power Sources. 19 (1987) 45-54. doi:10.1016/0378-7753(87)80006-X.

[247] K.M. Govindan, I.S. Moon, Evaluation of dual electrochemical cell design for cerium-vanadium redox flow battery to use different combination of electrodes, Int. J. Electrochem. Sci. (2013).

[248] S.K. Mondal, J. Rugolo, M.J. Aziz, Alloy oxide electrocatalysts for regenerative hydrogen-halogen fuel cell, MRS Proceedings. 1311 (2011) mrsf10-1311-gg10-09. doi:10.1557/opl.2011.108.

[249] J.W. Long, B. Dunn, D.R. Rolison, H.S. White, Three-dimensional battery architectures, Chem. Rev. 104 (2004) 4463-4492.

[250] H. Chen, Q. Zou, Z. Liang, H. Liu, Q. Li, Y.-C. Lu, Sulphur-impregnated flow cathode to enable high-energy-density lithium flow batteries, Nature Communications. 6 (2015) 5877. doi: $10.1038 /$ ncomms6877.

[251] M.K. Debe, R.T. Atanasoski, A.J. Steinbach, Nanostructured thin film electrocatalysts - current status and future potential, ECS Trans. 41 (2011) 937-954. doi:10.1149/1.3635628.

[252] L.F. Arenas, F.C. Walsh, C. Ponce de León, The importance of cell geometry and electrolyte properties to the cell potential of Zn-Ce hybrid flow batteries, J. Electrochem. Soc. 163 (2016) A5170-A5179. doi:10.1149/2.0261601jes.

[253] P. Leung, J. Palma, E. Garcia-Quismondo, L. Sanz, M.R. Mohamed, M. Anderson, Evaluation of electrode materials for all-copper hybrid flow batteries, J. Power Sources. 310 (2016) 1-11. doi:10.1016/j.jpowsour.2015.12.069.

[254] C. Tang, D. Zhou, Methanesulfonic acid solution as supporting electrolyte for zinc-vanadium redox battery, Electrochim. Acta. 65 (2012) 179-184. doi:10.1016/j.electacta.2012.01.036.

[255] S. Peng, N.F. Wang, X.J. Wu, S.Q. Liu, Vanadium species in $\mathrm{CH}_{3} \mathrm{SO}_{3} \mathrm{H}$ and $\mathrm{H}_{2} \mathrm{SO}_{4}$ mixed acid as the supporting electrolyte for vanadium redox flow battery, Int. J. Electrochem. Sci. 7 (2012) 643-649.

[256] Z. Xie, F. Xiong, D. Zhou, Study of the $\mathrm{Ce}^{3+} / \mathrm{Ce}^{4+}$ redox couple in mixed-acid media $\left(\mathrm{CH}_{3} \mathrm{SO}_{3} \mathrm{H}_{\text {and }}\right.$ $\mathrm{H}_{2} \mathrm{SO}_{4}$ ) for redox flow battery application, Energy Fuels. 25 (2011) 2399-2404. doi:10.1021/ef200354b.

[257] Y. Ito, M. Nyce, R. Plivelich, M. Klein, D. Steingart, S. Banerjee, Zinc morphology in zinc-nickel flow assisted batteries and impact on performance, J. Power Sources. 196 (2011) 2340-2345. doi:10.1016/j.jpowsour.2010.09.065. 
[258] Q. Liu, A.A. Shinkle, Y. Li, C.W. Monroe, L.T. Thompson, A.E.S. Sleightholme, Non-aqueous chromium acetylacetonate electrolyte for redox flow batteries, Electrochem. Commun. 12 (2010) 1634-1637. doi:10.1016/j.elecom.2010.09.013.

[259] Q. Liu, A.E.S. Sleightholme, A.A. Shinkle, Y. Li, L.T. Thompson, Non-aqueous vanadium acetylacetonate electrolyte for redox flow batteries, Electrochem. Commun. 11 (2009) 2312-2315. doi:10.1016/j.elecom.2009.10.006.

[260] J. Mun, M.-J. Lee, J.-W. Park, D.-J. Oh, D.-Y. Lee, S.-G. Doo, Non-aqueous redox flow batteries with nickel and iron tris(2,2'-bipyridine) complex electrolyte, Electrochem. Solid-State Lett. 15 (2012) A80-A82. doi:10.1149/2.033206esl.

[261] R.M. Darling, K.G. Gallagher, J.A. Kowalski, S. Ha, F.R. Brushett, Pathways to low-cost electrochemical energy storage: a comparison of aqueous and nonaqueous flow batteries, Energy Environ. Sci. 7 (2014) 3459-3477. doi:10.1039/C4EE02158D.

[262] K.B. Hatzell, M. Boota, E.C. Kumbur, Y. Gogotsi, Flowable conducting particle networks in redoxactive electrolytes for grid energy storage, J. Electrochem. Soc. 162 (2015) A5007-A5012. doi:10.1149/2.0011505jes.

[263] J. Cooper, Powering future vehicles with the refuelable zinc/air battery, Science \& Technology Review. 10 (1995).

[264] T.J. Petek, N.C. Hoyt, R.F. Savinell, J.S. Wainright, Slurry electrodes for iron plating in an all-iron flow battery, J. Power Sources. 294 (2015) 620-626. doi:10.1016/j.jpowsour.2015.06.050.

[265] M. Duduta, B. Ho, V.C. Wood, P. Limthongkul, V.E. Brunini, W.C. Carter, Y.-M. Chiang, Semi-solid lithium rechargeable flow battery, Adv. Energy Mater. 1 (2011) 511-516. doi:10.1002/aenm.201100152.

[266] F.Y. Fan, W.H. Woodford, Z. Li, N. Baram, K.C. Smith, A. Helal, G.H. McKinley, W.C. Carter, Y.M. Chiang, Polysulfide flow batteries enabled by percolating nanoscale conductor networks, Nano Lett. 14 (2014) 2210-2218. doi:10.1021/n1500740t.

[267] W. Li, Z. Liang, Z. Lu, X. Tao, K. Liu, H. Yao, Y. Cui, Magnetic field-controlled lithium polysulfide semiliquid battery with ferrofluidic properties, Nano Lett. 15 (2015) 7394-7399.

doi:10.1021/acs.nanolett.5b02818.

[268] S. Wu, Y. Zhao, D. Li, Y. Xia, S. Si, An asymmetric Zn//Ag doped polyaniline microparticle suspension flow battery with high discharge capacity, J. Power Sources. 275 (2015) 305-311. doi:10.1016/j.jpowsour.2014.11.012.

[269] J. Winsberg, S. Muench, T. Hagemann, S. Morgenstern, T. Janoschka, M. Billing, F.H. Schacher, G. Hauffman, J.-F. Gohy, S. Hoeppener, M.D. Hager, U.S. Schubert, Polymer/zinc hybrid-flow battery using block copolymer micelles featuring a TEMPO corona as catholyte, Polymer Chemistry. 7 (2016) 1711-1718. doi:10.1039/C5PY02036K.

[270] E. Ventosa, G. Zampardi, C. Flox, F. La Mantia, W. Schuhmann, J.R. Morante, Solid electrolyte interphase in semi-solid flow batteries: a wolf in sheep's clothing, Chem. Commun. 51 (2015) 1497314976. doi:10.1039/C5CC04767F.

[271] X. Wei, Bin Li, W. Wang, Porous polymeric composite separators for redox flow batteries, Polymer Reviews. 55 (2015) 247-272. doi:10.1080/15583724.2015.1011276.

[272] X. Wei, L. Li, Q. Luo, Z. Nie, W. Wang, B. Li, G.-G. Xia, E. Miller, J. Chambers, Z. Yang, Microporous separators for Fe/V redox flow batteries, J. Power Sources. 218 (2012) 39-45. doi:10.1016/j.jpowsour.2012.06.073.

[273] J. Drillkens, D. Schulte, D.U. Sauer, Long-term stability of nafion hybrid membranes for use in 
vanadium redox-flow batteries, ECS Trans. 28 (2010) 167-177. doi:10.1149/1.3505470.

[274] T.A. Davis, J.D. Genders, D. Pletcher, A First Course in Ion Permeable Membranes, Electrochemical Consultancy, 1997.

[275] D. Chen, M.A. Hickner, E. Agar, E.C. Kumbur, Selective anion exchange membranes for high coulombic efficiency vanadium redox flow batteries, Electrochem. Commun. 26 (2013) 37-40. doi:10.1016/j.elecom.2012.10.007.

[276] T. Mohammadi, M.S. Kazacos, Evaluation of the chemical stability of some membranes in vanadium solution, J. Appl. Electrochem. 27 (1997) 153-160. doi:10.1023/A:1018495722379.

[277] S.J. Peighambardoust, S. Rowshanzamir, M. Amjadi, Review of the proton exchange membranes for fuel cell applications, Int. J. Hydrogen Energy. 35 (2010) 9349-9384.

doi:10.1016/j.ijhydene.2010.05.017.

[278] S. Slade, S.A. Campbell, T.R. Ralph, F.C. Walsh, Ionic conductivity of an extruded Nafion 1100 EW series of membranes, J. Electrochem. Soc. 149 (2002) A1556-A1564. doi:10.1149/1.1517281.

[279] K.A. Mauritz, R.B. Moore, State of understanding of nafion, Chem. Rev. 104 (2004) 4535-4585.

[280] C. Sun, J. Chen, H. Zhang, X. Han, Q. Luo, Investigations on transfer of water and vanadium ions across Nafion membrane in an operating vanadium redox flow battery, J. Power Sources. 195 (2010) 890-897. doi:10.1016/j.jpowsour.2009.08.041.

[281] D. Chen, S. Wang, M. Xiao, Y. Meng, Preparation and properties of sulfonated poly(fluorenyl ether ketone) membrane for vanadium redox flow battery application, J. Power Sources. 195 (2010) 20892095.

[282] S. Kim, J. Yan, B. Schwenzer, J. Zhang, L. Li, J. Liu, Z. Yang, M.A. Hickner, Cycling performance and efficiency of sulfonated poly(sulfone) membranes in vanadium redox flow batteries, Electrochem. Commun. 12 (2010) 1650-1653. doi:10.1016/j.elecom.2010.09.018.

[283] D. Chen, S. Wang, M. Xiao, Y. Meng, Synthesis and characterization of novel sulfonated poly(arylene thioether) ionomers for vanadium redox flow battery applications, Energy Environ. Sci. 3 (2010) 622-628. doi:10.1039/B917117G.

[284] J. Xi, Z. Wu, X. Qiu, L. Chen, Nafion/SiO2 hybrid membrane for vanadium redox flow battery, J. Power Sources. 166 (2007) 531-536. doi:10.1016/j.jpowsour.2007.01.069.

[285] D. Schulte, J. Drillkens, B. Schulte, D.U. Sauer, Nafion hybrid membranes for use in redox flow batteries, J. Electrochem. Soc. 157 (2010) A989-A992. doi:10.1149/1.3456625.

[286] X. Teng, Y. Zhao, J. Xi, Z. Wu, X. Qiu, L. Chen, Nafion/organic silica modified TiO 2 composite membrane for vanadium redox flow battery via in situ sol-gel reactions, J. Membrane Sci. 341 (2009) 149-154. doi:10.1016/j.memsci.2009.05.051.

[287] C. Yao, H. Zhang, T. Liu, X. Li, Z. Liu, Cell architecture upswing based on catalyst coated membrane (CCM) for vanadium flow battery, J. Power Sources. 237 (2013) 19-25.

doi:10.1016/j.jpowsour.2013.03.014.

[288] Q. Luo, H. Zhang, J. Chen, P. Qian, Y. Zhai, Modification of Nafion membrane using interfacial polymerization for vanadium redox flow battery applications, J. Membrane Sci. 311 (2008) 98-103. doi:10.1016/j.memsci.2007.11.055.

[289] J. Grosse Austing, C. Nunes Kirchner, L. Komsiyska, G. Wittstock, Layer-by-layer modification of Nafion membranes for increased life-time and efficiency of vanadium/air redox flow batteries, J. Membrane Sci. 510 (2016) 259-269. doi:10.1016/j.memsci.2016.03.005. 
[290] X.L. Zhou, T.S. Zhao, L. An, Y.K. Zeng, X.B. Zhu, Performance of a vanadium redox flow battery with a VANADion membrane, Applied Energy. 180 (2016) 353-359.

doi:10.1016/j.apenergy.2016.08.001.

[291] B. Li, Q. Luo, X. Wei, Z. Nie, E. Thomsen, B. Chen, V. Sprenkle, W. Wang, Capacity decay mechanism of microporous separator-based all-vanadium redox flow batteries and its recovery, ChemSusChem. 7 (2014) 577-584. doi:10.1002/cssc.201300706.

[292] L. Carlsson, B. Sandegren, D. Simonsson, M. Rihovsky, Design and performance of a modular, multipurpose electrochemical reactor, J. Electrochem. Soc. 130 (1983) 342-346.

[293] A. Frías-Ferrer, J. González-García, V. Sáez, E. Expósito, C.M. Sánchez-Sánchez, V. Montiel, A. Aldaz, The entrance and exit effects in small electrochemical filter-press reactors used in the laboratory, J. Chem. Educ. 82 (2005) 1395. doi:10.1021/ed082p1395.

[294] T.R. Ralph, M.L. Hitchman, J.P. Millington, F.C. Walsh, Mass transport in an electrochemical laboratory filterpress reactor and its enhancement by turbulence promoters, Electrochim. Acta. 41 (1996) 591-603.

[295] D. Dendukuri, S.K. Karode, A. Kumar, Flow visualization through spacer filled channels by computational fluid dynamics-II: Improved feed spacer designs, J. Membrane Sci. 249 (2005) 41-49. doi:10.1016/j.memsci.2004.06.062.

[296] C.P. Koutsou, S.G. Yiantsios, A.J. Karabelas, A numerical and experimental study of mass transfer in spacer-filled channels: Effects of spacer geometrical characteristics and Schmidt number, J. Membrane Sci. 326 (2009) 234-251. doi:10.1016/j.memsci.2008.10.007.

[297] G.A. Fimbres-Weihs, D.E. Wiley, Numerical study of mass transfer in three-dimensional spacer-filled narrow channels with steady flow, J. Membrane Sci. 306 (2007) 228-243.

doi:10.1016/j.memsci.2007.08.043.

[298] F.F. Rivera, M.R. Cruz-Díaz, E.P. Rivero, I. González, Analysis and interpretation of residence time distribution experimental curves in FM01-LC reactor using axial dispersion and plug dispersion exchange models with closed-closed boundary conditions, Electrochim. Acta. 56 (2010) 361-371. doi:10.1016/j.electacta.2010.08.069.

[299] T. Shibata, T. Kumamoto, Y. Nagaoka, K. Kawase, K. Yano, Redox flow batteries for the stable supply of renewable energy, SEI Technical Review. (2013).

[300] A. Pellegri, B.M. Broman, Squirrel Holdings Ltd, Redox flow battery system and cell stack, US Patent 6,475,661 B1, 2002.

[301] J.A. Trainham, J. Newman, A comparison between flow-through and flow-by porous electrodes for redox energy storage, Electrochim. Acta. 26 (1981) 455-469. doi:10.1016/0013-4686(81)87024-7.

[302] K. Kinoshita, S.C. Leach, Mass-transfer study of carbon felt, flow-through electrode, J. Electrochem. Soc. 129 (1982) 1993-1997. doi:10.1149/1.2124338.

[303] J. González-García, P. Bonete, E. Expósito, V. Montiel, A. Aldaz, R. Torregrosa-Maciá, Characterization of a carbon felt electrode: structural and physical properties, J. Mater. Chem. 9 (1999) 419-426. doi:10.1039/a805823g.

[304] C.J. Brown, D. Pletcher, F.C. Walsh, J.K. Hammond, D. Robinson, Studies of three-dimensional electrodes in the FMO1-LC laboratory electrolyser, J. Appl. Electrochem. 24 (1994) 95-106. doi:10.1007/BF00247779.

[305] Q. Xu, T.S. Zhao, P.K. Leung, Numerical investigations of flow field designs for vanadium redox flow batteries, Applied Energy. 105 (2013) 47-56. doi:10.1016/j.apenergy.2012.12.041. 
[306] R.M. Darling, M.L. Perry, The influence of electrode and channel configurations on flow battery performance, J. Electrochem. Soc. 161 (2014) A1381-A1387. doi:10.1149/2.0941409jes.

[307] D. Reed, E. Thomsen, Bin Li, W. Wang, Z. Nie, B. Koeppel, J. Kizewski, V. Sprenkle, Stack developments in a kW class all vanadium mixed acid redox flow battery at the Pacific Northwest National Laboratory, J. Electrochem. Soc. 163 (2016) A5211-A5219. doi:10.1149/2.0281601jes.

[308] C.R. Dennison, E. Agar, B. Akuzum, E.C. Kumbur, Enhancing mass transport in redox flow batteries by tailoring flow field and electrode design, J. Electrochem. Soc. 163 (2016) A5163-A5169. doi:10.1149/2.0231601jes.

[309] E. Knudsen, P. Albertus, K.T. Cho, A.Z. Weber, A. Kojic, Flow simulation and analysis of highpower flow batteries, J. Power Sources. 299 (2015) 617-628. doi:10.1016/j.jpowsour.2015.08.041.

[310] R.J. Kee, H. Zhu, Distribution of incompressible flow within interdigitated channels and porous electrodes, J. Power Sources. 299 (2015) 509-518. doi:10.1016/j.jpowsour.2015.09.013.

[311] X. You, Q. Ye, P. Cheng, Scale-up of high power density redox flow batteries by introducing interdigitated flow fields, Int. Commun. Heat. Mass. 75 (2016) 7-12. doi:10.1016/j.icheatmasstransfer.2016.03.021.

[312] R.E.W. Jansson, R.J. Marshall, Axial dispersion in parallel channel electrochemical cells, Electrochim. Acta. 27 (1982) 823-831. doi:10.1016/0013-4686(82)80203-X.

[313] S.-W. Luo, S. Lee, Y.-K. Fuh, Micro-pillars enhanced all vanadium redox flow batteries and the effect of assembly torque on the electrochemical performance, Microsyst Technol. (2016) 1-10. doi:10.1007/s00542-016-2964-6.

[314] D.J. Pickett, K.L. Ong, The influence of hydrodynamic and mass transfer entrance effects on the operation of a parallel plate electrolytic cell, Electrochim. Acta. 19 (1974) 875-882. doi:10.1016/0013-4686(74)85036-X.

[315] A. Frías-Ferrer, J. González-García, V. Sáez, C. Ponce de León, F.C. Walsh, The effects of manifold flow on mass transport in electrochemical filter-press reactors, AIChE J. 54 (2008) 811-823. doi:10.1002/aic.11426.

[316] L. Vázquez, A. Alvarez-Gallegos, F.Z. Sierra, C.P. León, F.C. Walsh, CFD evaluation of internal manifold effects on mass transport distribution in a laboratory filter-press flow cell, J. Appl. Electrochem. 43 (2013) 453-465. doi:10.1007/s10800-013-0530-9.

[317] I. Tsuda, K. Kurokawa, K. Nozaki, Development of intermittent redox flow battery for PV system, in: Hawaii, 1994: pp. 946-949.

[318] A. Tang, J. Bao, M. Skyllas-Kazacos, Studies on pressure losses and flow rate optimization in vanadium redox flow battery, J. Power Sources. 248 (2014) 154-162.

[319] Q. Ye, J. Hu, P. Cheng, Z. Ma, Design trade-offs among shunt current, pumping loss and compactness in the piping system of a multi-stack vanadium flow battery, J. Power Sources. 296 (2015) 352-364. doi:10.1016/j.jpowsour.2015.06.138.

[320] S. Langlois, F. Coeuret, Flow-through and flow-by porous electrodes of nickel foam. I. Material characterization, J. Appl. Electrochem. 19 (1989) 43-50. doi:10.1007/BF01039388.

[321] D. Pletcher, I. Whyte, F.C. Walsh, J.P. Millington, Reticulated vitreous carbon cathodes for metal ion removal from process streams part I: Mass transport studies, J. Appl. Electrochem. 21 (1991) 659666. doi:10.1007/BF01034042.

[322] L.F. Arenas, C. Ponce de León, F.C. Walsh, Pressure drop through platinised titanium felt and micromesh electrodes for cerium-based redox flow batteries, to be submitted. 
[323] M.D. Birkett, R.L. Clarke, A.T. Kuhn, Design concepts and construction of bipolar filterpress cells, J. Chem. Technol. Biotechnol. 30 (1980) 711-720. doi:10.1002/jctb.503300192.

[324] C.R. Horne, K. Kinoshita, D.B. Hickey, Redox flow battery system for distributed energy storage, US Patent 7,820,321 B2, 2010.

[325] P. Lex, N. Coad, Battery flow frame material formulation, US Patent appplication 20140162096 A1, 2014.

[326] A. Oury, A. Kirchev, Y. Bultel, A numerical model for a soluble lead-acid flow battery comprising a three-dimensional honeycomb-shaped positive electrode, J. Power Sources. 246 (2014) 703-718. doi:10.1016/j.jpowsour.2013.07.101.

[327] M.N. Nandanwar, S. Kumar, Modelling of effect of non-uniform current density on the performance of soluble lead redox flow batteries, J. Electrochem. Soc. 161 (2014) A1602-A1610. doi:10.1149/2.0281410jes.

[328] H. Wu, J.R. Selman, P. Hollandsworth, Mass transfer and current distribution in a zinc redox-battery flow cell, Indian J. Technol. 24 (1986) 372-380.

[329] A.I. Maslii, N.P. Poddubnyi, A.Z. Medvedev, Distribution of geometrical current density inside a flow-by porous electrode: Effect of electrode parameters and electrochemical reactions, Russ. J. Electrochem. 52 (2016) 576-583.

[330] A.T. Kuhn, J.S. Booth, Electrical leakage currents in bipolar cell stacks, J. Appl. Electrochem. 10 (1980) 233-237. doi:10.1007/BF00726091.

[331] I. Rousar, V. Cezner, Experimental determination and calculation of parasitic currents in bipolar electrolyzers with application to chlorate electrolyzer, J. Electrochem. Soc. 121 (1974) 648-651.

[332] E.A. Kaminski, R.F. Savinell, A technique for calculating shunt leakage and cell currents in bipolar stacks having divided or undivided cells, J. Electrochem. Soc. 130 (1983) 1103-1107. doi:10.1149/1.2119891.

[333] R.E. White, C.W. Walton, H.S. Burney, R.N. Beaver, Predicting shunt currents in stacks of bipolar plate cells, J. Electrochem. Soc. 133 (1986) 485-492. doi:10.1149/1.2108606.

[334] S.K. Rangarajan, V. Yegnanarayanan, Current losses in a bipolar cell—an analysis of the Tafel regime, Electrochim. Acta. 42 (1997) 153-165. doi:10.1016/0013-4686(96)00165-X.

[335] E.R. Henquín, J.M. Bisang, Simplified model to predict the effect of the leakage current on primary and secondary current distributions in electrochemical reactors with a bipolar electrode, J. Appl. Electrochem. 35 (2005) 1183-1190. doi:10.1007/s10800-005-9029-3.

[336] M.-Z. Yang, H. Wu, J.R. Selman, A model for bipolar current leakage in cell stacks with separate electrolyte loops, J. Appl. Electrochem. 19 (1989) 247-254. doi:10.1007/BF01062308.

[337] G. Bonvin, C. Comninellis, Scale-up of bipolar electrode stack dimensionless numbers for current bypass estimation, J. Appl. Electrochem. 24 (1994) 469-474. doi:10.1007/BF00249844.

[338] C. Comninellis, E. Plattner, P. Bolomey, Estimation of current bypass in a bipolar electrode stack from current-potential curves, J. Appl. Electrochem. 21 (1991) 415-418. doi:10.1007/BF01024577.

[339] F.T. Wandschneider, S. Röhm, P. Fischer, K. Pinkwart, J. Tübke, H. Nirschl, A multi-stack simulation of shunt currents in vanadium redox flow batteries, J. Power Sources. 261 (2014) 64-74. doi:10.1016/j.jpowsour.2014.03.054.

[340] D.A. Szánto, Characterization of electrochemical filter-press reactors, University of Portsmouth, $\mathrm{PhD}$ thesis, 1999. 
[341] M. Vijayakumar, L. Li, G. Graff, J. Liu, H. Zhang, Z. Yang, Z. Yang, J.Z. Hu, Towards understanding the poor thermal stability of $\mathrm{V}^{5+}$ electrolyte solution in Vanadium Redox Flow Batteries, J. Power Sources. 196 (2011) 3669-3672. doi:10.1016/j.jpowsour.2010.11.126.

[342] B. Xiong, J. Zhao, K.J. Tseng, M. Skyllas-Kazacos, T.M. Lim, Y. Zhang, Thermal hydraulic behavior and efficiency analysis of an all-vanadium redox flow battery, J. Power Sources. 242 (2013) 314-324. doi:10.1016/j.jpowsour.2013.05.092.

[343] T.A. Zawodzinski, C. Derouin, S. Radzinski, R.J. Sherman, Van T Smith, T.E. Springer, S. Gottesfeld, Water uptake by and transport through Nafion ${ }^{\circledR} 117$ membranes, J. Electrochem. Soc. 140 (1993) 1041-1047. doi:10.1149/1.2056194.

[344] T. Mohammadi, S.C. Chieng, M. Skyllas-Kazacos, Water transport study across commercial ion exchange membranes in the vanadium redox flow battery, J. Membrane Sci. 133 (1997) 151-159. doi:10.1016/S0376-7388(97)00092-6.

[345] T. Sukkar, M. Skyllas-Kazacos, Water transfer behaviour across cation exchange membranes in the vanadium redox battery, J. Membrane Sci. (2003).

[346] L.H. Thaller, NASA, Electrochemical cell for rebalancing redox flow system, US patent 4,159,366 A, 1979.

[347] F. Goodridge, K. Scott, Electrochemical Process Engineering, Springer, 1995.

[348] G. Nikiforidis, R. Cartwright, D. Hodgson, D. Hall, L. Berlouis, Factors affecting the performance of the Zn-Ce redox flow battery, Electrochim. Acta. 140 (2014) 139-144. doi:10.1016/j.electacta.2014.04.150.

[349] C.T.J. Low, C.P. de Leon, F.C. Walsh, The rotating cylinder electrode (RCE) and its application to the electrodeposition of metals, Aust. J. Chem. 58 (2005) 246-262. doi:10.1071/CH05034.

[350] C. Zelger, J. Laumen, A. Laskos, B. Gollas, Rota-Hull cell study on pulse current zinc electrodeposition from alkaline electrolytes, Electrochim. Acta. 213 (2016) 208-216. doi:10.1016/j.electacta.2016.07.108.

[351] S. Nam, D. Lee, J. Kim, D.G. Lee, Development of a fluoroelastomer/glass fiber composite flow frame for a vanadium redox flow battery (VRFB), Composite Structures. (2016). doi:10.1016/j.compstruct.2016.02.052.

[352] S. Nam, D. Lee, I. Choi, D.G. Lee, Smart cure cycle for reducing the thermal residual stress of a cocured E-glass/carbon/epoxy composite structure for a vanadium redox flow battery, Composite Structures. 120 (2015) 107-116.

[353] L.F. Arenas, F.C. Walsh, C. Ponce de León, 3D-printing of redox flow batteries for energy storage: A rapid prototype laboratory cell, ECS J. Solid State Sci. Technol. 4 (2015) P3080-P3085. doi:10.1149/2.0141504jss.

[354] T. Cui, Y.J. Chao, J.W. Van Zee, Sealing force prediction of elastomeric seal material for PEM fuel cell under temperature cycling, Int. J. Hydrogen Energy. 39 (2014) 1430-1438. doi:10.1016/j.ijhydene.2013.10.086.

[355] J. Tan, Y.J. Chao, X. Li, J.W. Van Zee, Degradation of silicone rubber under compression in a simulated PEM fuel cell environment, J. Power Sources. 172 (2007) 782-789. doi:10.1016/j.jpowsour.2007.05.026. 


\section{$\underline{\text { Tables }}$}

Table 1. Half-cell reactions, electrode materials, electrolyte composition and potentials of selected redox flow batteries.

\begin{tabular}{|c|c|c|c|c|c|c|}
\hline RFB system & $\begin{array}{l}\text { Typical electrode } \\
\text { materials }\end{array}$ & $\begin{array}{l}\text { Common } \\
\text { electrolyte }\end{array}$ & $\begin{array}{l}\text { Standard potential of the redox couple at } \\
\text { the positive electrode, } E^{\circ} \text { vs. SHE }\end{array}$ & $\begin{array}{l}\text { Standard potential of the } \\
\text { redox couple at the negative } \\
\text { electrode, } E^{\circ} v s . \mathrm{SHE}\end{array}$ & Overall main cell reaction & $\begin{array}{c}\text { Standard } \\
\text { cell } \\
\text { potential, } \\
E_{\text {cell }}^{\circ} v s . \\
\text { SHE } \\
\end{array}$ \\
\hline $\begin{array}{l}\text { All-vanadium } \\
{[14]}\end{array}$ & $\begin{array}{l}\text { Graphite felt (both } \\
\text { electrodes) }\end{array}$ & Sulphuric acid & $\begin{aligned} \mathrm{VO}_{2}^{+}+2 \mathrm{H}^{+} & +e^{-} \rightleftharpoons \mathrm{VO}^{2+}+\mathrm{H}_{2} \mathrm{O} \\
& +1.00 \mathrm{~V}\end{aligned}$ & $\begin{array}{l}\mathrm{V}^{3+}+e^{-} \rightleftharpoons \mathrm{V}^{2+} \\
-0.26 \mathrm{~V}\end{array}$ & $\mathrm{VO}^{2+}+\mathrm{V}^{3+}+\mathrm{H}_{2} \mathrm{O} \underset{\text { discharge }}{\stackrel{\text { charge }}{\longrightarrow}} \mathrm{VO}_{2}^{+}+\mathrm{V}^{2+}+2 \mathrm{H}^{+}$ & $1.26 \mathrm{~V}$ \\
\hline $\begin{array}{l}\mathrm{Zn}-\mathrm{Br}_{2} \\
{[63,109]}\end{array}$ & $\begin{array}{l}\text { Carbon (both } \\
\text { electrodes) }\end{array}$ & Zinc(II) bromine & $\begin{aligned} \mathrm{Br}_{2} & +2 e^{-} \rightleftharpoons 2 \mathrm{Br}^{-} \\
& +1.09 \mathrm{~V}\end{aligned}$ & $\begin{array}{l}\mathrm{Zn}^{2+}+e^{-} \rightleftharpoons \mathrm{Zn} \\
-0.76 \mathrm{~V}\end{array}$ & $\mathrm{Zn}^{2+}+2 \mathrm{Br}^{-} \underset{\text { discharge }}{\stackrel{\text { charge }}{\longrightarrow}} \mathrm{Br}_{2}+\mathrm{Zn}$ & $1.85 \mathrm{~V}$ \\
\hline $\begin{array}{l}\text { Br-polysulfide } \\
{[12,71]}\end{array}$ & $\begin{array}{c}\text { Graphite } \\
\text { (positive) } \\
\text { Porous nickel } \\
\text { (negative) }\end{array}$ & $\begin{array}{l}\text { Sodium bromide } \\
\text { (positive) } \\
\text { Sodium } \\
\text { polysulfide } \\
\text { (negative) } \\
\end{array}$ & $\begin{aligned} \mathrm{Br}_{3}^{-} & +2 e^{-} \rightleftharpoons 3 \mathrm{Br}^{-} \\
& +1.09 \mathrm{~V}\end{aligned}$ & $\begin{array}{l}\mathrm{S}_{4}^{2-}+2 e^{-} \rightleftharpoons 2 \mathrm{~S}_{2}^{2-} \\
\quad-0.48 \mathrm{~V}\end{array}$ & $\mathrm{~S}_{4}^{2-}+3 \mathrm{Br}^{-} \underset{\text { discharge }}{\stackrel{\text { charge }}{\rightleftarrows}} 2 \mathrm{~S}_{2}^{2-}+\mathrm{Br}_{3}^{-}$ & $1.54 \mathrm{~V}$ \\
\hline Zn-Ni [88] & $\begin{array}{c}\text { Nickel oxide } \\
\text { (both electrodes) }\end{array}$ & $\begin{array}{l}\text { Potassium } \\
\text { hydroxide }\end{array}$ & $\begin{array}{r}2 \mathrm{NiOOH}+2 \mathrm{H}_{2} \mathrm{O}+2 \mathrm{e}^{-} \rightleftharpoons \\
2 \mathrm{Ni}(\mathrm{OH})_{2}+2 \mathrm{OH}^{-} \\
+0.49 \mathrm{~V}\end{array}$ & $\begin{aligned} \mathrm{Zn}(\mathrm{OH})_{4}^{2-} & +2 e^{-} \rightleftharpoons \mathrm{Zn}+4 \mathrm{OH}^{-} \\
& -1.21 \mathrm{~V}\end{aligned}$ & $2 \mathrm{Ni}(\mathrm{OH})_{2}+\mathrm{Zn}(\mathrm{OH})_{4}^{2-} \underset{\text { discharge }}{\stackrel{\text { charge }}{\longrightarrow}} \mathrm{Zn}+2 \mathrm{OH}^{-}+2 \mathrm{H}_{2} \mathrm{O}+2 \mathrm{~N}$ & $1.71 \mathrm{~V}$ \\
\hline $\mathrm{Zn}-\mathrm{Ce}[31]$ & $\begin{array}{c}\text { Graphitized } \\
\text { carbon polymer } \\
\text { (negative), } \\
\text { platinized } \\
\text { titanium (positive) } \\
\end{array}$ & $\begin{array}{l}\text { Methanesulfonic } \\
\text { acid }\end{array}$ & $\begin{array}{l}\mathrm{Ce}^{4+}+e^{-} \rightleftharpoons \mathrm{Ce}^{3+} \\
\quad+1.44 \mathrm{~V}\end{array}$ & $\begin{array}{l}\mathrm{Zn}^{2+}+2 e^{-} \rightleftharpoons \mathrm{Zn} \\
-0.76 \mathrm{~V}\end{array}$ & $\mathrm{Ce}^{3+}+\mathrm{Zn}^{2+} \underset{\text { discharge }}{\stackrel{\text { charge }}{\longleftrightarrow}} \mathrm{Ce}^{4+}+\mathrm{Zn}$ & $2.20 \mathrm{~V}$ \\
\hline $\begin{array}{l}\text { Soluble lead } \\
{[85]}\end{array}$ & $\begin{array}{c}\text { Graphitized } \\
\text { carbon polymer } \\
\text { (both) }\end{array}$ & $\begin{array}{l}\text { Methanesulfonic } \\
\text { acid }\end{array}$ & $\begin{aligned} \mathrm{PbO}_{2}+4 \mathrm{H}^{+} & +2 e^{-} \rightleftharpoons \mathrm{Pb}^{2+}+2 \mathrm{H}_{2} \mathrm{O} \\
& +1.47 \mathrm{~V}\end{aligned}$ & $\begin{array}{l}\mathrm{Pb}^{2+}+e^{-} \rightleftharpoons \mathrm{Pb} \\
-0.13 \mathrm{~V}\end{array}$ & $\mathrm{~Pb}^{2+}+2 \mathrm{H}_{2} \mathrm{O} \underset{\text { discharge }}{\stackrel{\text { charge }}{\longrightarrow}} \mathrm{Pb}+\mathrm{PbO}_{2}+4 \mathrm{H}^{+}$ & $1.60 \mathrm{~V}$ \\
\hline $\mathrm{Fe}-\mathrm{Cr}[53]$ & $\begin{array}{l}\text { Carbon felt (both } \\
\text { electrodes) }\end{array}$ & Hydrochloric acid & $\begin{array}{l}\mathrm{Fe}^{3+}+e^{-} \rightleftharpoons \mathrm{Fe}^{2+} \\
\quad+0.77 \mathrm{~V}\end{array}$ & $\begin{array}{l}\mathrm{Cr}^{3+}+e^{-} \rightleftharpoons \mathrm{Cr}^{2+} \\
-0.41 \mathrm{~V}\end{array}$ & $\mathrm{Cr}^{3+}+\mathrm{Fe}^{2+} \underset{\text { discharge }}{\stackrel{\text { charge }}{\longrightarrow}} \mathrm{Cr}^{2+}+\mathrm{Fe}^{3+}$ & $1.18 \mathrm{~V}$ \\
\hline All-iron [66] & $\begin{array}{l}\text { Iron (negative), } \\
\text { carbon (positive) }\end{array}$ & Iron(II) chloride & $\begin{array}{l}\mathrm{Fe}^{3+}+e^{-} \rightleftharpoons \mathrm{Fe}^{2+} \\
\quad+0.77 \mathrm{~V}\end{array}$ & $\begin{array}{c}\mathrm{Fe}^{2+}+2 e^{-} \rightleftharpoons \mathrm{Fe} \\
-0.44 \mathrm{~V}\end{array}$ & $2 \mathrm{Fe}^{2+} \underset{\text { discharge }}{\stackrel{\text { charge }}{\rightleftarrows}} \mathrm{Fe}^{3+}+\mathrm{Fe}$ & $1.21 \mathrm{~V}$ \\
\hline $\mathrm{V}-\mathrm{Ce}[80]$ & $\begin{array}{l}\text { Carbon fibres } \\
\text { (both electrodes) }\end{array}$ & Sulfuric acid & $\begin{array}{c}\mathrm{Ce}^{4+}+e^{-} \rightleftharpoons \mathrm{Ce}^{3+} \\
+1.44 \mathrm{~V}\end{array}$ & $\begin{array}{l}\mathrm{V}^{3+}+e^{-} \rightleftharpoons \mathrm{V}^{2+} \\
-0.26 \mathrm{~V}\end{array}$ & $\mathrm{Ce}^{3+}+\mathrm{V}^{3+} \underset{\text { discharge }}{\stackrel{\text { charge }}{\rightleftarrows}} \mathrm{Ce}^{4+}+\mathrm{V}^{2+}$ & $1.70 \mathrm{~V}$ \\
\hline Fe-Ti [110] & Graphite foil & Hydrochloric acid & $\begin{array}{l}\mathrm{Fe}^{3+}+e^{-} \rightleftharpoons \mathrm{Fe}^{2+} \\
\quad+0.77 \mathrm{~V}\end{array}$ & $\begin{array}{c}\mathrm{TiO}^{2+}+2 \mathrm{H}^{+}+e^{-} \rightleftharpoons \mathrm{Ti}^{3+}+\mathrm{H}_{2} \mathrm{O} \\
+0.10 \mathrm{~V}\end{array}$ & $\mathrm{TiO}^{2+}+\mathrm{Fe}^{2+}+2 \mathrm{H}^{+} \underset{\text { discharge }}{\stackrel{\text { charge }}{\rightleftarrows}} \mathrm{Ti}^{3+}+\mathrm{Fe}^{3+}+\mathrm{H}_{2} \mathrm{O}$ & $0.67 \mathrm{~V}$ \\
\hline
\end{tabular}


Table 2. Dimensionless groups and relevant flow and cell normalization expressions for the description of mass transport environment in rectangular-channel electrochemical reactors [9].

\begin{tabular}{|l|c|l|l|}
\hline Name & Expression & Normalized parameters & Equation \\
\hline $\begin{array}{l}\text { Sherwood } \\
\text { number, } S h\end{array}$ & $S h=\frac{k_{m} d_{e}}{v}$ & $\begin{array}{l}\text { Mass transport coefficient, } k_{m} \\
\text { Equivalent hydraulic diameter of the } \\
\text { cell, } d_{e} \\
\text { Electrolyte viscosity, } v\end{array}$ & $(12)$ \\
\hline $\begin{array}{l}\text { Reynolds } \\
\text { number, } R e\end{array}$ & $S e=\frac{v d_{e}}{v}$ & $\begin{array}{l}\text { Mean linear flow rate of } \\
\text { electrolyte, } \mathrm{v} \\
\text { Equivalent hydraulic diameter of the } \\
\text { cell, } d_{e} \\
\text { Electrolyte viscosity, } v\end{array}$ & $(13)$ \\
\hline $\begin{array}{l}\text { Schmidt } \\
\text { number, } S c\end{array}$ & $\begin{array}{l}\text { Electrolyte viscosity, } v \\
\text { Diffusion coefficient of the } \\
\text { electroactive species, } D\end{array}$ & (14) \\
\hline $\begin{array}{l}\text { Dimensionless } \\
\text { length group, } L e\end{array}$ & $v=\frac{d_{e}}{L}$ & $\begin{array}{l}\text { Equivalent hydraulic diameter of the } \\
\text { cell, } d_{e} \\
\text { Length of the rectangular channel, } L\end{array}$ & (15) \\
\hline $\begin{array}{l}\text { Mean linear flow } \\
\text { rate, } v\end{array}$ & $\begin{array}{l}\text { Volumetric flow rate, } Q_{V} \text {. } \\
\text { Breadth, } B \text {, and span, } S, \text { of the } \\
\text { rectangular channel of cross- } \\
\text { sectional area } A_{x} \text {. Electrode porosity, } \\
\varepsilon \text {. }\end{array}$ & (16) \\
\hline $\begin{array}{l}\text { Equivalent } \\
\text { (hydraulic) } \\
\text { diameter, } d_{e}\end{array}$ & $d_{e}=\frac{2 A_{x}}{B+S}$ & $\begin{array}{l}\text { Breadth, } B \text {, and span, } S \text {, of the } \\
\text { rectangular channel of cross- } \\
\text { sectional area } A_{x} .\end{array}$ & (17) \\
\hline
\end{tabular}


Table 3. Fractional conversion reactor models for concentration-time relationships. After Walsh et al. [142].

\begin{tabular}{|l|c|c|l|}
\hline Reactor & $\begin{array}{l}\text { Definition of } \\
\text { fractional reactant } \\
\text { conversion }\end{array}$ & $\begin{array}{l}\text { Design expression for fractional reactant } \\
\text { conversion }\end{array}$ & Equation \\
\hline $\begin{array}{l}\text { Simple batch } \\
\text { reactor }\end{array}$ & $X_{A}=1-\frac{c_{(t)}}{c_{(0)}}$ & $X_{A, t}=1-\exp \left(-\frac{k_{m} A}{V_{T}} t\right)$ & $(19)$ \\
\hline $\begin{array}{l}\text { Single pass } \\
\text { plug flow } \\
\text { reactor }\end{array}$ & $X_{A}=1-\frac{c_{(\text {out })}}{c_{(\text {in })}}$ & $X_{A}=1-\exp \left(-\frac{k_{m} A}{Q_{V}}\right)$ & $(20)$ \\
\hline $\begin{array}{l}\text { Plug flow } \\
\text { reactor in } \\
\text { batch } \\
\text { recirculation }\end{array}$ & $X_{A, t}=1-\frac{c_{\text {in }(t)}}{c_{\text {in }(0)}}$ & $X_{A, t}=1-\exp \left\{-\frac{t}{\tau_{T}}[1\right.$ & $(21)$ \\
\hline $\begin{array}{l}\text { A cascade of } \\
N \text { identical } \\
\text { plug flow } \\
\text { reactors }\end{array}$ & $X_{A, N_{R}}=1-\frac{c_{(\text {out }, N)}}{c_{(\text {in })}}$ & $\left.\left.X_{A, N}=1-\exp \left(-\frac{k_{m} A}{Q_{V}}\right)\right]\right\}$ & $(22)$ \\
\hline
\end{tabular}


Table 4. Reactor and electrolyte characteristics for mass transport and fluid flow studies in a vertical XL10 bipolar filter-press redox flow cell stack of 10 electrodes [159].

\begin{tabular}{|l|l|}
\hline Feature of cell & Characteristics \\
\hline Electrode material & $\begin{array}{l}\text { PVDF-activated carbon particle } \\
\text { composite laminated on a HDPE-carbon } \\
\text { core }\end{array}$ \\
\hline Separator & Nafion ${ }^{B} 115$ proton exchange membrane \\
\hline Inter-electrode gap & $1.95 \pm 0.15 \mathrm{~mm}$ \\
\hline Electrode to membrane (channel) gap, $S$ & $0.95 \pm 0.15 \mathrm{~mm}$ \\
\hline Length of electrode, $L$ & $108 \pm 0.20 \mathrm{~cm}$ \\
\hline Breadth of electrode, $B$ & $66.8 \pm 0.10 \mathrm{~cm}^{2}$ \\
\hline Geometrical area of the electrode, $A$ & $7,200 \mathrm{~cm}^{2}$ \\
\hline Equivalent diameter of flow channel, $d_{e}$ & $0.19 \mathrm{~cm}^{-1}$ \\
\hline Nominal channel volume, $V=S B L$ & $700 \mathrm{~cm}^{3}$ \\
\hline $\begin{array}{l}\text { Nominal reactor electrolyte volume ('bromine' } \\
\text { compartment), } V_{R}\end{array}$ & $7,000 \mathrm{~cm}^{3}$ \\
\hline $\begin{array}{l}\text { Volumetric flow rate through each 'bromine' } \\
\text { compartment, } Q\end{array}$ & $0-24,000 \mathrm{~cm}^{3} \mathrm{~min}^{-1}$ \\
\hline $\begin{array}{l}\text { Mean linear flow velocity of the electrolyte past the } \\
\text { electrode, } v\end{array}$ & $0-5-6.2 \mathrm{~cm} \mathrm{~s}^{-1}$ \\
\hline $\begin{array}{l}\text { Mean residence time in the 'bromine' reactor } \\
\text { compartment, } \tau_{R}=V_{R} Q\end{array}$ & $17-84 \mathrm{~s}^{-1}$ \\
\hline Volume of (bromine) electrolyte in the tank, $V_{T}$ & $50,000 \mathrm{~cm}^{3}$ \\
\hline $\begin{array}{l}\text { Mean residence time in the bromine tank, } \tau_{T}= \\
V_{T} Q\end{array}$ & $127-1,500 \mathrm{~s}$ \\
\hline
\end{tabular}




\section{$\underline{\text { Figures }}$}

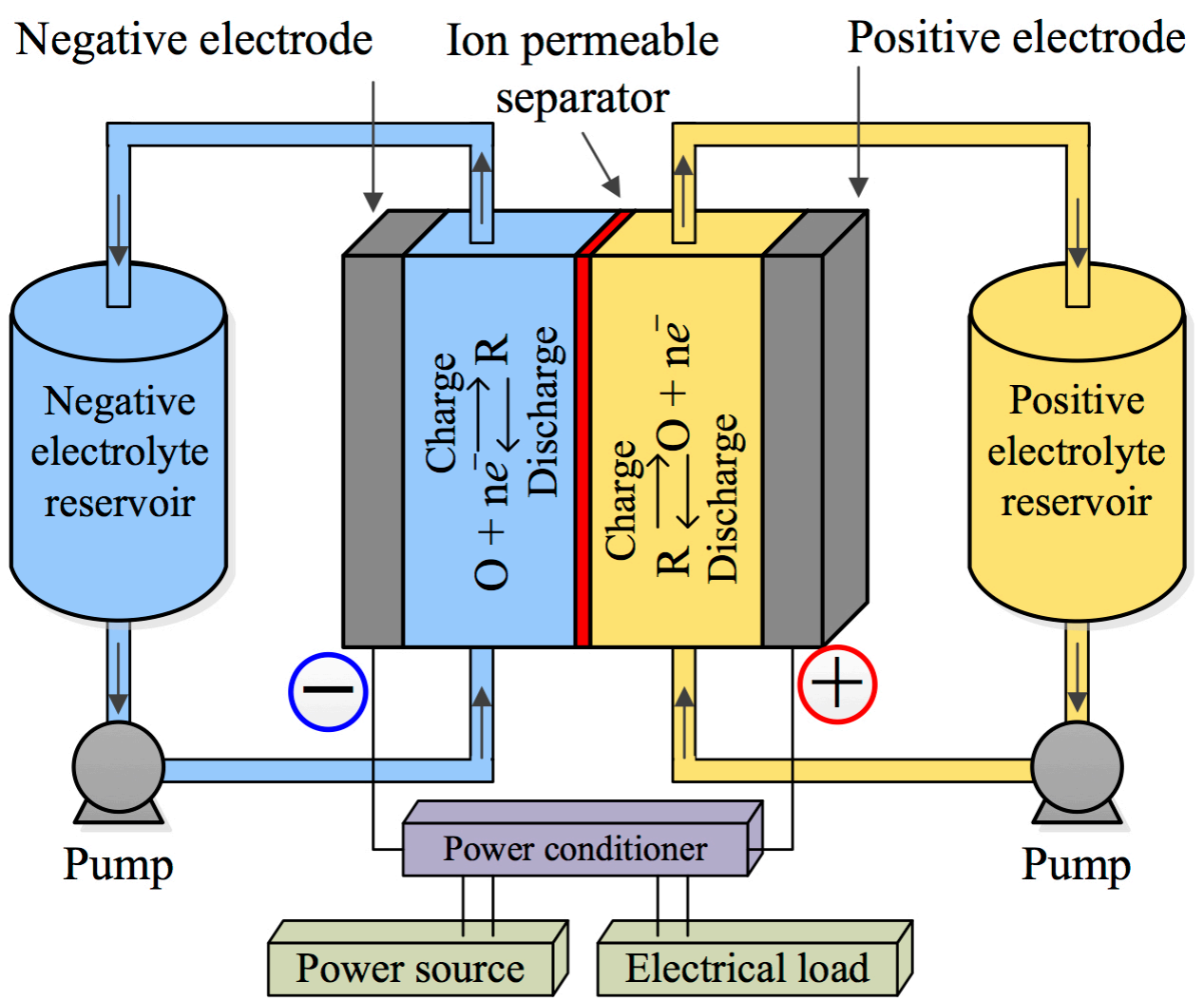

Figure 1. A classical RFB system, showing a divided cell, electrolyte recirculation to holding tanks and electrical controls. 


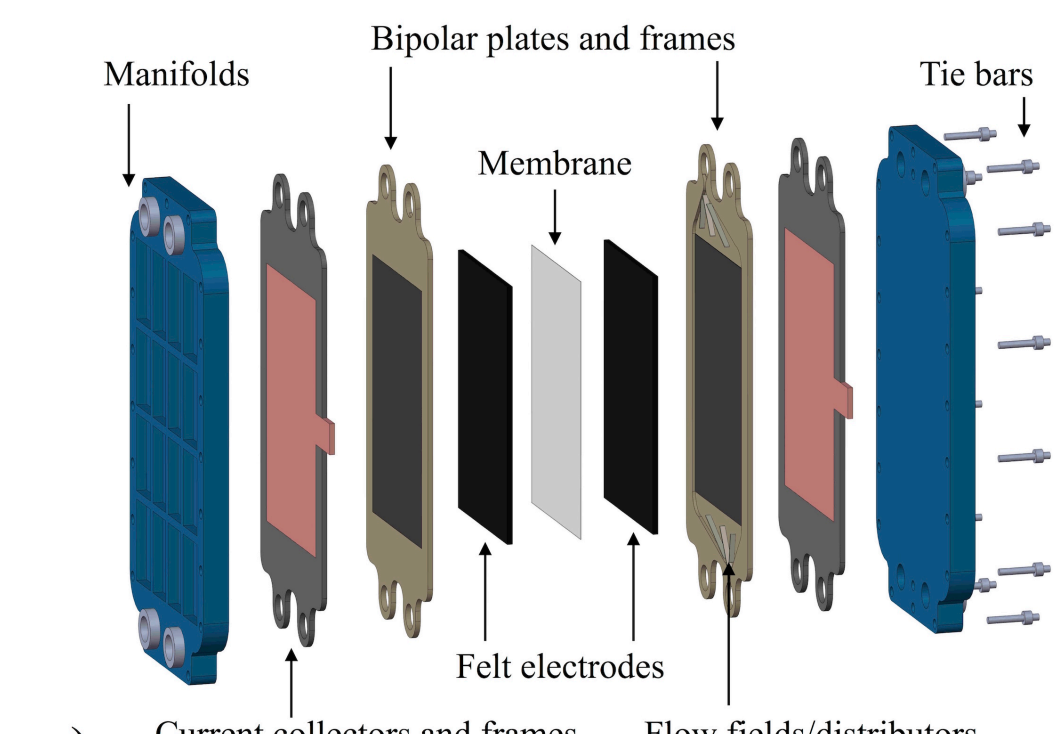

a) Current collectors and frames Flow fields/distributors

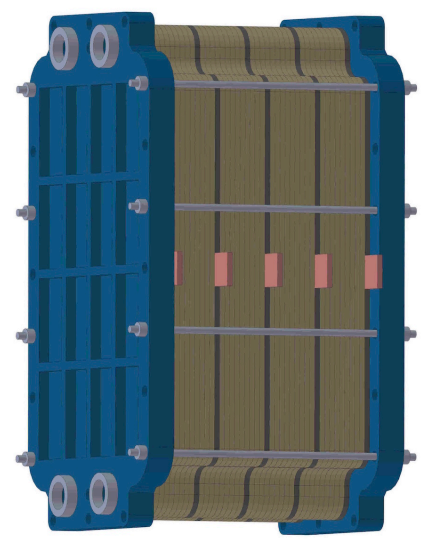

b) Stack

Figure 2. Components of an RFB stack. a) exploded view of a unit cell showing its components and b) an assembled stack. 


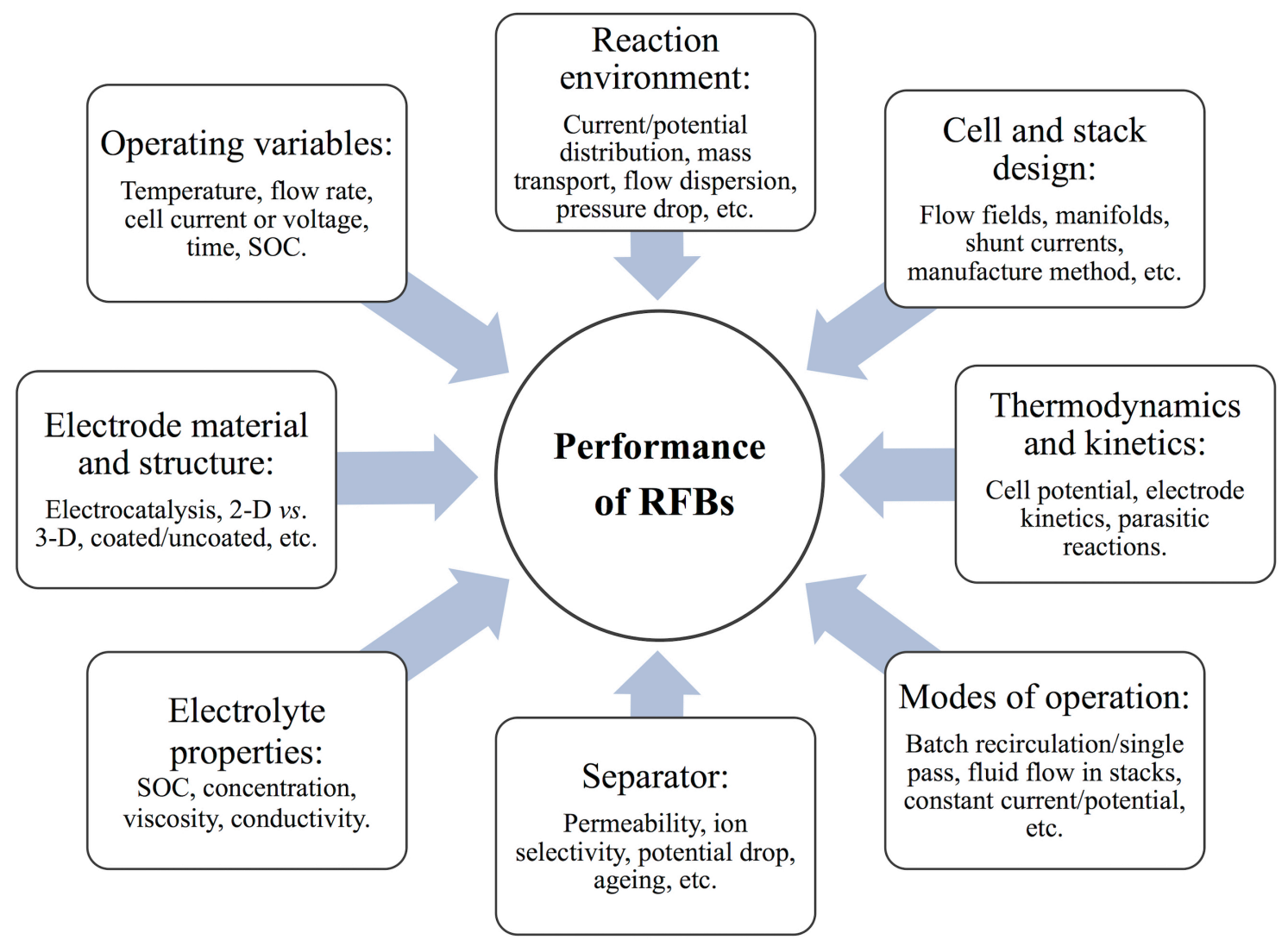

Figure 3. Factors affecting the performance of a divided RFB cell in an electrolyte reservoir batch recirculation flow loop. 
1. Bipolar electrode and frame
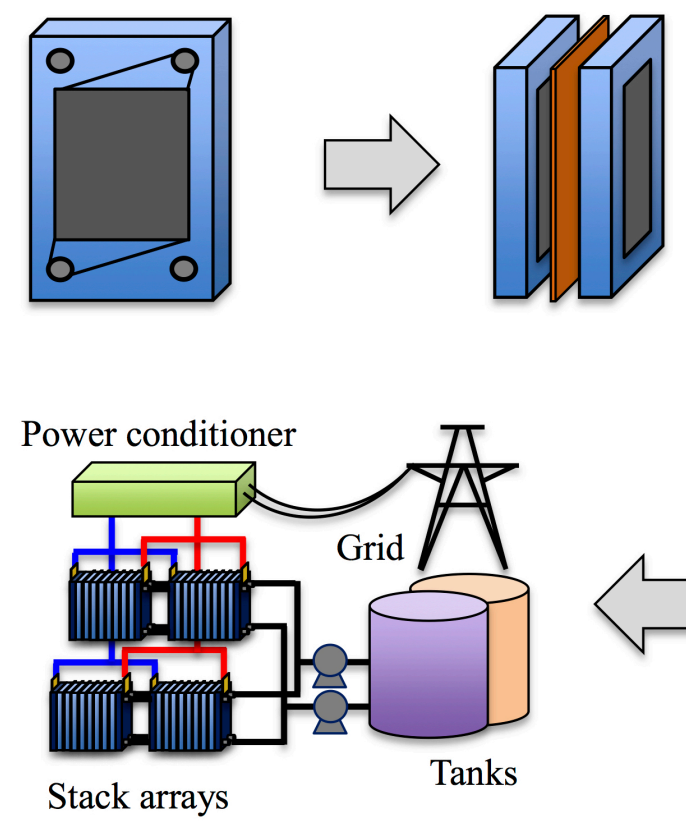

5. RFB system

2. Unit cell
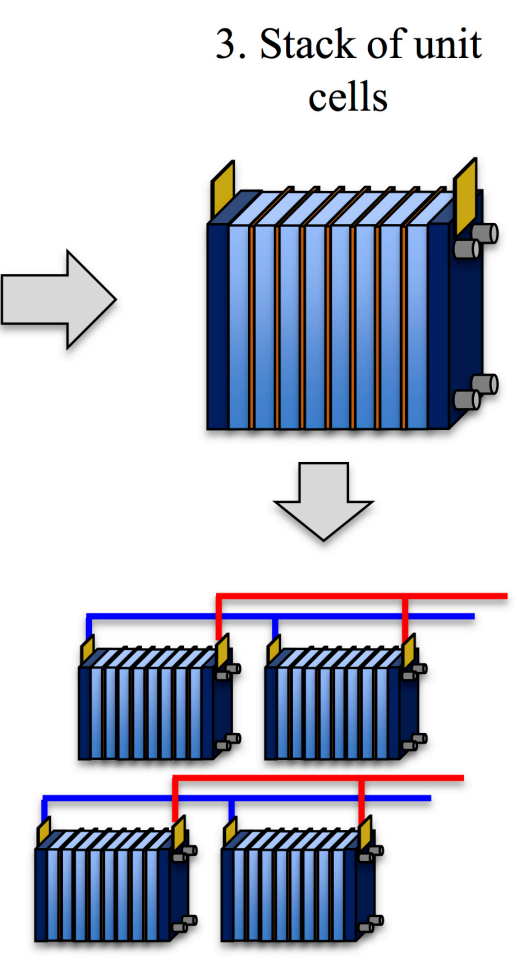

4. Arrays of stacks

Figure 4. Individual cells build up into modular stacks, with strategic electrolyte flow and electrical connections, to create RFB systems. 


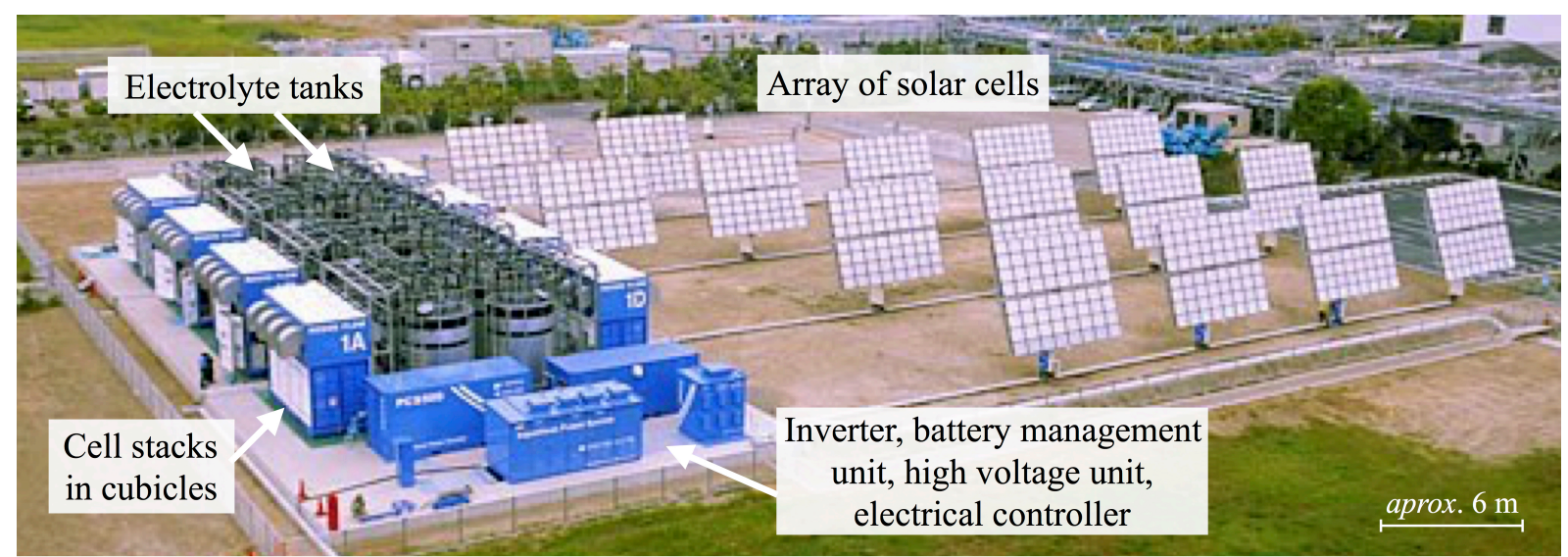

Figure 5. A $5 \mathrm{MW}$ h energy storage system at Yokohama Works in Yokohama (Japan) due to Sumitomo Electric Company. The system was installed in 2012 and includes modular vanadium cell stacks inside cubicles, 16 electrolyte tanks, electrical power conditioners for the RFBs, a photovoltaic array and battery management unit. Reproduced and adapted with permission of Sumitomo Electric Company [106]. 


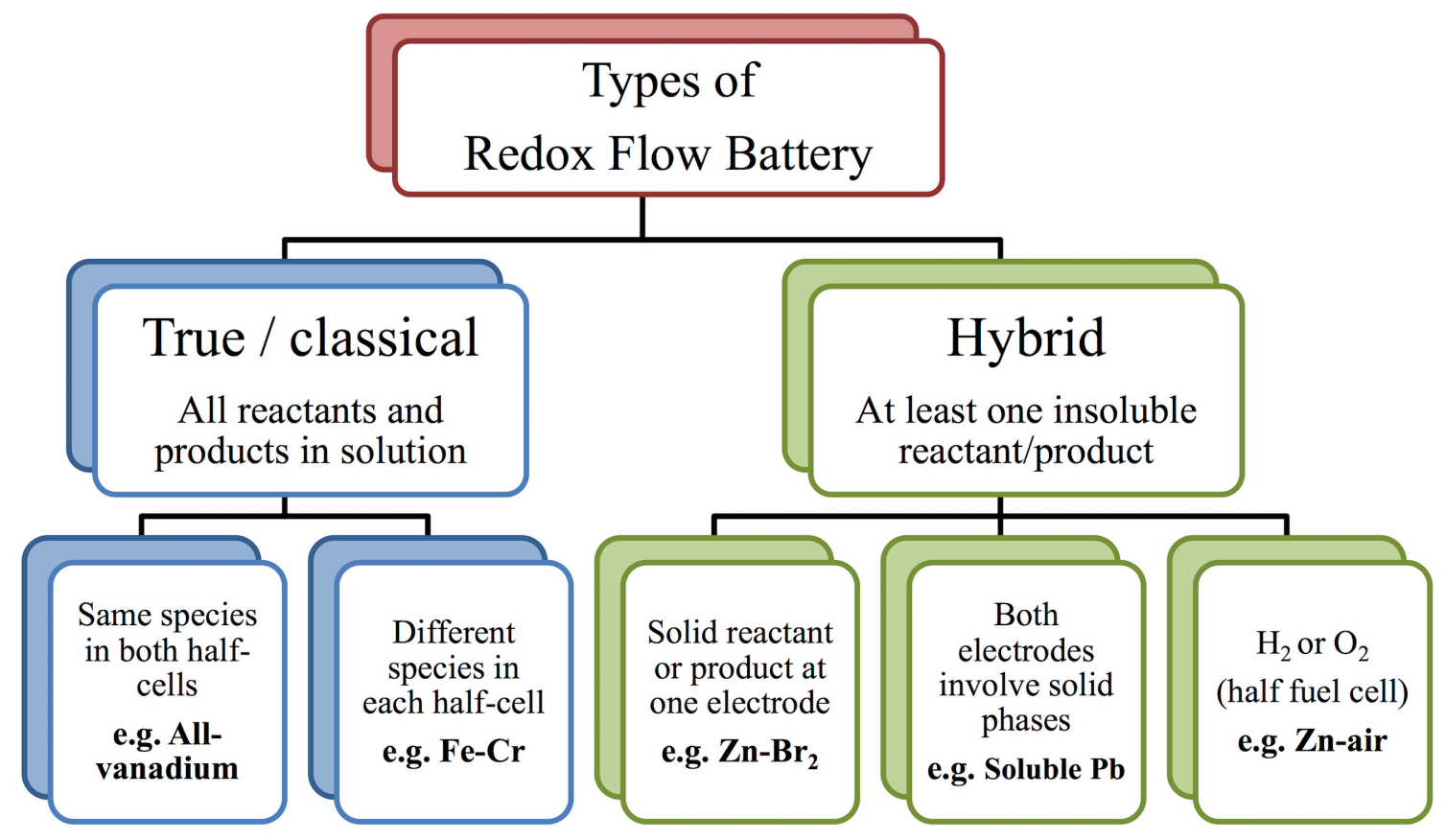

Figure 6. Classification of redox flow batteries, showing classical (redox/redox) and hybrid (solid layer/redox or gas/redox) types. 


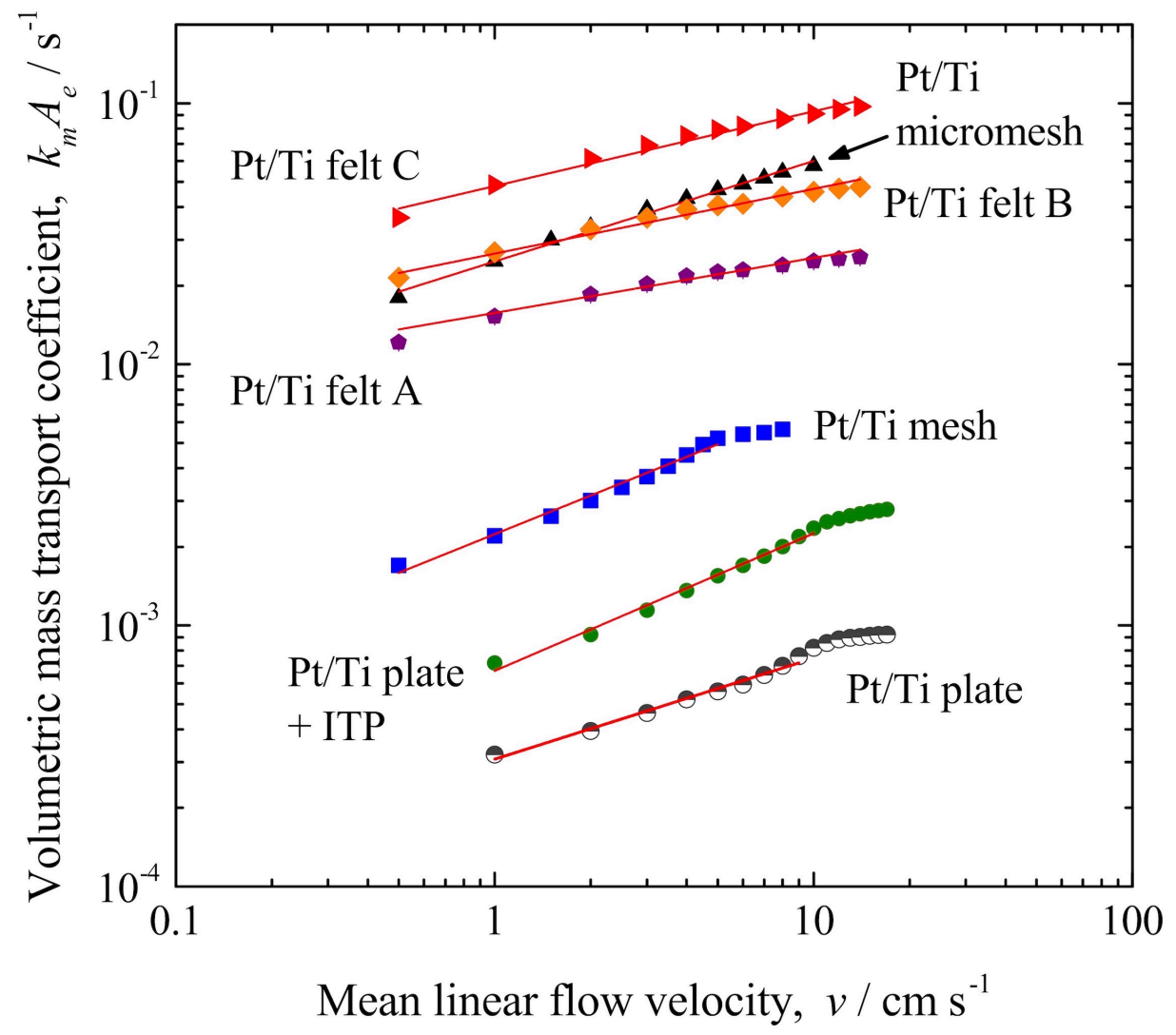

Figure 7. Log-log plot of electrode performance factor $k_{m} A_{e} v s$. electrolyte mean linear velocity for various $\mathrm{Pt} / \mathrm{Ti}$ porous electrodes for Ce-based RFBs [127]. The limiting current was measured at $25{ }^{\circ} \mathrm{C}$ for the reduction of $0.1 \mathrm{~mol} \mathrm{dm}^{-3} \mathrm{Ce}$ (IV) in an electrolyte containing $0.7 \mathrm{~mol} \mathrm{dm}^{-3} \mathrm{Ce}(\mathrm{III})$ and $4.0 \mathrm{~mol} \mathrm{dm}^{-3}$ methanesulfonic acid. Pt/Ti felt 'A', 'B' and 'C' have an average volumetric loading of $4.6 \mathrm{mg} \mathrm{cm}^{-}$ ${ }^{3}, 9.3 \mathrm{mg} \mathrm{cm}^{-3}$ and $18.6 \mathrm{mg} \mathrm{cm}^{-3}$, respectively. 

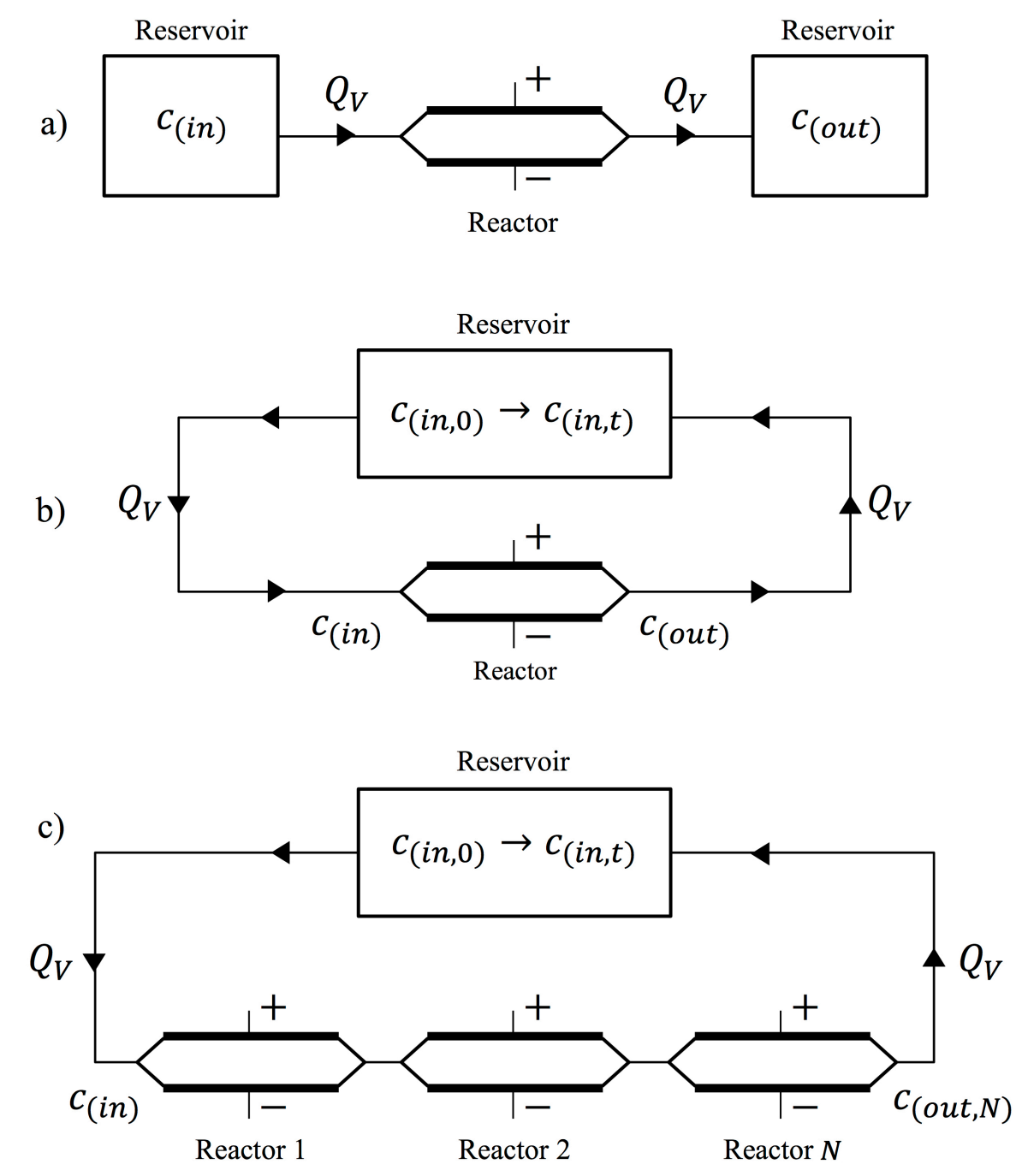

Figure 8. Plug flow reactor models according to electrolyte fluid flow: a) single pass, b) batch recirculation and c) cascade of identical reactors in series flow. 


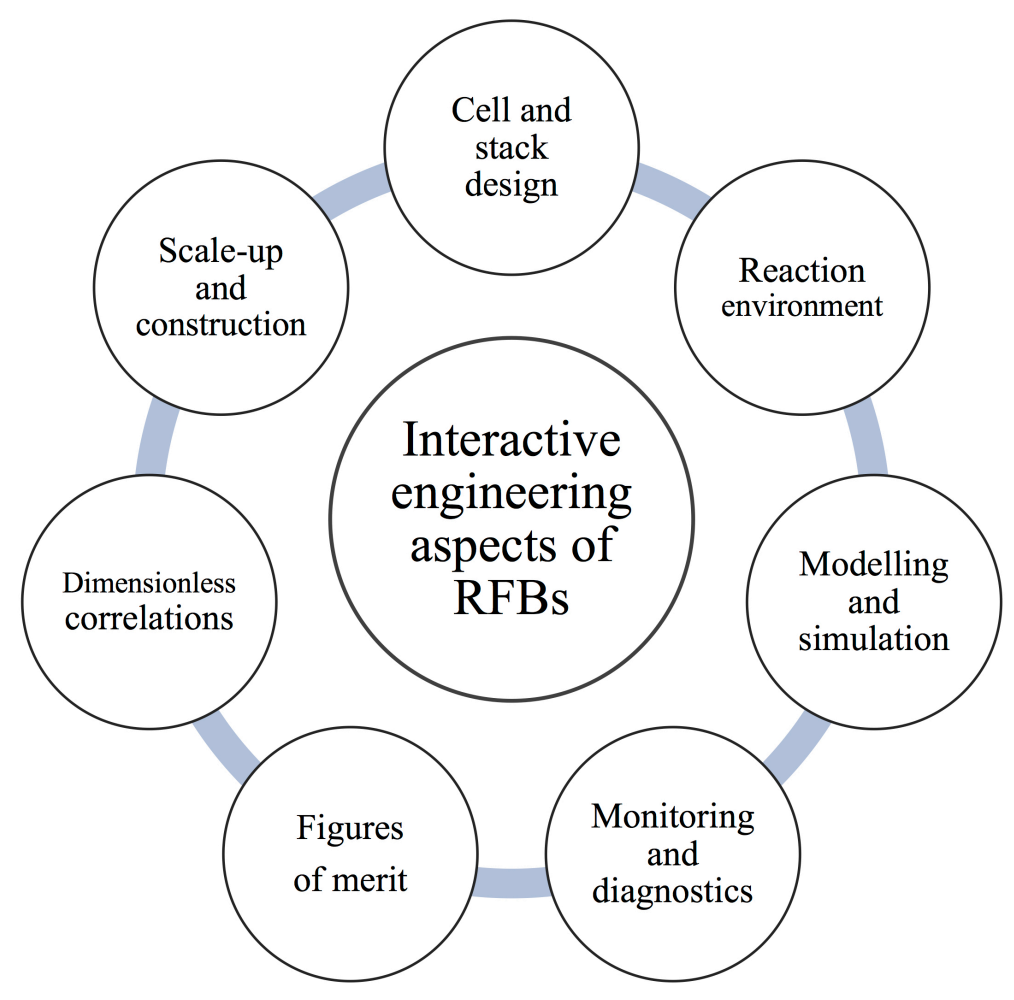

Figure 9. Interactive aspects of reaction environment in a redox flow cell, including fluid flow, mass transport and potential/current distribution. 


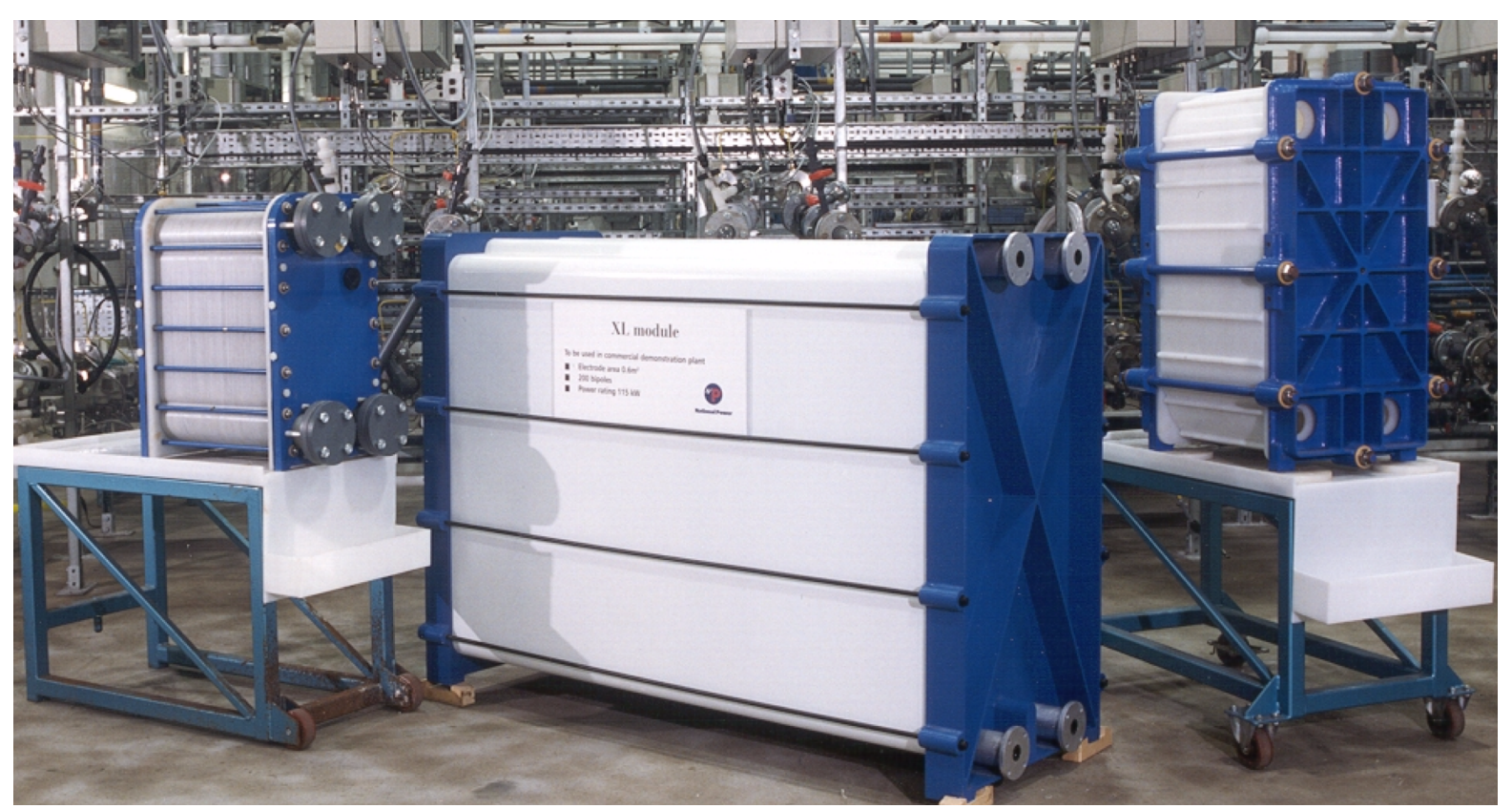

Figure 10. Sizes of modular Br-polysulfide RFB stacks developed by Regenesys ${ }^{\circledR}$ by 2001 . From left to right: $\mathrm{S}$ series $\left(<1.4 \mathrm{~kW}, 20 \times 0.1 \mathrm{~m}^{2}\right.$ electrode $)$, XL series $(<100 \mathrm{~kW}$, $200 \times 0.7 \mathrm{~m}^{2}$ electrode), and M series $\left(<8.1 \mathrm{~kW}, 60 \times 0.2 \mathrm{~m}^{2}\right.$ electrode) [160]. 

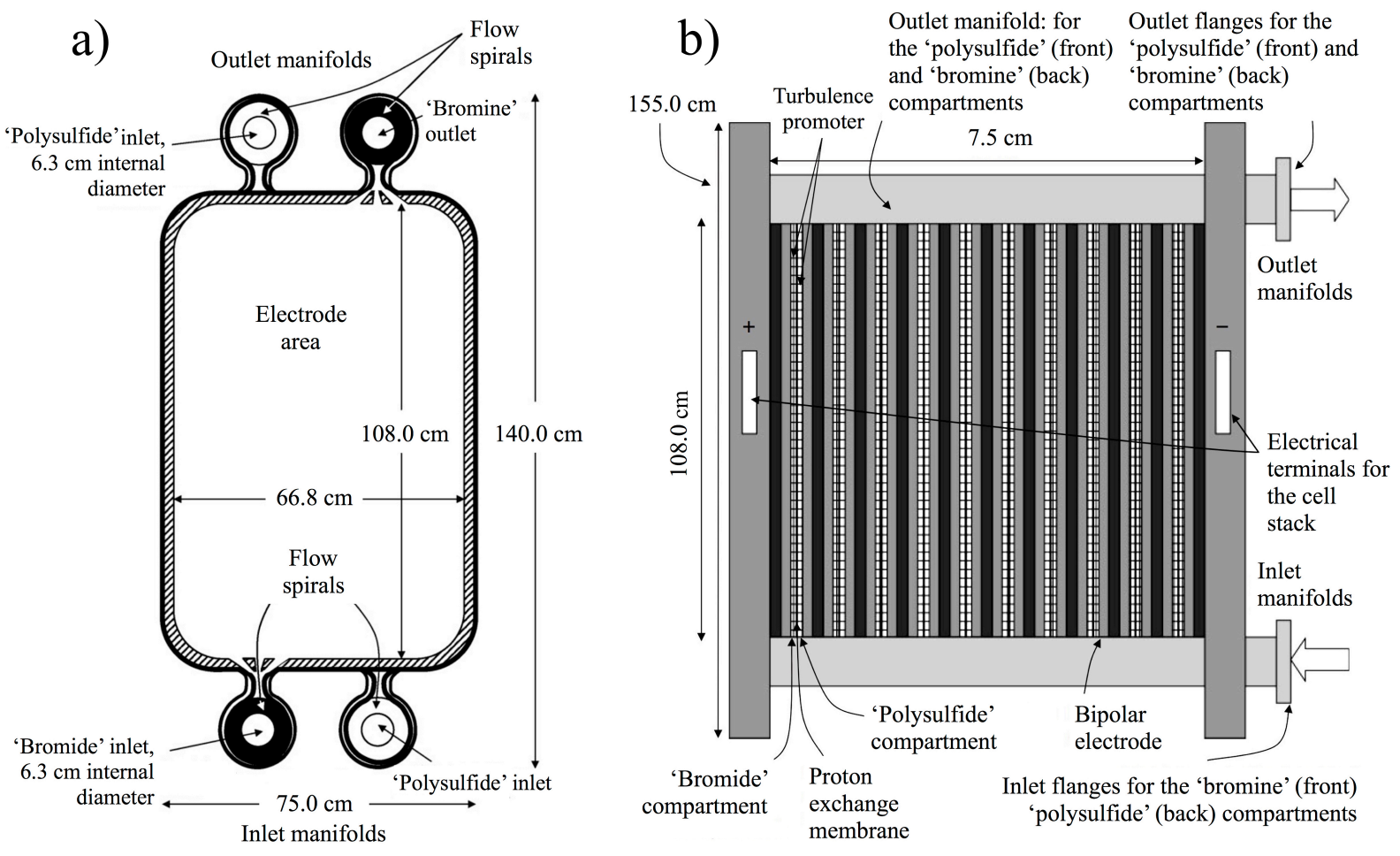

Figure 11. a) Single electrode frame [128] and b) 10 cell pilot stack of a Regenesys XL Brpolysulfide RFB for mass transport studies [159]. Not to scale. 


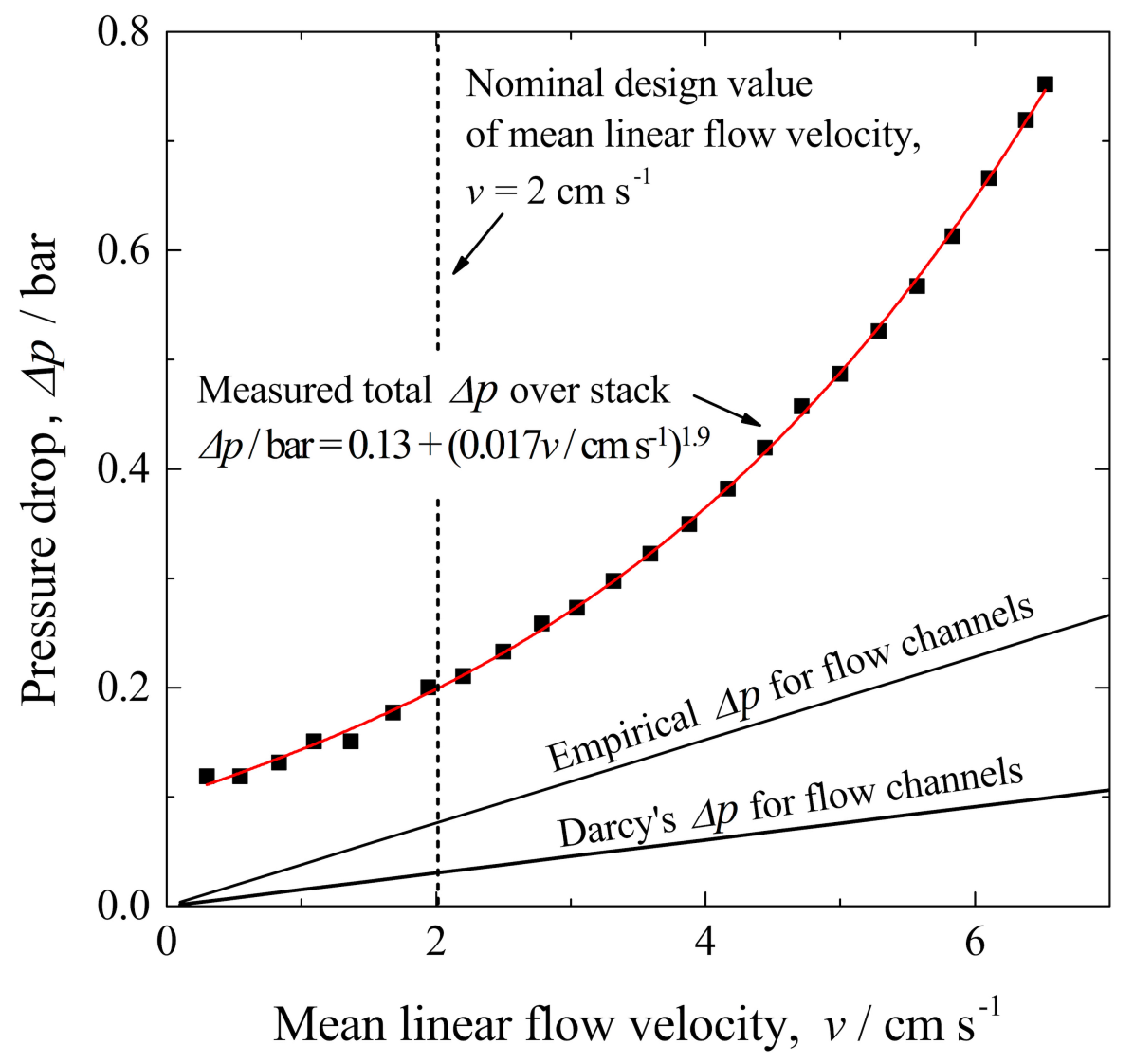

Figure 12. Fluid pressure drop over stack vs. electrolyte flow rate for a Regenesys XL cell stack. The difference in the value for the flow channels and the measured value for the stack is due to the pressure drop at inlet/outlet manifolds and at spiral manifolds for shunt current prevention. After Ponce de León et al. [159]. 


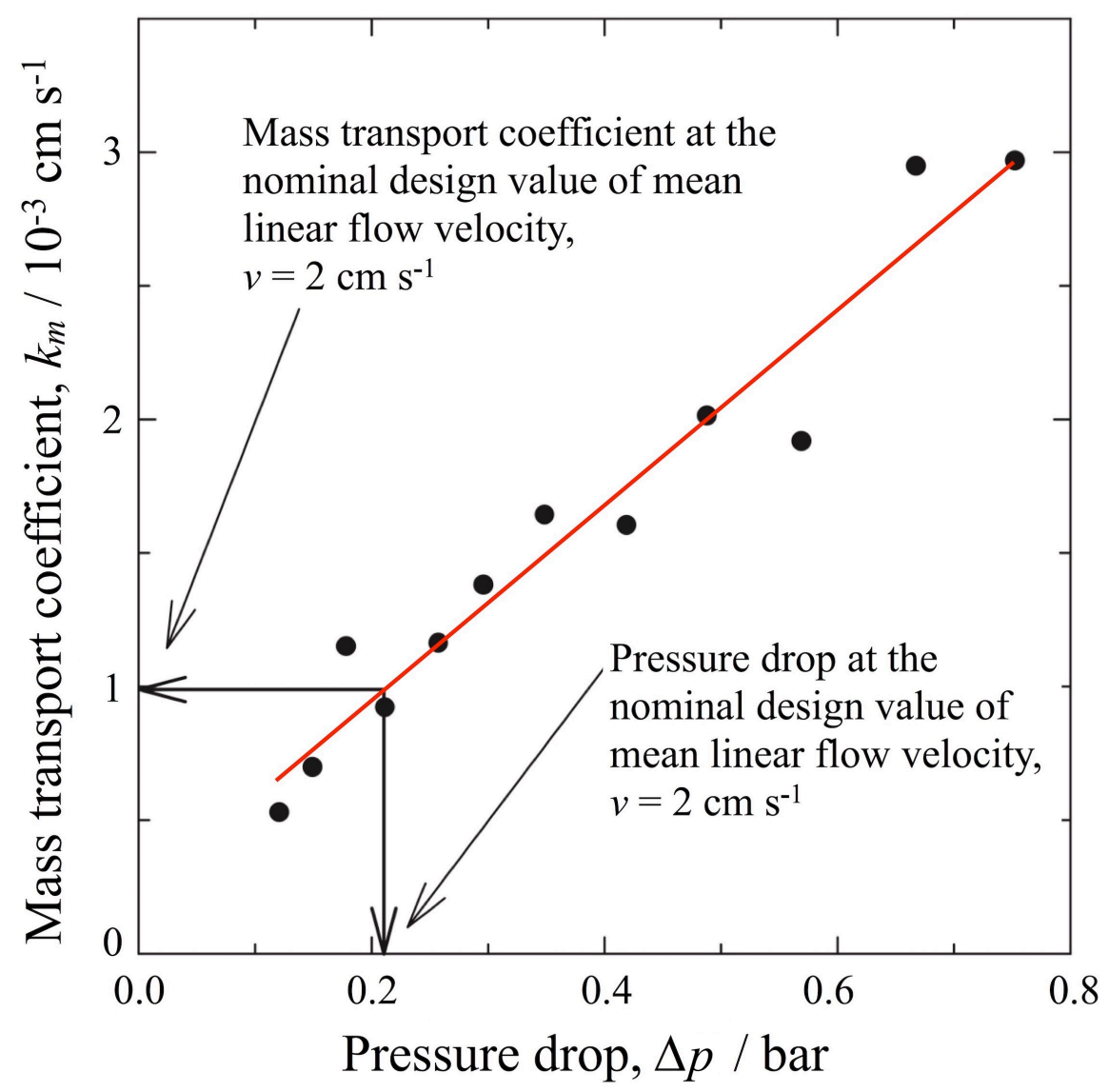

Figure 13. Mass transport coefficient vs. pressure drop for the 'bromine' compartment of a Regenesys XL 10 cell stack [159]. Electrolyte composition: $1 \mathrm{~mol} \mathrm{dm}^{-3} \mathrm{NaBr}$ in $0.5 \mathrm{~mol} \mathrm{dm}^{-3} \mathrm{Na}_{2} \mathrm{SO}_{4}$ at $\mathrm{pH} 2$ in the 'bromine' compartment and $\mathrm{Na}_{2} \mathrm{SO}_{4}$ at $\mathrm{pH} 2$ was used in the 'polysulfide' compartment. 


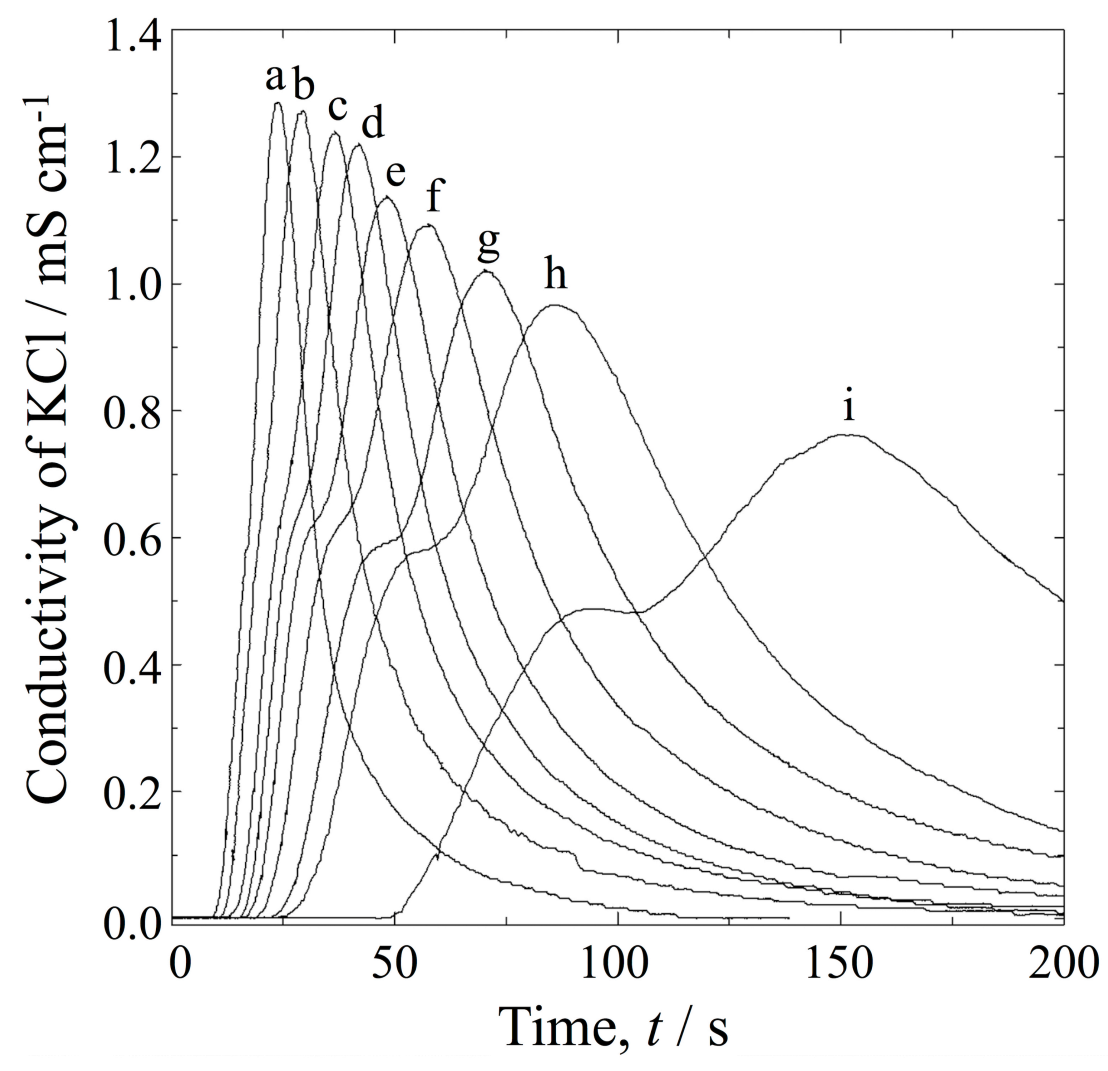

Figure 14. Flow dispersion $v s$. electrolyte mean flow velocity and residence time distribution as given by a $\mathrm{KCl}$ conductivity perturbation-response technique for a Regenesys XL10 cell stack [159]. Mean linear electrolyte velocity: a) 6.2, b) 5.2, c) 4.2, d) 3.7, e) 3.1, f) 2.6, g) 2.1 , h) 1.6 , i) $1.0 \mathrm{~cm} \mathrm{~s}^{-1}$. 


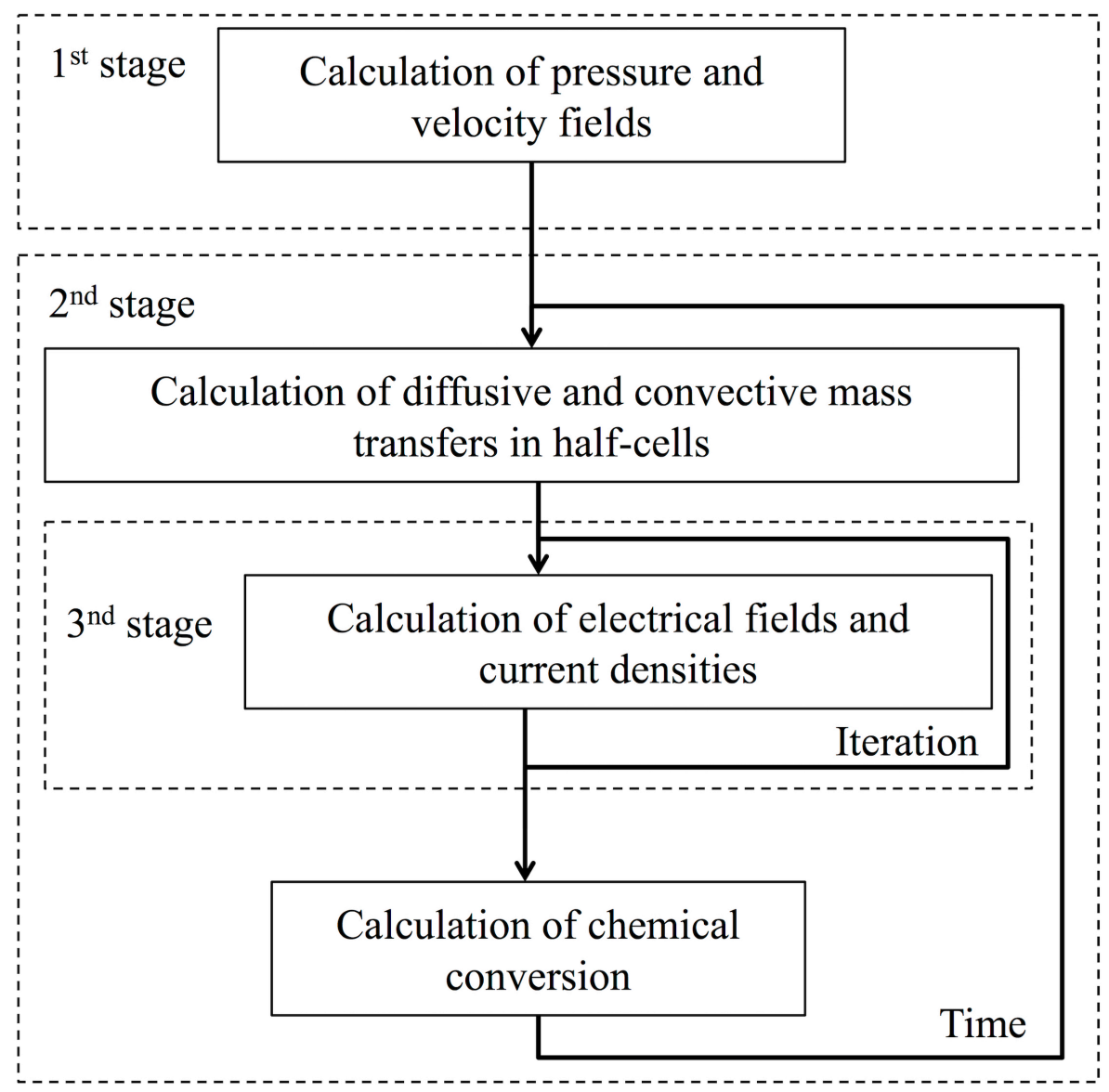

Figure 15. An example of an organisational flow chart for modelling of an all-vanadium RFB. After Bayanov et al. [171]. 


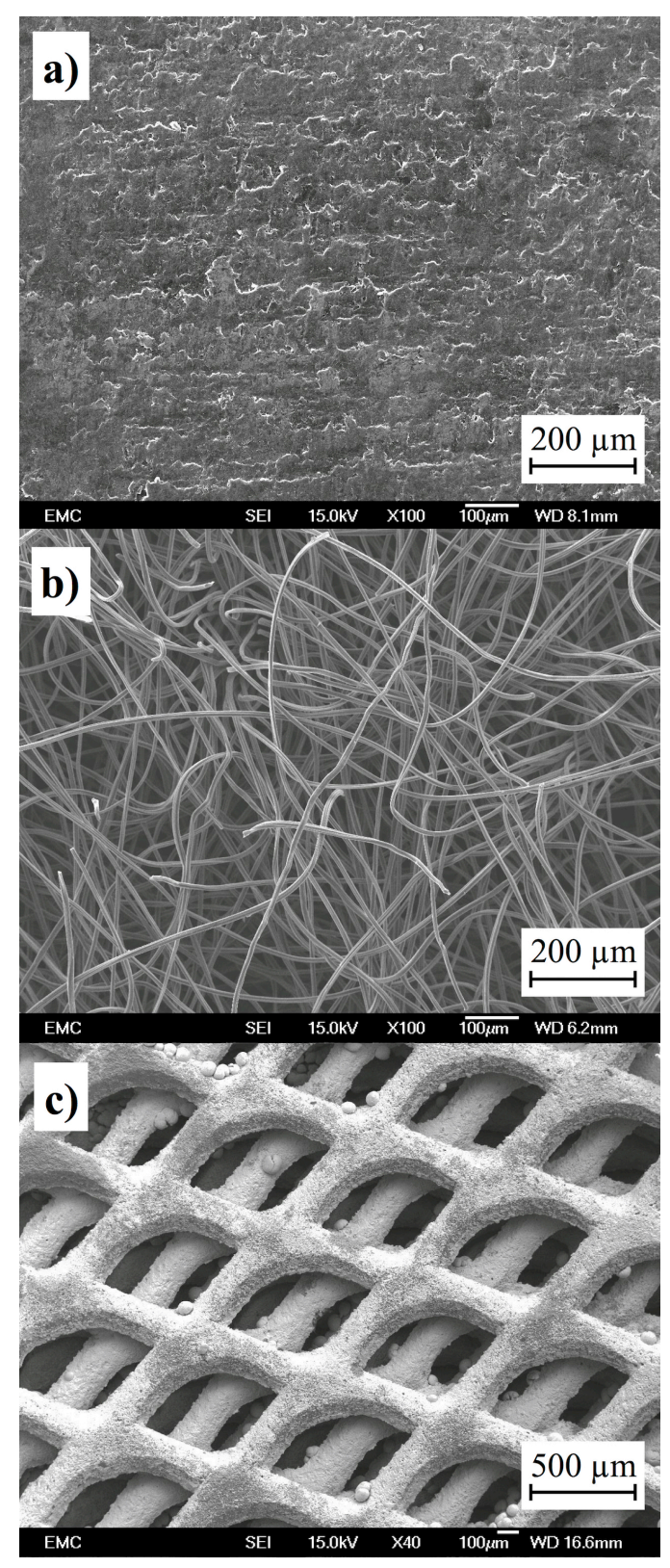

Figure 16. SEM micrographs of electrode materials for RFBs. a) carbon-polymer composite bipolar tile, b) carbon felt, and c) platinised titanium expanded mesh. 


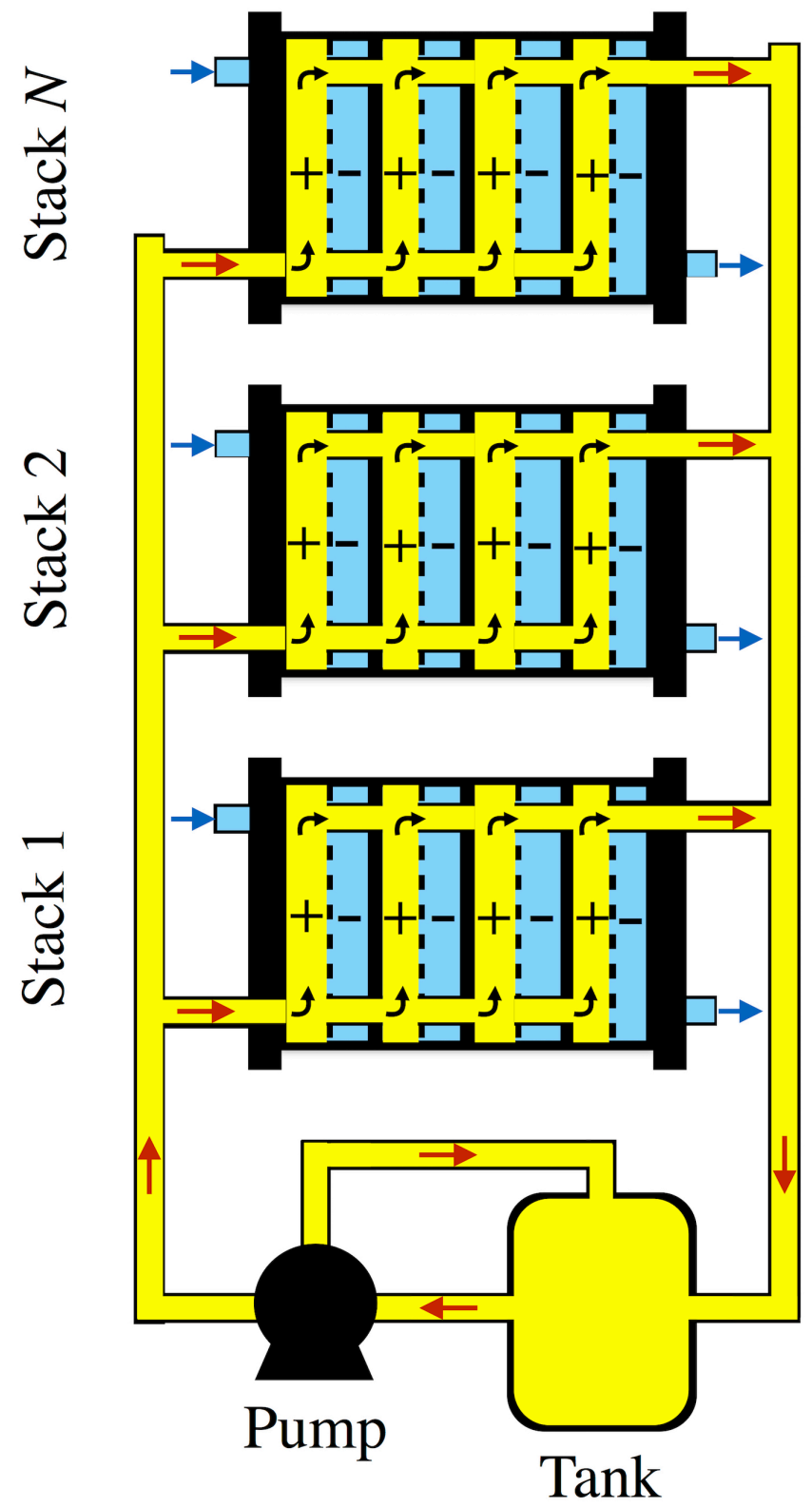

Figure 17. Stacks of cells fed with parallel steams of electrolyte. 


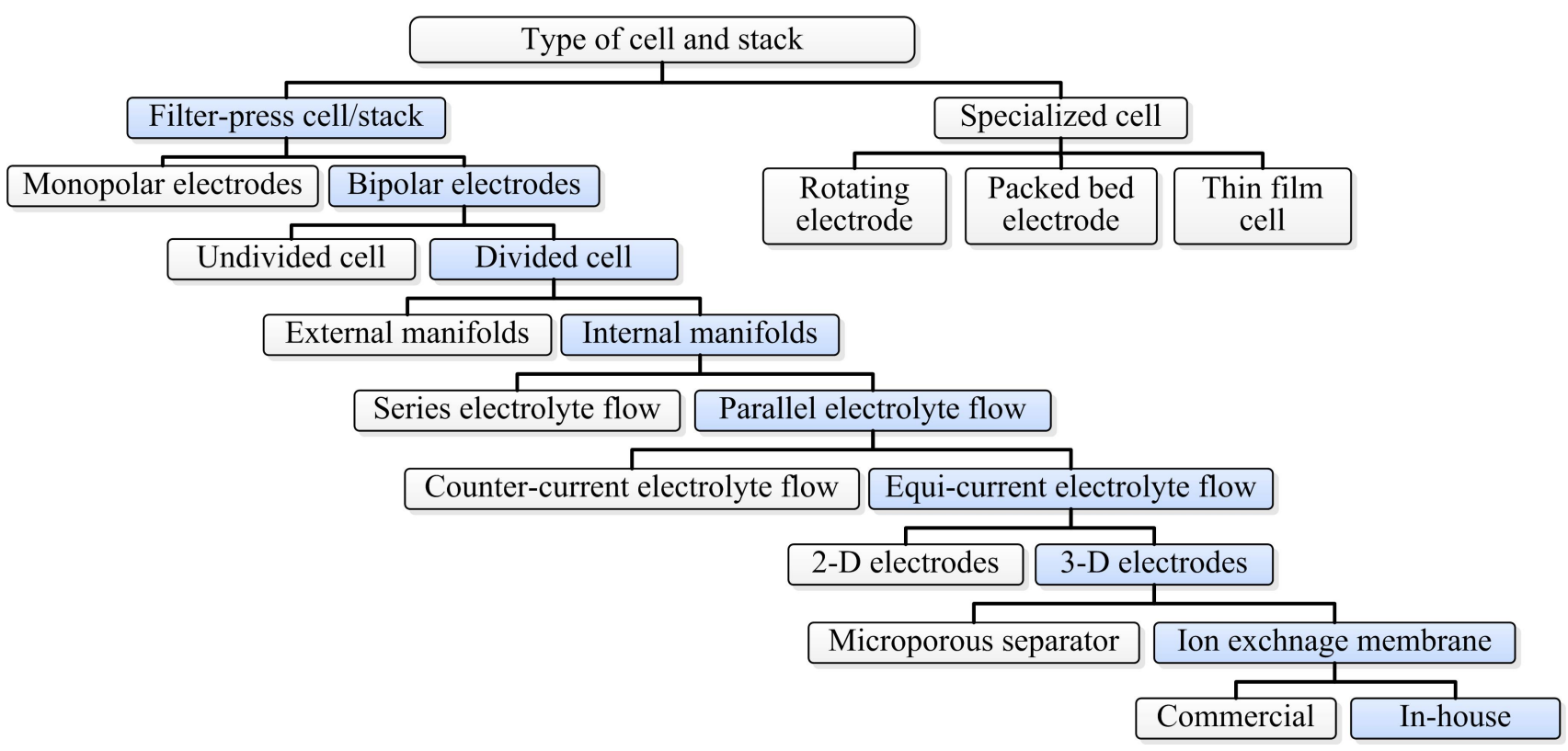

Figure 18. A decision tree indicating choices in the selection of features in an RFB cell design. 


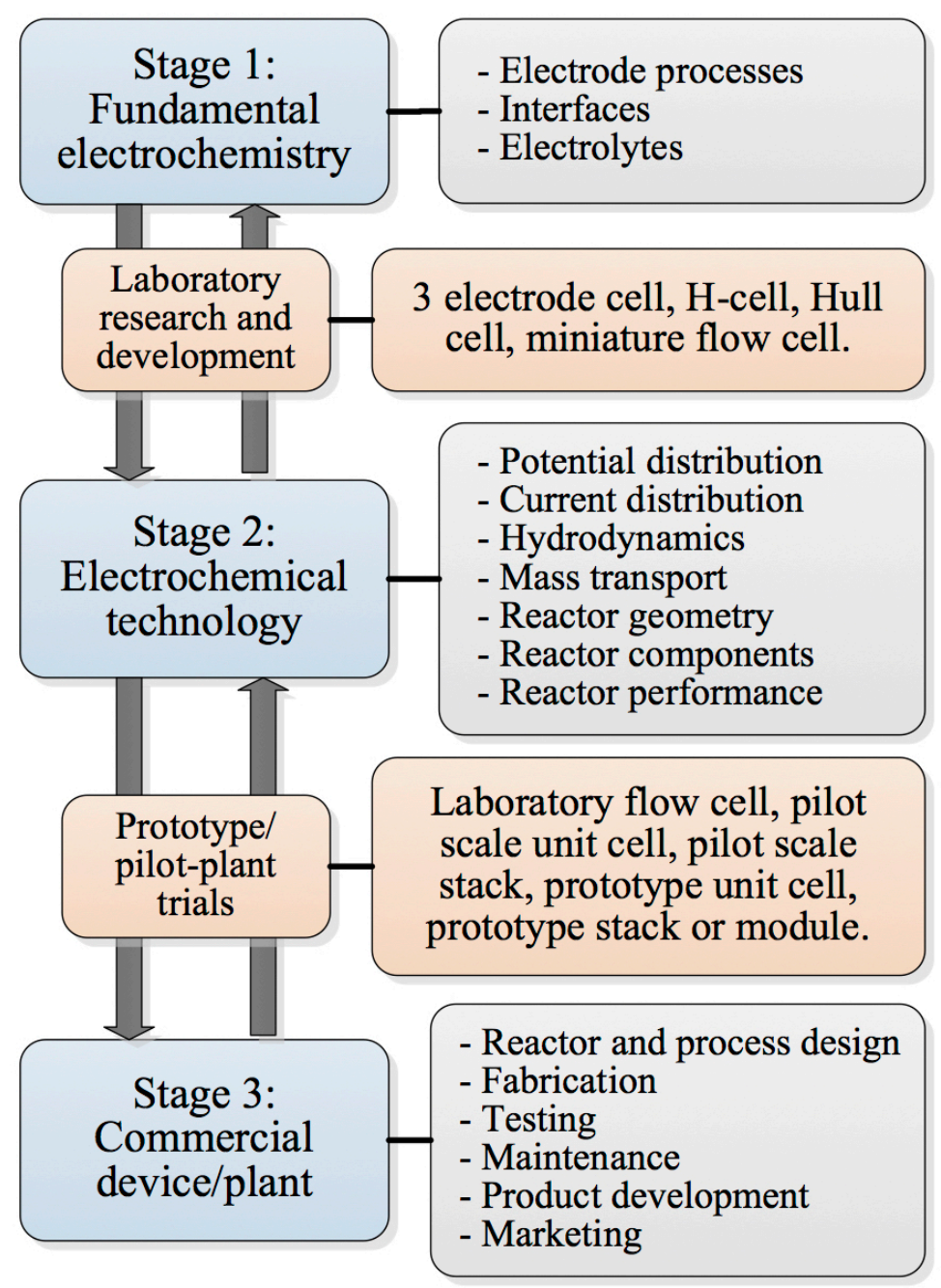

Figure 19. The typical stages involved in the scale-up of an RFB. 


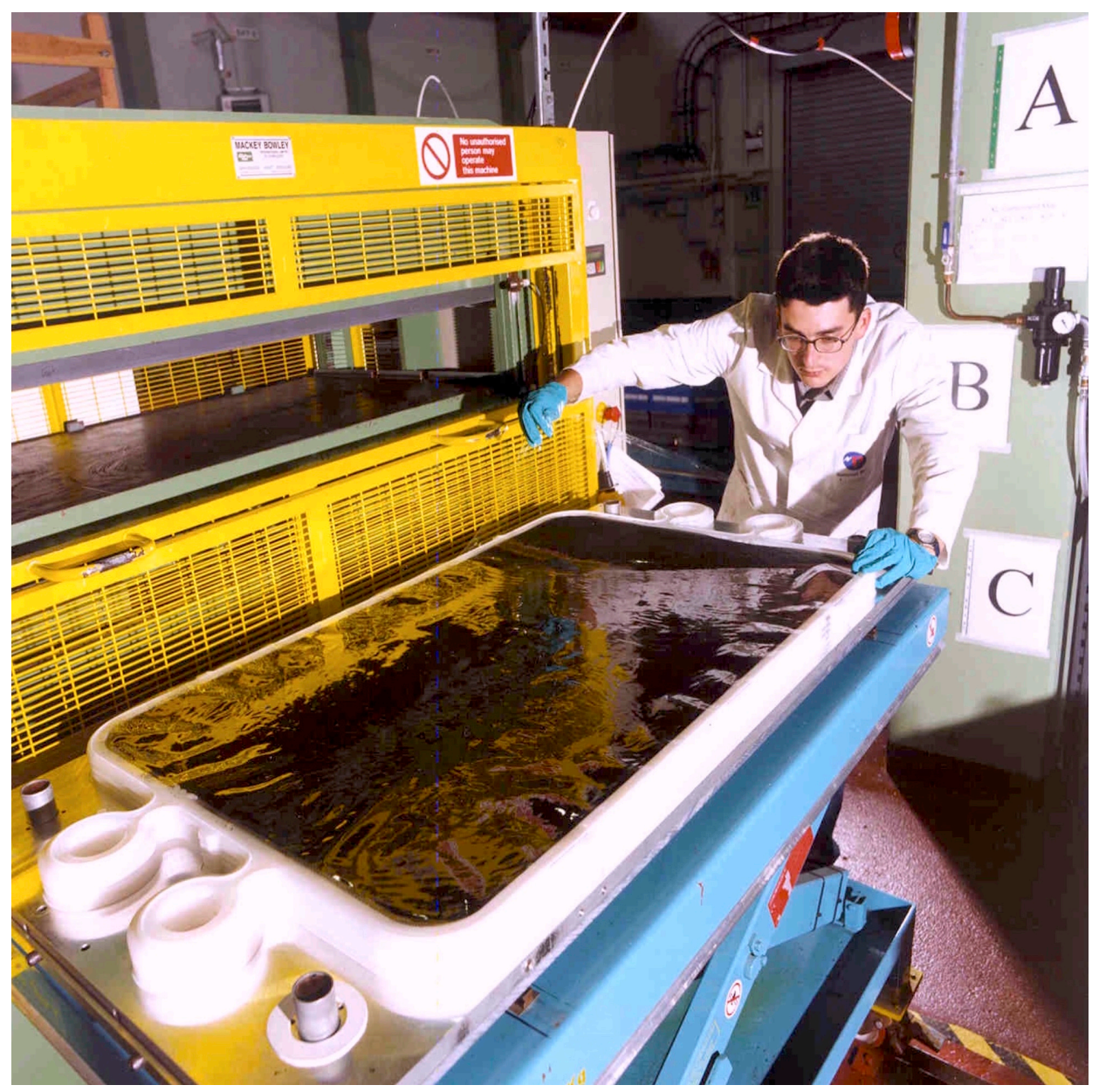

Figure 20. Construction of an RFB stack, showing the fitting of an ion exchange membrane to a heat-welded polymer frame and electrode. 